\title{
PLATINUM RESISTANCE THERMOMETRY AT HIGH TEMPERATURES.
}

\author{
By C. W. Waidner and G. K. Burgess.
}

\section{CONTENTS.}

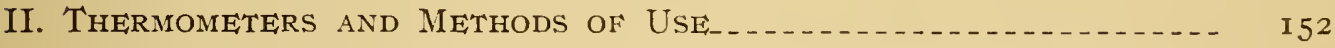

Methods of measurement; construction of thermometers; heating by measuring current; calibration of thermometers; constants of the thermometers.

III. MEASUREMENT AND RePRoducibility of FreEzing and Melting

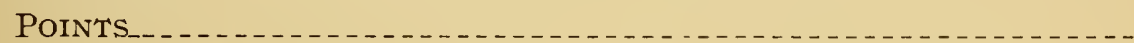

Electric furnaces; furnace manipulation; crucibles; surface oxidation; depth of immersion; undercooling; the observations; freezing points of $\mathrm{Sn}, \mathrm{Cd}, \mathrm{Pb}, \mathrm{Zn}, \mathrm{Sb}, \mathrm{Ag}, \mathrm{Cu}, \mathrm{Al}, \mathrm{Ag}_{3}-\mathrm{Cu}_{2}$ and $\mathrm{Cu}-\mathrm{Cu}_{2} \mathrm{O}$ eutectics; metals from different sources.

IV. The Scale of the Platinum Thermometer

Corrections for thermometers of impure platinum; precision of measurement with platinum thermometer; modification of Callendar's formula; other calibration formulæ; other methods of calibration at high temperatures.

V. Changes in Constants of Thermomeiters at High TEMPERATURES.Changes with discontinuous heating; changes during a freezing point determination.

VI. COMPARISON OF RESISTANCE AND THERMOELECTRIC SCALES . . . . .

VII. THE PALLAdIUM THERMOMETER

VIII. The BoIling PoINT OF SUlPhuR

Variation of S. B. P. with pressure; the S. B. P. tubes; gas and electric heating; superheating; radiation shields; temperature distribution within S. B. P. tube; temperature distribution within radiation shield; on the uncertainty in the accepted value of the S. B. P.

IX. General Conclusions

X. ApPendix: TABLES_._. 198

XI. BIBLIOGRAPHY 


\section{INTRODUCTION.}

The present investigation was undertaken to determine the advantages and limitations of platinum resistance thermometers at high temperatures, especially with reference to reproducibility of scale, method of calibration, formulæ best expressing the relation between resistance and temperature, effect of impurities in the platinum wire, changes due to high temperatures, and the most satisfactory method of construction and use. The reproducibility of high temperatures by the melting or freezing points of metals obtained from different sources and furnished as chemically pure was also studied.

We realize that a very considerable amount of most valuable work has been done by several investigators in the domain of platinum thermometry of precision at high temperatures, yet it seemed to us that with the facilities at our disposal there was opportunity to study some of the questions above referred to with still greater exactness, especially in view of the publication of several recent researches on the gas thermometer at high temperatures, which afford, through the temperatures of the freezing points of pure metals, an indirect but very certain comparison of the gas and platinum scales.

The platinum resistance thermometer was first seriously proposed and used for the measurement of high temperatures by Siemens,* who in I87 I submitted several such thermometers to the British association for test. The results of these tests ${ }^{8}$ showed large and progressive changes in resistance after each exposure to high temperatures. The further investigation of the platinum thermometer by Callendar, ${ }^{12}$ fifteen years later, showed that if the thermometer was so constructed that the platinum wire was protected from contamination by the supporting frame, the changes in resistance after some hours' exposure to high temperatures (red heat), were very small (a few parts in Io,ooo).

Callendar ${ }^{12}$ has shown that if we define the platinum temperature, $p t$, by the relation

* References will be found in the Bibliography, Sec. XI, p. 223. 


$$
p l=100 \frac{R-R_{0}}{R_{100}-R_{0}}
$$

where $R=$ observed resistance at the temperature, $t^{\circ}$,

$$
\begin{aligned}
& R_{0}=\text { " " } \quad \text { " } \quad \text { " } \quad 0^{\circ} \mathrm{C} ., \text { } \\
& R_{100}=0^{\circ} \mathrm{C} \text {., }
\end{aligned}
$$

the relation between the platinum temperature, $p t$, and the temperature, $t$, on the scale of the gas thermometer is represented by the relation

$$
t-p t=\delta\left\{\frac{t}{\mathrm{IOO}}-\mathrm{I}\right\} \frac{t}{\mathrm{IOO}}
$$

where $\delta$ is a constant for any given sample of platinum, having a value of about $\mathrm{x} .50$ for pure platinum and a higher value for impure platinum.

'The fundamental interval, FI, of a thermometer, is defined by the relation

$$
F I=R_{100}-R_{0}
$$

and the fundamental coefficient, $c$, by the relation

$$
c=F I / \text { I OO } R_{0}
$$

Three temperatures only are necessary for the standardization of a platinum thermometer. 'Iwo of these temperatures generally chosen are the melting point of ice and the temperature of saturated steam at known pressure. The third point recommended by Callendar and Griffiths, ${ }^{15}$ and generally used on account of the numerous careful determinations that have been made of it, is the boiling point of sulphur, observed under carefully specified conditions.

The work of numerous investigators has established the validity of the above relation (Eq. 2) and has shown that the platinum thermometer, standardized by observations in ice, steam, and sulphur vapor, will serve to reproduce temperatures on the gas scale within the range $-80^{\circ}$ to $+\mathrm{I} 100^{\circ} \mathrm{C}$ almost, if not quite, within the limits of accuracy of the gas thermometer. The scale defined by the constant $\delta$, determined by such a calibration, begins to depart appreciably from the scale of the Hydrogen or 
Helium thermometer at temperatures below- $100^{\circ}$, and for the measurement of temperatures in the interval $0^{\circ}$ to $-200^{\circ}$, it is best to choose as calibration temperatures melting ice, solid $\mathrm{CO}_{2}$ and ether, and the boiling point of liquid oxygen. If still lower temperatures are to be measured, it is necessary to use the temperatures of boiling or solidification of hydrogen, and if the highest attainable accuracy is desired it will probably be necessary to use more than three calibration temperatures, and an equation of a higher degree connecting the resistance and the temperature. For the calibration of calorimetric resistance thermometers intended for the measurement of small temperature changes, the transition point of sodium sulphate $\left(32^{\circ} \cdot 384\right)$ may be used with advantage as the third calibration temperature. ${ }^{117}$

\section{THERMOMETERS AND METHODS OF USE}

In the present investigation i I resistance thermometers were used, made of wire of varying degrees of purity and of various sizes from $0 . \mathrm{I}$ to $0.6 \mathrm{~mm}$ diameter, and with resistances, $R_{0}$, ranging from $0.1 \mathrm{I} \mathrm{ohm} \mathrm{to} 2 \mathrm{I} .5 \mathrm{ohms}$. Two of these thermometers were made of pure palladium wire $0.3 \mathrm{~mm}$ diameter, while the other 9 were of platinum.

Three types of thermometer were used, which may be briefly designated as

a. Compensated lead type.

b. Potential terminal type.

c. Combined compensated lead and potential terminal type. These three types are illustrated diagrammatically in Plates I and II. In the compensated lead type, due to Callendar, ${ }^{18}$ two fairly large platinum leads (preferably over $0.6 \mathrm{~mm}$ diameter), as nearly identical as possible with the leads to the coil, run down the stem of the thermometer, and are connected at their lower ends. When these leads are put into the arm of the Wheatstone bridge adjacent to the arm in which the thermometer coil is inserted the thermometer is compensated for variations in temperature of the leads to the coil, due to variable depth of immersion. To compensate for the effects of heat conduction from the coil along the heavier platinum leads, the ends of the compensating leads are 


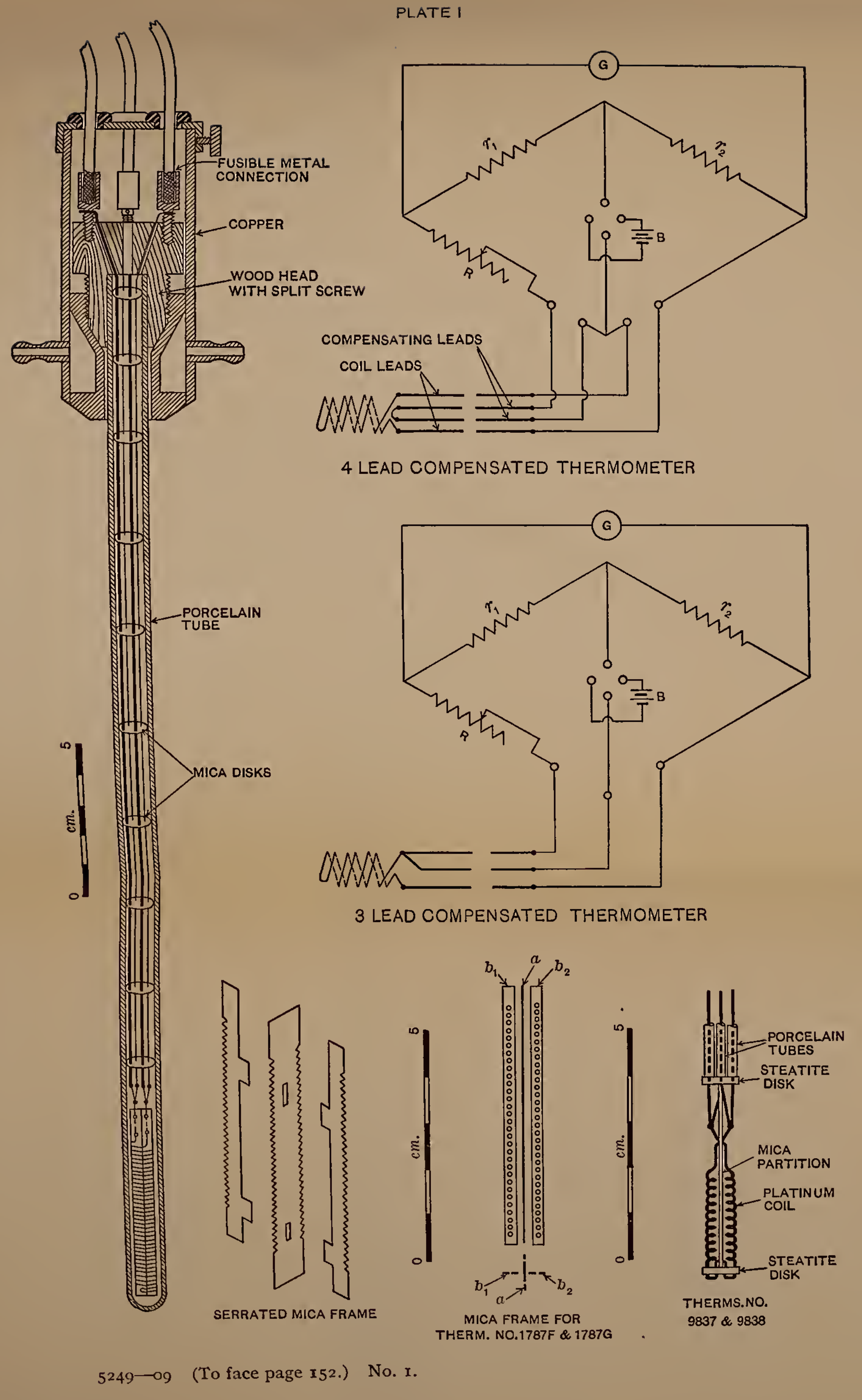




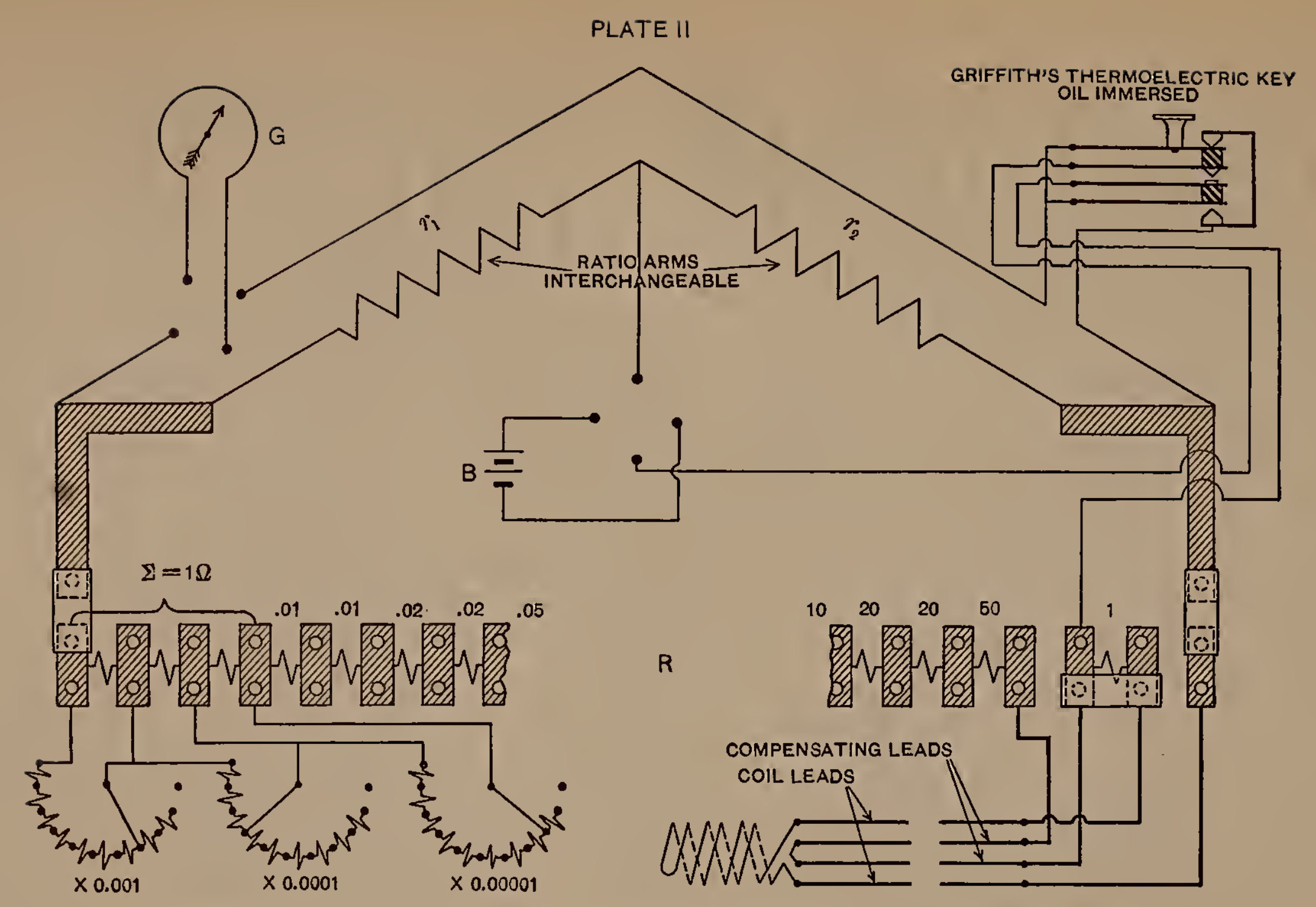

DIAGRAMMATIC SKETCH OF BRIDGE AND 4 LEAD COMPENSATED THERMOMETER.

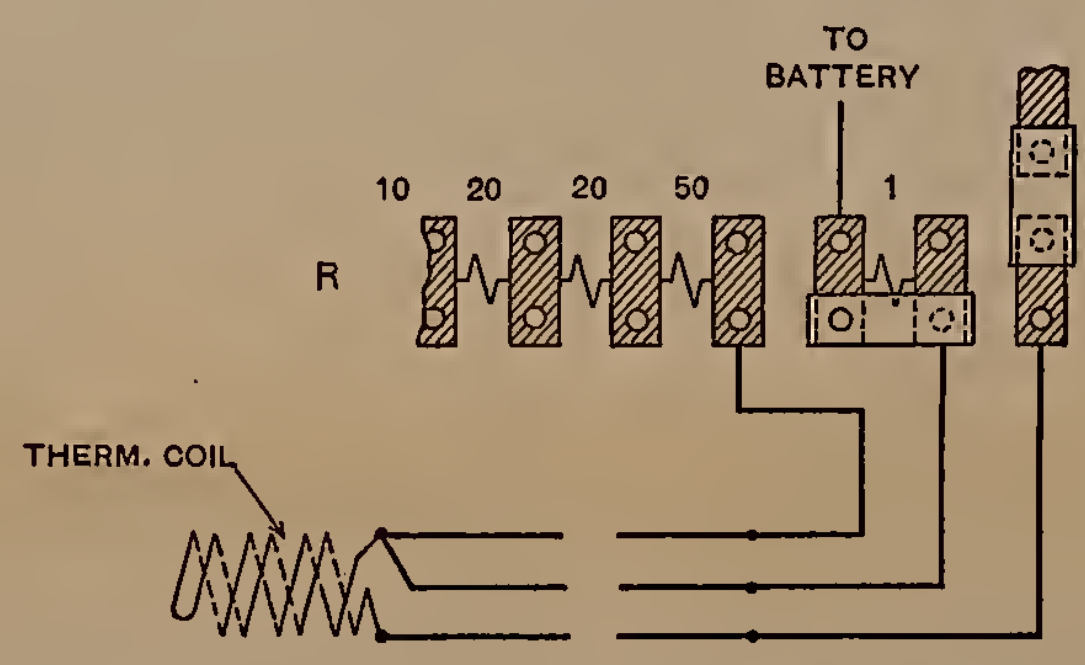

CONNECTIONS FOR 3 LEAD COMPENSATED THERMOMETER.

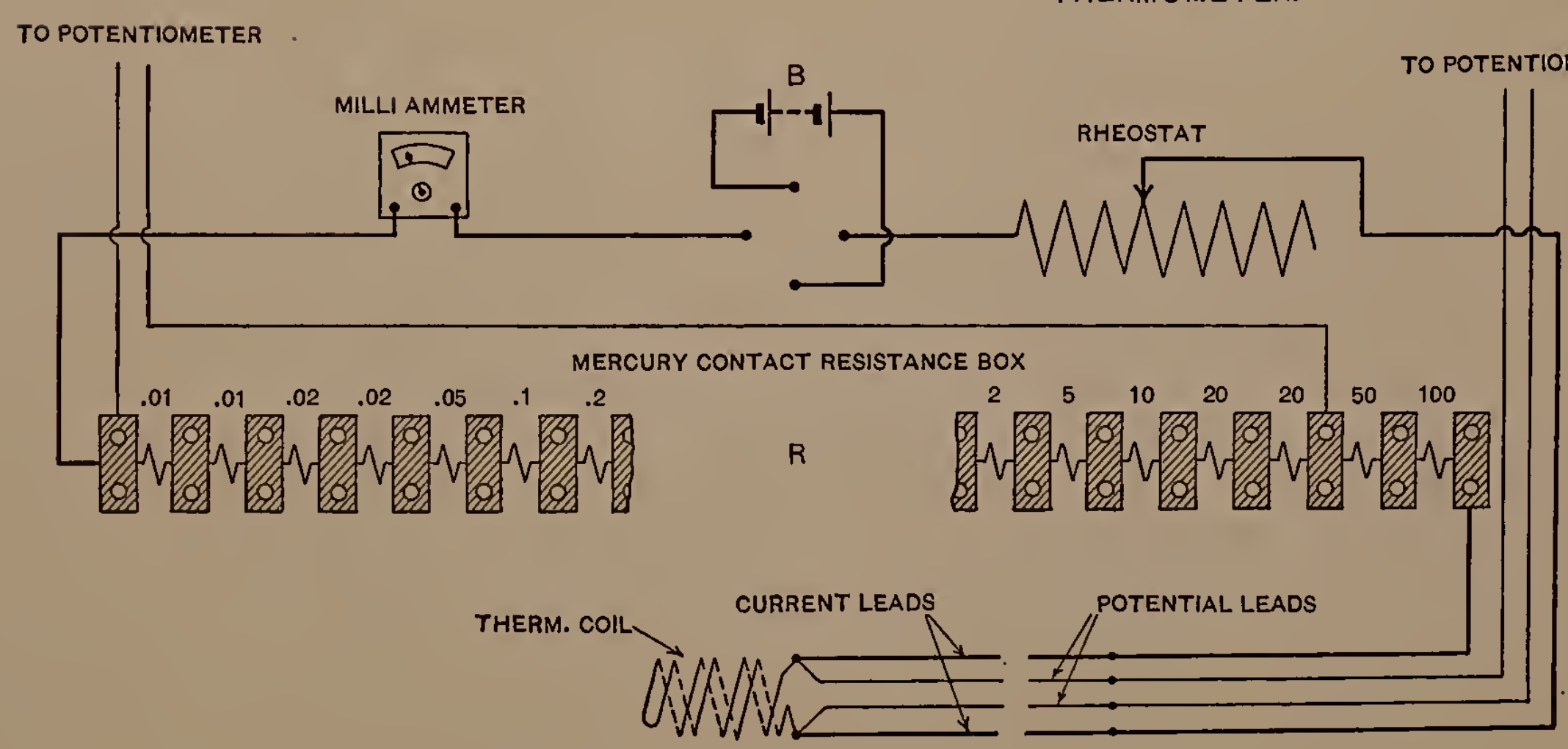

CONNECTIONS FOR POTENTIAL TERMINAL THERMOMETER.

$5249-09$ (To face page 152.$) \quad$ No. 2. 
joined by a short length of fine platinum wire of the same size as the wire of which the coil is made. In thermometers of the potential terminal type two leads are fused to each end of the coil. In this type of thermometer both the current and potential leads may obviously be made of much smaller wire than for the compensating lead type. The method of using this thermometer, which consists in comparing the potential difference at the terminals of the coil with the potential difference at the terminals of a known resistance carrying the same current, will be understood from the diagram. In thermometers of the combined compensated lead and potential terminal type the current leads should be made of fairly large wire to secure better compensation. If one of the potential leads is omitted we have a three-lead compensated thermometer of the Siemens type. ${ }^{5}$

Methods of Measurement.-The compensated lead thermometers (type $a$, and type $c$ when so used) were used (see Plate II) with a specially designed Wheatstone bridge, ${ }^{92}$ having mercury contact plugs and manganin resistance coils ranging from o.or to 50 ohms. The coils were immersed in a motor-stirred and thermostatically controlled oil bath. The finer steps were obtained on three shunt dials giving steps of $0.00 \mathrm{I}, 0.000 \mathrm{I}$, and o.0000 I ohm, respectively. The Iooo-ohm ratio coils were used throughout this work. The ratio coils could be quickly reversed by interchanging two mercury contact links, thus eliminating the effect of inequality of the ratio coils. The bridge was used with a Griffiths' oil immersed key, ${ }^{24}$ which kept the galvanometer circuit always closed except at the instant of making the battery circuit, thus eliminating the effects of small thermoelectric currents in the circuits. As a further precaution measurements were made with the battery and galvanometer circuits alternately reversed, as well as with the ratio arms interchanged, in the following sequence:

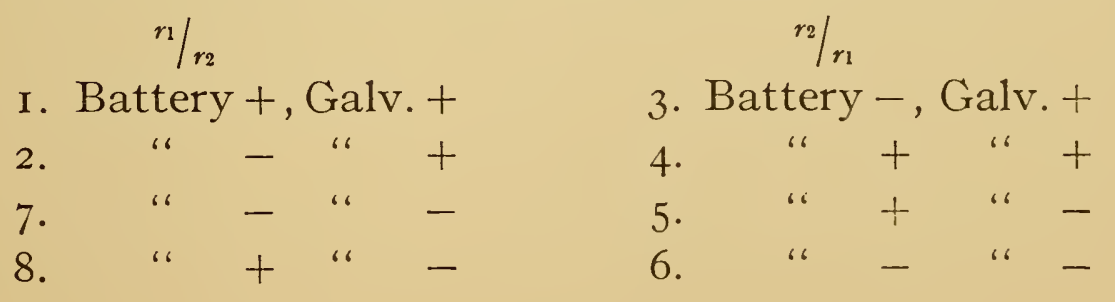


The connections are shown diagrammatically in Plate II.

This bridge has been calibrated several times a year since its construction in 1903 and at intervals of about eight weeks during the progress of this investigation. The small changes, amounting to a few parts in 100,000 , are apparently seasonal and are undoubtedly due to the effects of moisture.

The method of using the potential terminal thermometers is shown in Plate II. The potential difference at the terminals of the thermometer coil was compared with the potential difference at the terminals of the resistance $R$ by means of a special Leeds and Northrup type $\mathrm{K}$ potentiometer. In some of the later work a Diesselhorst potentiometer, constructed by Otto Wolff, of Berlin, was also used. The resistance $R$, which was taken from a mercury contact resistance box of manganin coils in a stirred and thermostatically controlled oil bath, could be adjusted, to the nearest o.or ohm, to equality with the resistance of the thermometer coil, so that nearly equal potential differences were compared.

The low resistance thermometers $\left(R_{0}=\right.$ O.II ohm) were used as potential terminal instruments. In some of the earlier tests these thermometers were calibrated in connection with a special slide-wire double Kelvin bridge submitted with the thermometers by the makers, Messrs. Leeds and Northrup, who have applied this method of resistance thermometry to industrial work.

The order of accuracy of the resistance measurements throughout the work was I or 2 parts in 100,000 .

Construction of Thermometers.-The thermometers, with the exception of Nos. 479 and 480, from the Cambridge Scientific Instrument Company, and the two low-resistance thermometers $\left(R_{0}=0.1 \mathrm{I} \mathrm{ohm}\right) 9837$ and 9838, from Leeds and Northrup, were very kindly constructed for this investigation by Mr. H. C. Dickinson and Mr. J. J. Crowe of this Bureau. The essential details of construction are shown in Plate I. The coil is wound on a notched mica frame. The several leads are insulated from one another by mica washers. The platinum leads terminate in the head of the thermometer in small copper cups containing a fusible alloy by means of which connection is made to stranded leads (carefully adjusted to equality for the compensated lead thermometers) 
which serve to connect the thermometer to the measuring apparatus. The head of the thermometer is made of wood thoroughly dried and boiled in paraffine. This head terminates at the bottom in a split screw which serves to grip the porcelain stem when the surrounding double walled copper head is screwed on to the wooden head. The thick metal head insures a quite uniform temperature distribution throughout the inclosure and thus reduces to a minimum the thermal electromotive forces within the head of the thermometer. Undue heating of the head of the thermometer at high temperatures, with consequent increase in these emf's., can be avoided by passing a current of air through the space between the walls.

The containing tubes were of Berlin porcelain glazed on the outside only, except for thermometers 9837 and 9838, which were inclosed in quartz.

A modified form of mica frame was used in the construction of thermometers $\mathrm{I} 787 \mathrm{~F}$ and $\mathrm{I} 787 \mathrm{G}$, with a view to diminishing the possible effects of strains in the platinum wire of the coil due to thickening of the mica after repeated exposures to high temperatures. The construction of the mica frame for these thermometers will be understood from the illustration. The wire was threaded through holes in the mica, and the two independent mica strips, $b_{1}, b_{2}$, not being in contact with the mica strip $a$, gave a flexible mounting for the wire.

The wire of which the thermometer coils were constructed was of varying degrees of purity, with values of $\delta$ ranging from I.5O to I.80. In Table I will be found a summary of the constants of the thermometers.

Heating by Measuring Current.-The measuring current through the coils of the thermometers was from 0.004 to 0.010 ampere for the different thermometers, except for the low-resistance thermometers. For any given thermometer the same measuring current was always used. Measurements made with other currents showed that the resulting values of $p t$ were practically identical with the $p t$ corresponding to infinitely small current. Two different currents were used with the low resistance thermometers, viz., o. I and 0.5 ampere. While with the larger cur- 
rent the excess of temperature of the coil above its surroundings was more than $\mathrm{I}^{\circ}$ in the observed value of $R_{0}$, the value of $F I$ found was practically identical for both these currents.

TABLE 1.

Range of Constants of Platinum Thermometers.

\begin{tabular}{|c|c|c|c|c|c|c|c|}
\hline $\begin{array}{l}\text { No. of } \\
\text { Ther- } \\
\text { mometer }\end{array}$ & $\mathbf{R}_{0}$ & FI & c & $\delta$ & $\begin{array}{l}\text { Method of } \\
\text { Measure- } \\
\text { ment }\end{array}$ & $\begin{array}{c}\text { Meas. } \\
\text { current, } \\
\text { amp. }\end{array}$ & $\begin{array}{l}\text { Diam. } \\
\text { of wire. } \\
\text { mm }\end{array}$ \\
\hline 1787 A & $\begin{array}{l}21.3476 \\
21.0617\end{array}$ & $\begin{array}{l}4.4067 \\
4.4203\end{array}$ & $\begin{array}{r}.00206426 \\
210065\end{array}$ & $\begin{array}{l}1.571 \\
1.569\end{array}$ & $\begin{array}{l}\text { Poten- } \\
\text { tiometer. }\end{array}$ & .004 & 0.1 \\
\hline $1787 \mathrm{C}$ & $\begin{array}{l}3.48779 \\
3.48174\end{array}$ & $\begin{array}{l}1.34298 \\
1.34114\end{array}$ & $\begin{array}{r}.00385052 \\
385192\end{array}$ & $\begin{array}{l}1.504 \\
1.504\end{array}$ & $\begin{array}{l}\text { Poten- } \\
\text { tiometer. }\end{array}$ & .010 & .15 \\
\hline $1787 \mathrm{~F}$ & $\begin{array}{l}2.85355 \\
2.85567\end{array}$ & $\begin{array}{l}1.11228 \\
1.11312\end{array}$ & $\begin{array}{r}.00389787 \\
389793\end{array}$ & $\begin{array}{l}1.503 \\
1.503\end{array}$ & $\begin{array}{l}\text { Bridge, } \\
3 \text { leads. }\end{array}$ & .006 & .2 \\
\hline $1787 \mathrm{~F}$ & $\begin{array}{l}2.84782 \\
2.84987\end{array}$ & $\begin{array}{l}1.11069 \\
1.11119\end{array}$ & $\begin{array}{r}.00390014 \\
389909\end{array}$ & $\begin{array}{l}1.503 \\
1.503\end{array}$ & $\begin{array}{l}\text { Poten- } \\
\text { tiometer. }\end{array}$ & .010 & .2 \\
\hline 479 & $\begin{array}{l}4.27342 \\
4.28823\end{array}$ & $\begin{array}{l}1.64585 \\
1.64513\end{array}$ & $\begin{array}{r}.00385136 \\
383638\end{array}$ & $\begin{array}{l}1.516 \\
1.508\end{array}$ & $\begin{array}{l}\text { Bridge, } \\
4 \text { leads. }\end{array}$ & .006 & .2 \\
\hline 478 & $\begin{array}{l}5.15665 \\
5.16566\end{array}$ & $\begin{array}{l}1.99745 \\
2.00000\end{array}$ & $\begin{array}{r}.00387354 \\
387172\end{array}$ & $\begin{array}{l}1.507 \\
1.507\end{array}$ & $\begin{array}{l}\text { Poten- } \\
\text { tiometer. }\end{array}$ & .007 & .2 \\
\hline 480 & 2.62081 & 1.00503 & .00383480 & 1.551 & $\begin{array}{l}\text { Bridge, } \\
4 \text { leads. }\end{array}$ & .006 & .2 \\
\hline $1787 \mathrm{E}$ & $\begin{array}{l}2.92482 \\
2.92226\end{array}$ & $\begin{array}{r}0.50511 \\
.50540\end{array}$ & $\begin{array}{r}.00172630 \\
172948\end{array}$ & $\begin{array}{l}1.803 \\
1.803\end{array}$ & $\begin{array}{l}\text { Poten- } \\
\text { tiometer. }\end{array}$ & .005 & .3 \\
\hline 9837 & $\begin{array}{r}0.11275 \\
.11307\end{array}$ & $\begin{array}{l}.04324 \\
.04325\end{array}$ & $\begin{array}{r}.0038350 \\
38251\end{array}$ & $\begin{array}{l}1.54 \\
1.54\end{array}$ & $\begin{array}{l}\text { Poten- } \\
\text { tiometer. }\end{array}$ & .50 & .6 \\
\hline 9838 & $\begin{array}{l}.10951 \\
.10954\end{array}$ & $\begin{array}{l}.04192 \\
.04184\end{array}$ & $\begin{array}{r}.0038280 \\
39196\end{array}$ & $\begin{array}{l}1.56 \\
1.56\end{array}$ & $\begin{array}{l}\text { Poten- } \\
\text { tiometer. }\end{array}$ & .50 & .6 \\
\hline
\end{tabular}

Range of Constants of Palladium Thermometers.

\begin{tabular}{|c|c|c|c|c|c|c|c|}
\hline $1787 \mathrm{G}$ & $\begin{array}{l}1.87254 \\
1.86284\end{array}$ & $\begin{array}{r}0.62761 \\
.62696\end{array}$ & $\begin{array}{c}0.00335163 \\
33590\end{array}$ & 2.890 & $\begin{array}{l}\text { Bridge, } \\
3 \text { leads. }\end{array}$ & .006 & .3 \\
\hline $1787 \mathrm{G}$ & $\begin{array}{l}1.87345 \\
1.86802\end{array}$ & $\begin{array}{l}.62809 \\
.62890\end{array}$ & $\begin{array}{r}.00335258 \\
336667\end{array}$ & 2.890 & $\begin{array}{l}\text { Poten- } \\
\text { tiometer. }\end{array}$ & .015 & .3 \\
\hline Pd II & 1.30897 & .43591 & .00333017 & 2.947 & $\begin{array}{l}\text { Poten- } \\
\text { tiometer. }\end{array}$ & .01 & .35 \\
\hline
\end{tabular}

The effect of using different measuring currents (with thermometer 1787 C.) ranging from 0.0025 to 0.100 ampere, is shown in Table $2 *$. The current normally used with this thermometer 
throughout the investigation was o.o I ampere. It will be seen that a measuring current almost, if not quite, five times as great might have been used without appreciably affecting the results.

For a given small excess in temperature of the platinum coil above the temperature of its surroundings, the energy radiated in steam is 3.7 and in sulphur 52 times that radiated at $0^{\circ} \mathrm{C}$, assuming that the radiation from platinum is proportional to the fifth power of the absolute temperature. For constant measuring current the energy supplied to the coil at the S. B. P. is only 2.6 times the energy supplied at $\mathrm{O}^{\circ} \mathrm{C}$. Hence, since it is observed that the excess of temperature of the coil at the S. B. P. is only about 25 per cent less than the excess of temperature at $0^{\circ} \mathrm{C}$, it follows that only a relatively small portion of the energy supplied to the coil by the measuring current is lost by radiation, by far the greater part of the loss being due to convection and conduction.

Calibration of Thermometers. - The thermometers were calibrated by the Callendar-Griffiths method by observations of the resistance in melting ice, steam, and the vapor of boiling sulphur.

The resistance in ice, $R_{0}$, was determined in a finely divided mixture of pure ice saturated with distilled water. The resistance in steam was determined in the usual laboratory form of Regnault hypsometer. The temperature of the steam in this type of hypsometer was compared with the temperature of the steam in the International Bureau type of hypsometer, designed by Chappuis, by taking measurements with the same thermometer in the two hypsometers alternately. The observed temperature of the steam in the Regnault agreed with that in the Chappuis hypsometer to within $\mathrm{O}^{\circ} . \mathrm{OI}$, being about $\mathrm{O}^{\circ} .003$ higher for slow rate of boiling and about $0^{\circ} .006$ higher for fairly rapid rate of boiling. The observations in steam were accompanied by simultaneous observations of the atmospheric pressure with a Fuess standard barometer, accurate to $0.02 \mathrm{~mm}$. The temperature of the steam was then obtained from the observed barometric height reduced to $0^{\circ}$, latitude $45^{\circ}$, sea level, and from Broch's steam tables.

The observations in sulphur, together with simultaneous barometer observations, were carried out with the apparatus and 
in the manner fully described under the head of "The boiling point of sulphur," p. I 84 .

The S. B. P. was taken as $444^{\circ} .70$ at standard atmospheric pressure.

Each thermometer was recalibrated at frequent intervals throughout the progress of the work. Several consecutive freezing (or melting) point determinations were usually made, requiring several hours, during which time the temperature of the crucible of metal varied only a few degrees above and below the melting point. Before and after each group of such determinations the thermometer was recalibrated. For the observations at the higher temperatures, where the changes in the constants of the thermometer become appreciable, the resulting freezing points are given in Tables* 8-10, as deduced from both the calibration before and the calibration after the observations in the metal.

Constants of the Thermometers.-In Table I (p. I56) are indicated, for each thermometer, the values of its characteristic constants, $R_{0}, F I, c$, and $\delta$, as observed at the beginning of this investigation and at its close, and also the method of measurement used with each instrument. The changes in the constants due to use of the thermometers at high temperatures are discussed subsequently (p. I 78).

\section{MEASUREMENT AND REPRODUCIBILITY OF FREEZING AND MELTING POINTS.}

The determinations with thermometers of pure platinum of the freezing and melting points of the several metals used in this investigation are given below. The results of measurements, by means of thermocouples calibrated at the temperatures of freezing of zinc, antimony, and copper, made by one of the authors, $\dagger$ over a period of several years, on the reproducibility of these fixed points, as given by metals from different makers, are also included. The thermoelectric determinations at the lower temperatures are less precise than those with resistance thermometers.

* All tables except Nos. I, I I, I2, I5, and 25, are in the appendix.

$\dagger$ Burgess. 
With the exception of the silver from the United States Mint in Philadelphia, the copper from the Baltimore Copper Works, and the aluminium from the Pittsburgh Reduction Works, all the materials were purchased without specifying other than the usual purest product of the several chemical manufacturers. All the metals were protected from oxidation and the measurements were carried out as explained below. A very sharp freezing point, i. e., a constant temperature extending over some minutes, can be obtained with all the metals used except aluminium, if they are pure and of sufficient bulk. This fact eliminates all ambiguity in the definition of the temperature of a freezing point.

Electric Furnaces.-The freezing and melting points were taken in well-insulated resistance furnaces, mounted vertically, with two separate heating coils of platinum ribbon, o.o $\mathrm{mm}$ thick and $2 \mathrm{~cm}$ wide, wound on porcelain tubes, with the turns so spaced as to allow the establishment of a uniform temperature over a considerable length of furnace by using a separate rheostat control in each circuit. The arrangement of a furnace containing a crucible of metal with a thermometer in place is shown in Plate III.

Furnace Manipulation.-With the above set-up, it is possible to hold a metal at its freezing point for an indefinite time. In practice it was the custom, when taking a freezing point, to so adjust the currents in the heating circuits as to obtain a freeze extending over ten to fifteen minutes, during which interval, for a pure metal, the temperature would usually remain constant to a few hundredths of a degree. At the higher temperatures it was deemed desirable to prevent overheating of the thermometer head in order to reduce to a minimum the thermal emf's. This was effected by passing an air current through the double-walled head of the thermometer. When this was done the head could be grasped by the hand for stirring without discomfort. In order to avoid breaking the porcelain containing tube, it was preheated in a gas furnace before introducing it into the metal.

Crucibles.- Two kinds of crucible were used, of Dixon graphite and of Acheson graphite, the latter being turned from rods. The crucibles were about $13.5 \mathrm{~cm}$ inside depth, $5 \mathrm{~cm}$ inside diameter at the top, and $3.5 \mathrm{~cm}$ at the bottom, holding therefore about 

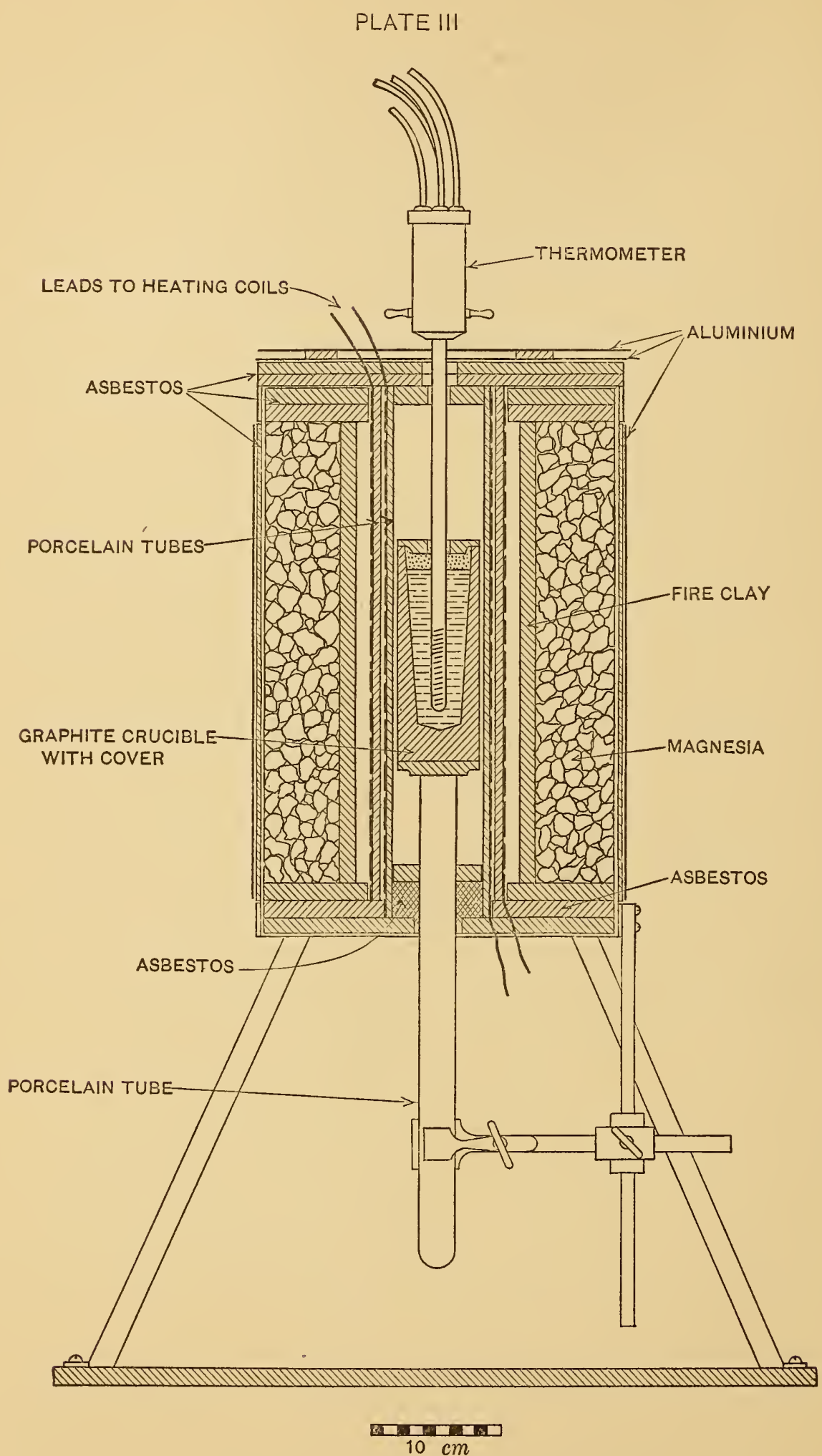

CRUCIBLE RESISTANCE FURNACE 
r8o cc of metal, or about I.5 kilograms. A chemical analysis of the Acheson graphite, cut from several crucibles, was made by Dr. W. F. Hillebrand of this bureau. The total ash was found to be 0.3 per cent, one-half of which was $\mathrm{Fe}_{2} \mathrm{O}_{3}$ (equivalent to o.I I per cent $\mathrm{Fe}$ ). No differences in the observed values of any of the freezing points could be traced to the effects of impurities introduced from the crucibles.

Surface Oxidation and sublimation of the metals were practically eliminated, even for antimony, by putting a layer of powdered graphite and a graphite crucible cover over the surface.

Depth of Immersion.-Measurements were usually taken with the thermometer immersed to within I cm of the bottom of the crucible. The effect of varying depths of immersion was carefully studied by taking several consecutive freezes in each metal, everything else remaining the same. No difference greater than a few hundredths of a degree in the freezing points could be detected when the thermometer was raised $2 \mathrm{~cm}$ from its normal position in zinc, antimony, silver, and copper. Raising a thermometer 4 $\mathrm{cm}$ in zinc gave a freezing point too low by $\mathrm{I}^{\circ} \cdot 3$.

Undercooling.-To avoid any considerable undercooling, as well as to insure a more certain uniformity of temperature over the length of the thermometer coil, especially when working with such metals as antimony, which, when left quiet, naturally undercools considerably and which has also a low heat conductivity, it was the practice to stir the liquid metal as long as possible by means of the thermometer itself.

Most, if not all, of these metals develop some undercooling, which is in general the more marked the higher the temperature to which the metal is brought above its freezing point, or the more rapid the rate of cooling, unless the liquid metal is stirred. When undercooling occurs, the temperature to which the metal rises is not appreciably different from the freezing point as determined when undercooling is practically eliminated by stirring.

The Observations. - In tables 3 to Io in the appendix are given the necessary data relating to all the freezing and melting point determinations with thermometers of pure platimum $[\delta=\mathrm{I} .50$ to $\mathrm{I} .5 \mathrm{I}$ ], of impure platinum [Therm. No. I $787 \mathrm{~A}(\delta=\mathrm{I} .57 \pm)$ and No. I $787 \mathrm{E}(\delta=\mathrm{I} .80)$ ] and of palladium [Therm. No. I $787 \mathrm{G}(\delta=$ $5249-N o .2-09-2$ 
2.88土)]. No observations are omitted except a single day's work on copper, when a leak was found in the bridge circuits.

It will be seen that the thermometers of impure platinum and the palladium thermometer invariably give a lower temperature, $t$, than those of pure platinum for temperatures below the S. B. P. and a higher temperature above the S. B. P.

Tin.-Eileven determinations of the freezing point were made on three samples of tin: Eimer \& Amend C. P. rods of 1905 in a Dixon graphite crucible, Baker \& Adamson C. P. rods of 1905 in a Dixon crucible, and "Kahlbaum" tin of 1909 in an Acheson graphite crucible. The essential details of these determinations are given in Tables 3 , and 12 (p. I 74), from which it would appear that on the scale of the resistance thermometer of pure platinum the freezing point of "Kahlbaum" tin is $231^{\circ} .92 \pm 0.02$, and that of each of the other two samples is about $0^{\circ} .05$ lower. Undercooling, which is considerable when the metal cools without stirring from a relatively high temperature, could not be completely eliminated by stirring for any of these samples.

Measurements made with $P t-R h$ and $P t-I r$ thermocouples in 1903-I905, assuming "Kahlbaum" tin to freeze at 23I .92 , gave the following results:

F. P. of Tin.--Thermoelectric Determinations.

\begin{tabular}{|c|c|c|c|}
\hline Source & $\begin{array}{l}\text { Number of } \\
\text { Couples } \\
\text { Used }\end{array}$ & $\begin{array}{c}\text { Number of } \\
\text { Dets. }\end{array}$ & $\begin{array}{c}\text { Freezing } \\
\text { Point }\end{array}$ \\
\hline "Kahlbaum" . ......................... & 4 & 6 & $231^{\circ} .92$ \\
\hline Eimer \& Amend (Metallic, Henderson Bros.) .... & 4 & 8 & 231.99 \\
\hline Eimer \& Amend C. P. sticks . & 4 & 4 & 231.85 \\
\hline Baker and Adamson C. P. sticks & 2 & 2 & 231.97 \\
\hline
\end{tabular}

In these earlier experiments no undercooling was observed for the Baker \& Adamson tin.

The freezing point of tin is therefore readily reproducible to within $0^{\circ}$.I with material purshased from various chemical firms. Even "Metallic" tin, i. e., tin of commercial purity, seems to have about the same freezing point as the pure metal. This may be due to the fact that the effect of some impurities on the freezing 
point of tin is first to lower this temperature very slightly, and then to raise it with increasing percentage of impurity. This would explain why the commercial tin appears to have the highest freezing point of all the samples. Its freezing point curve is less flat than for the purer tin, as should be the case when impurities are present.

Cadmium.-The samples of cadmium used were "Kahlbaum," Baker \& Adamson, and J. T. Baker,* all purchased in r909. As shown in Tables 4 and 12 , the freezing point of the "Kahlbaum" sample is $32 \mathrm{I}^{\circ} . \mathrm{OI} \pm 0.04$; of the Baker \& Adamson metal, $320^{\circ} \cdot 39$, and of J. T. Baker's, $320^{\circ} \cdot 44$.

The undercooling of cadmium before freezing can be nearly eliminated by stirring.

Lead.-Three samples of this metal were used, "Kahlbaum," J. T. Baker's "Lead Granulated, Test Lead," stated to contain no silver; and Baker \& Adamson's "Test Lead, free from Ag," all of 1909. As shown in Tables 5 and I2, the mean value of the freezing point of lead is $327^{\circ} .43$, the determinations for a single sample agreeing to $0^{\circ} .03$. The "Kahlbaum" lead is about $0^{\circ} .3$ lower than Baker's and $0^{\circ} .2$ lower than Baker \& Adamson's. Lead undercools slightly even with stirring.

Determinations with four thermocouples, in 1903 and 1905, of the freezing point of Eimer \& Amend C. P. lead gave from $327^{\circ} \cdot 3$ to $327^{\circ} .5$. Pig lead had a less sharp freezing point some $\mathrm{I}^{\circ} .5$ low, and lead pipe was about $2^{\circ}$ low. The data for these commercial samples of lead are given for the reason that lead hardening and annealing baths are used in the industries, and the question has often arisen whether this grade of lead can be used as a control point for industrial pyrometers.

Zinc.-More determinations of the freezing point were made with zinc than with any other metal, and the results obtained with the platinum thermometers, as shown in Tables 6 and 12 , indicate a remarkable degree of concordance, both for determinations by means of different thermometers of the freezing point of the same material and for determinations with material from different sources. Thus, samples of "Kahlbaum" zinc bought in I 903, I 907 ,

\footnotetext{
* Marked "Cadmium Metal" with an indicated analysis showing iron 0.004 per cent and arsenic, trace.
} 
and 1908 give a freezing point of $419^{\circ} .37 \pm 0.02$, one of these being in Acheson and the others in Dixon graphite crucibles. One of these samples had been in use in the same crucible since 1903 for calibrating thermocouples.

Determinations of the freezing points were also made on the following samples:

Eimer \& Amend "C. P. in sticks," two crucibles of 1903 and 1905 mixed, and Baker \& Adamson "C. P. in sticks." The former,* which had been repeatedly used, gave a lower value, 41 $9^{\circ} .25$, and the latter a slightly higher value, $419^{\circ} \cdot 42$, than the Kahlbaum zinc.

Measurements made with thermocouples in I 905 gave the following results for the freezing point taken in a gas furnace:

F. P. of Zinc-Thermoelectric Determinations.

\begin{tabular}{|c|c|c|c|}
\hline Source & $\begin{array}{c}\text { Number of } \\
\text { Couples } \\
\text { Used }\end{array}$ & $\begin{array}{l}\text { Number of } \\
\text { Dets. }\end{array}$ & $\begin{array}{c}\text { Freezing } \\
\text { Point }\end{array}$ \\
\hline "Kahlbaum" "............. & 8 & 10 & $419^{\circ} .3$ \\
\hline Eimer \& Amend "C. P. in sticks". & 8 & 12 & 419.0 \\
\hline Eimer \& Amend "Metallic". & 4 & 6 & 416.8 \\
\hline Baker \& Adamson "C. P. in sticks". & 4 & 8 & 419.1 \\
\hline
\end{tabular}

Other thermoelectric determinations made in 1907 gave equally concordant results.

The undercooling of zinc is almost inappreciable, being only a few hundredths of a degree unless the metal has been considerably overheated. It is therefore unnecessary to stir when taking a freeze.

A considerable number of determinations of the melting point of zinc, made with the resistance thermometers, gave results agreeing to $\mathrm{O}^{\circ}$. I with the freezing point, even for fairly rapid heating.

Antimony.- "Kahlbaum" antimony $\dagger$ has been used as a fixed point for a number of years with satisfaction, and this material,

* Dr. E. T. Allen finds, for two samples from different lots of Eimer \& Amend zinc "C. P. in sticks," total impurities 0.063 and 0.049 per cent, with lead as the principle component, it being 0. 05I and o.04I; see Phys.Rev. 19, p. I77； 1904; Am. J1. Sci. 26, p. $454 ;$ igo8.

$\dagger$ An analysis of this material has been published; Fritz Henz, Inaugural Dissertation, Zurich, 1903 (Pub. in Leipzig), $\mathrm{Fe}=0.012, \mathrm{Cu}=0.004, \mathrm{~Pb}=0.003$ per cent. 


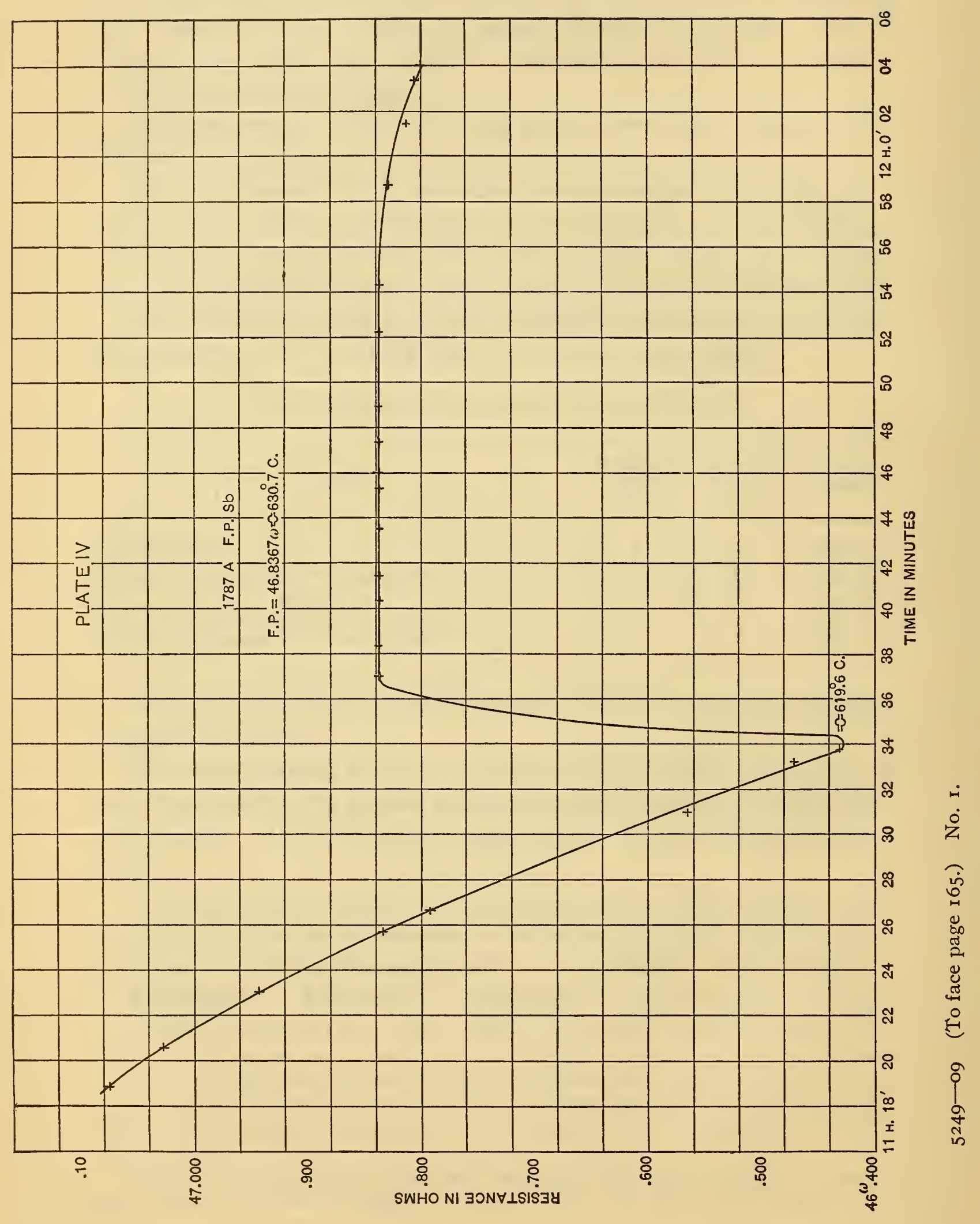


purchased at different times over a period of six years, appears to be a very uniform product as determined by the constancy of the freezing point. Antimony from other sources, however, so far as our experience goes $*$ is not to be relied upon as being of sufficient purity to warrant its use for defining a fixed temperature by means of its freezing point.

Antimony oxidizes very rapidly in the air and somewhat even in the presence of graphite, but this oxidation does not appear to affect the freezing point appreciably. This metal normally undercools very considerably, even to the extent of $30^{\circ}$ or more, but whether this is nearly eliminated or not, by stirring, practically the same temperature of freezing is obtained. In Plate IV is given a freezing point curve for antimony when the metal is stirred with the thermometer. The melting point agrees with the freezing point to within $\mathrm{O}^{\circ} . \mathrm{I}$, and they approach each other as the slowness of freeze and melt are increased.

Seven determinations of the freezing point of three samples of "Kahlbaum" antimony with two resistance thermometers gave $630^{\circ} .7 \mathrm{I} \pm 0.13$. (See tables 7 and I2.)

Thermoelectric determinations in gas and electric furnaces of the freezing point of antimony from various sources gave the following results, assuming $\mathrm{Sb}$ "Kahlbaum" $=630^{\circ} \cdot 7$ :

F. P. of Antimony-Thermoelectric Determinations.

\begin{tabular}{|c|c|c|c|c|}
\hline Source & $\begin{array}{l}\text { Date of Pur- } \\
\text { chase }\end{array}$ & $\begin{array}{l}\text { Number of } \\
\text { Couples }\end{array}$ & $\begin{array}{l}\text { Number of } \\
\text { Dets. }\end{array}$ & $\begin{array}{l}\text { Tempera- } \\
\text { ture }\end{array}$ \\
\hline "Kahlbaum" ............. & 1903-1909 & 6 & 8 & $630^{\circ} .7$ \\
\hline Eimer \& Amend C. P. . . . . . & 1903 & 4 & 6 & 621.0 \\
\hline Eimer \& Amend "Metallic" ... & 1903 & 2 & 6 & 619.1 \\
\hline J. T. Baker $\dagger$ " Antimony metal " & 1909 & 2 & 4 & 626.2 \\
\hline Baker \& Adamson. . . . . . . . . . . & 1909 & 2 & 4 & 626.0 \\
\hline Merck " Highest Purity". & 1907 & 1 & 2 & 624.7 \\
\hline
\end{tabular}

* See also Day and Allen, Phys. Rev. 19, p. i 77 ; 1904. $\dagger$ Analysis on label: $\mathrm{Fe}=0.01, \mathrm{Cu}=0.005, \mathrm{As}=0.002$. $\mathrm{Pb}=0.002, \mathrm{Zn}=0.000, \mathrm{Sn}=0.000 \%$. 
It is evident that for this metal the determination of the freezing point is a very delicate test of the purity of the sample.

Silver.-Only one sample of silver was used, purchased in the form of drops from the Philadelphia mint, as the purest silver obtainable. Its analysis was given as 99.995 fine. An analysis of another sample of this grade of silver has also been made by Dr. E. F. Allen,* who found only 0.0032 per cent impurities, onethird of which was iron.

Eight determinations with three resistance thermometers gave a freezing point of $960^{\circ} .88 \pm 0.16$. See Tables 8 and 12 , which also show how constant the indications of these thermometers remain even at such a high temperature, as is seen from a comparison of the calibrations made before and after the freezing point determinations.

The silver point is very sharply defined, as might be expected from the high conductivity and purity of this metal, and although there is some slight undercooling if the freezing point is approached from a high temperature this disappears entirely with stirring or when the rate of cooling before freezing is small. Sample freezing point determinations with and without undercooling are shown in Plate V.

Copper.-As an upper limit for the exact determination of temperatures by the usual type of platinum resistance thermometer, the freezing point of copper was chosen, and an examination of the data in Tables 9 and 12 shows that the precision attainable at this temperature is already considerably less than at the silver F. P., though still sufficiently good for work within about $I^{\circ}$. On account of the changes in the constants of the platinum thermometer, which occur at this high temperature, it is better to depend on the thermocouple for temperature measurements in this region, since the advantages of very great sensitiveness of the resistance instrument are masked by these changes.

Copper from several sources was used. The only product furnished with an analysis was that obtained from the Baltimore Copper Smelting and Rolling Company, which company very 
kindly furnished us, in 1908 , with a specially prepared electrolytic sample in the form of cathode plates.*

This copper had a freezing point of $1083^{\circ} .0 \pm 0.5$ from seven determinations with three resistance thermometers.

Kahlbaum electrolytic copper in a Dixon crucible gave $108 \mathrm{I}^{\circ} .4$; a Dixon crucible filled with copper of uncertain origin, but which had been in use for several years, $1082^{\circ} .7$; and Eimer \& Amend's "Copper, $\dagger$ C. P. drops, cooled in hydrogen" of 1909, $1083^{\circ} .9$ in Acheson graphite for two determinations with the same thermometer.

It should be noticed that very slight changes in either the fundamental or the difference coefficient will cause considerable differences in the computed temperatures at the copper point. Thus a change in $\delta$ from $\mathrm{I} .5^{\circ}$ to $\mathrm{I} .5 \mathrm{I}$ is equivalent to about $\mathrm{I}^{\circ}$ temperature difference at $1083^{\circ}$.

When the metal is protected from oxidation, the copper freezing point is very sharp, the undercooling being at most only $0^{\circ} .2$ to $0^{\circ} \cdot 3$ (see Plate VI), and often inappreciable.

The copper freezing point has been used with entire satisfaction as a fixed point in calibrating pyrometers at the Bureau of Standards since 1903 . This metal is so readily obtained sufficiently pure, at small cost, that its freezing point is particularly adapted for use as a standardizing temperature.

Even commercially pure copper in the form of bars or wire usually has a freezing point within a degree of that of the specially prepared material.

A great many determinations of this temperature were made by means of thermocouples from 1903 to 1909 , on material from various sources, both in gas and electric furnaces. Among the kinds of copper used were copper wire, copper in bars, Baker \&

* Mr. Wm. M: Pierce reports the analysis of this copper as follows.

$\mathrm{Ag}, \mathrm{Au}, \mathrm{As}, \mathrm{Sb}, \mathrm{Pb}$, none; Fe, S, trace; $\mathrm{Cu} 99.995$ per cent by direct electrolytic test.

"In making the test for $\mathrm{Ag}, \mathrm{As}, \mathrm{Sb}, \mathrm{Fe}, \mathrm{S}$, and $\mathrm{Pb}$, large quantities of the samples were used: six assay tons for $\mathrm{Ag}, 300$ grams for $\mathrm{As}$ and $\mathrm{Sb}$, and 200 grams for $\mathrm{Fe}$, $\mathrm{S}$, and $\mathrm{Pb} . "$

† An analysis of this grade of copper is given by Day and Allen, Phys. Rev. 10, p. I 80, r904, showing total impurities $=0.040$ per cent, of which $\mathrm{Fe}=0.0$ I, $\mathrm{Zn}=0.0$ Io, $\mathrm{Ag}=0.0 \mathrm{I}$, and $\mathrm{Pb}=0.00 \mathrm{r}$. 
Adamson's "copper, C. P. reduced by hydrogen," and Kahlbaum's electrolytic granulated. No certain difference could be detected in the freezing points of any of these materials, but when using the powdered copper reduced by hydrogen great care has to be taken not to oxidize the metal. When determinations are made in a gas furnace the metal tends to oxidize partially, even in graphite,

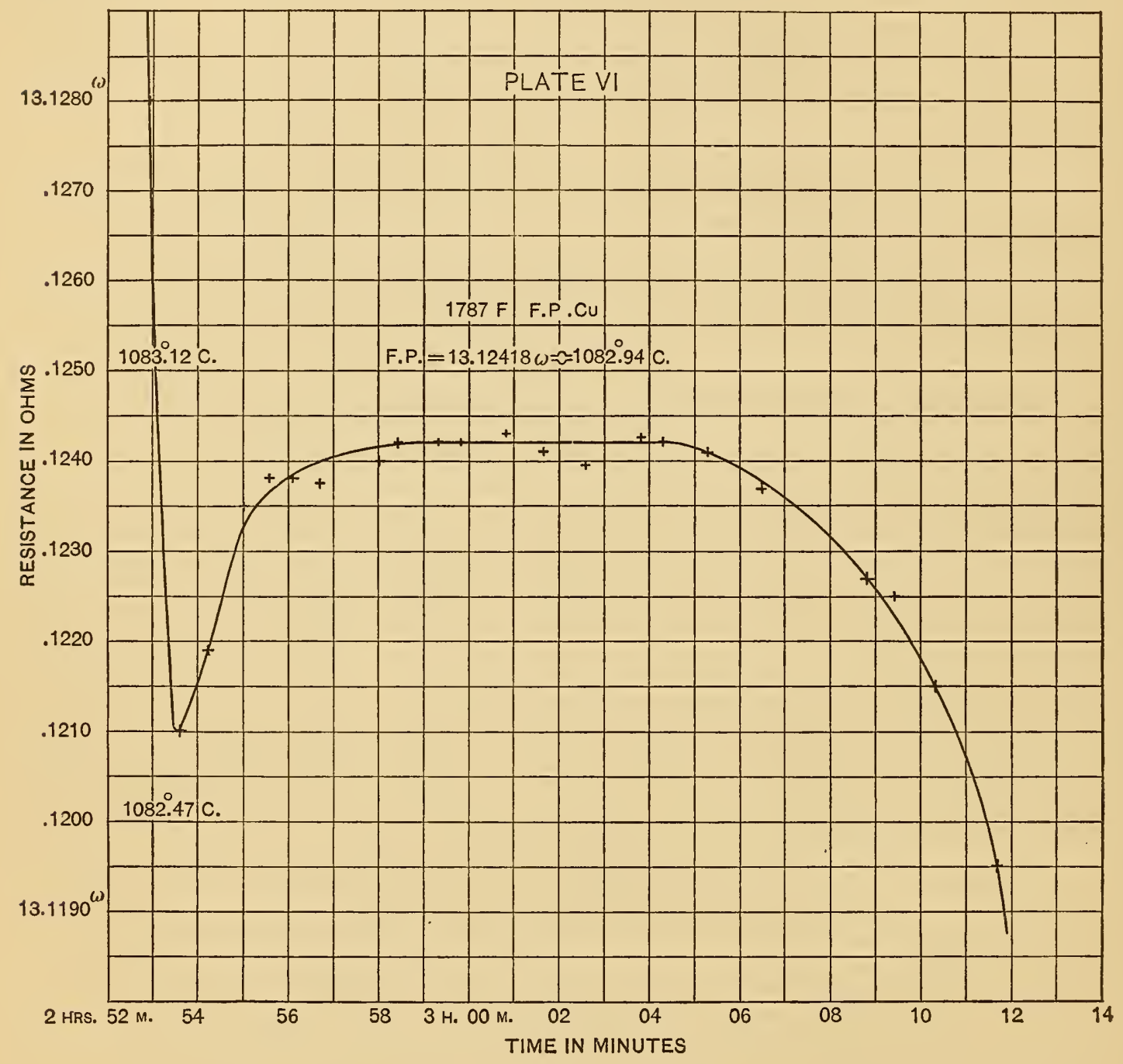

unless a reducing flame is used. The presence of the soluble oxide, $\mathrm{Cu}_{2} \mathrm{O}$, lowers the copper freezing point until, at saturation, the copper-cuprous oxide eutectic point is reached at about $\mathrm{I}, 063^{\circ}$. In a gas furnace, however, unless special precautions are taken, neither the freezing point of pure copper nor that of the eutectic of $\mathrm{Cu}-\mathrm{Cu}_{2} \mathrm{O}$, is obtained alone, but an intermediate temperature, which is usually nearer the $\mathrm{Cu}$ F.P. The eutectic point can always be detected except for very small percentages of the oxide. 
Silver-Copper Eutectic.-With the exception of the "Kahlbaum" antimony point at $630^{\circ} .7$ there is no satisfactory fixed point between zinc and silver or copper, and it is especially desirable to have such a temperature located in the neighborhood of $800^{\circ}$. We have found that the $\mathrm{Ag}-\mathrm{Cu}$ eutectic alloy $\left(\mathrm{Ag}_{3} \mathrm{Cu}_{2}\right)$ meets this requirement in a very satisfactory way.

A preliminary study of the conditions necessary for the constancy of this eutectic temperature was made with a thermocouple and gave the following results, using as components silver from the Philadelphia mint, and copper, "C. P. drops cooled in hydrogen," from Eimer \& Amend:

Silver-Copper Eutectic-Thermoelectric Determinations.

\begin{tabular}{|c|c|c|c|c|c|}
\hline Per cent $\mathrm{Ag}-\mathrm{Cu}$ & $\begin{array}{l}\text { Composition in } \\
\text { Grams } \mathrm{Ag}-\mathrm{Cu}\end{array}$ & $\begin{array}{c}\text { Range of } \\
\text { Transforma- } \\
\text { tion } \\
\text { Temperature }\end{array}$ & $\begin{array}{l}\text { Alloy, cooled } \\
\text { from }\end{array}$ & $\begin{array}{c}\text { Eutectic Tem- } \\
\text { perature }\end{array}$ & Remarks \\
\hline $50-50$ & $150-150$ & $1^{\circ} .5$ & $828^{\circ}$ & $777^{\circ} .50$ & \multirow{5}{*}{$\begin{array}{c}\text { Slight under- } \\
\text { cool. }\end{array}$} \\
\hline $50-50$ & $150-150$ & .3 & 812 & 777.89 & \\
\hline $50-50$ & $150-150$ & 1.1 & 821 & 778.72 & \\
\hline $50-50$ & $150-150$ & .2 & 906 & 778.23 & \\
\hline $50-50$ & $150-150$ & .5 & 977 & 777.89 & \\
\hline $50-50$ & $150-150$ & .4 & 857 & 776.33 & Stirred. \\
\hline $50-50$ & $150-150$ & .4 & 929 & 776.43 & Stirred. \\
\hline $60-40$ & $255-150$ & .8 & 945 & 773.07 & Stirred. \\
\hline $60-40$ & $255-150$ & .7 & 818 & 774.99 & \\
\hline $71-29$ & $355-145$ & .0 & 825 & 779.49 & $\left\{\begin{array}{c}\text { Slight but long } \\
\text { undercool. }\end{array}\right.$ \\
\hline
\end{tabular}

These results show that the presence of an excess of copper is disadvantageous in two ways: first, the eutectic temperature is not sharply marked, as shown by the column headed "range of transformation temperature"; and second, the value of the eutectic temperature observed depends upon the degree of mixture of the excess component with the eutectic, as is shown by comparing the freezes taken with and without stirring. Although the lowest temperature is obtained when stirring the noneutectic mixture, yet this appears to be considerably below the true eutectic temperature, as obtained when the alloy of the eutectic composition 


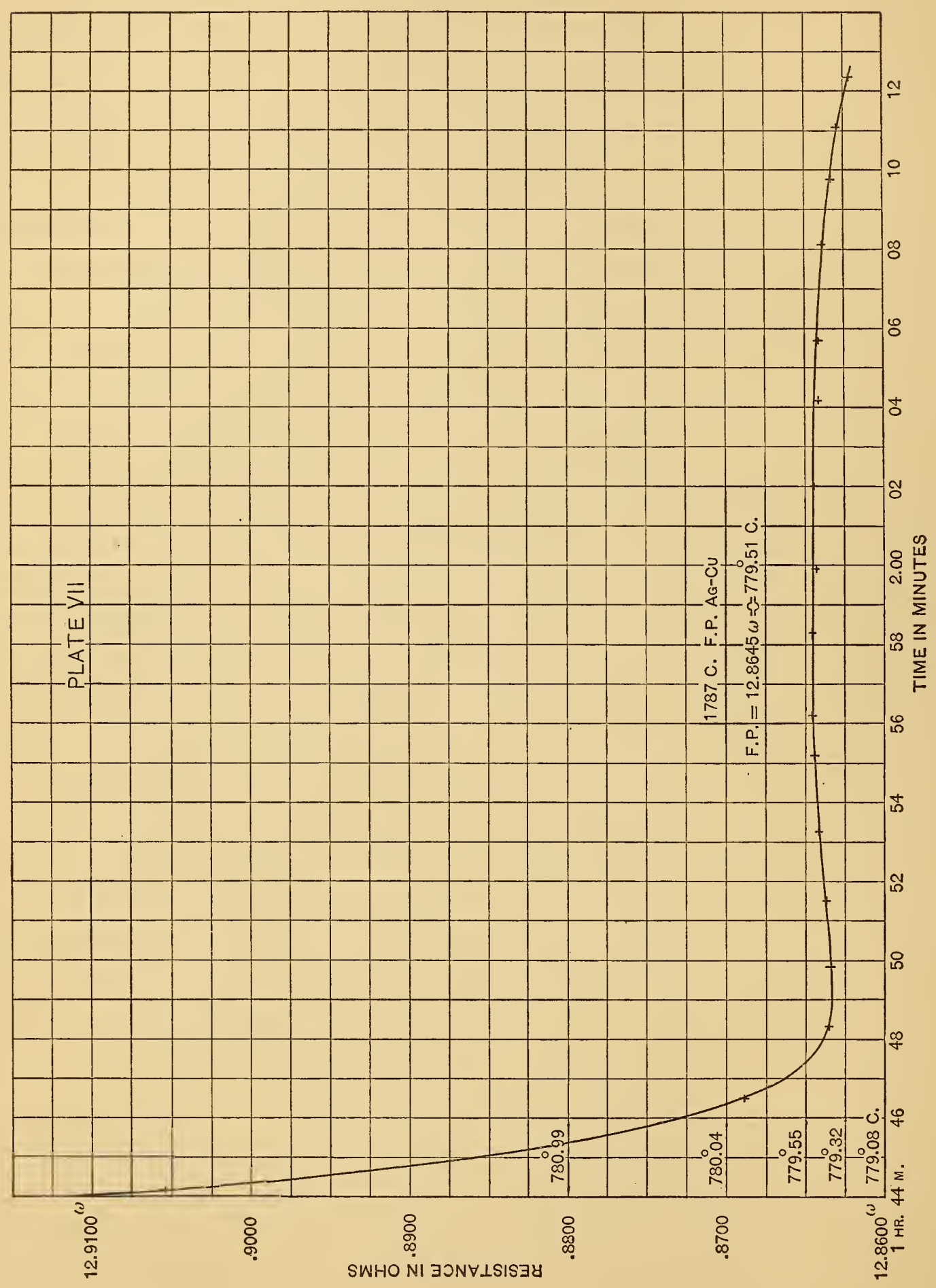


is used. The reason for this retarding of the separation of the eutectic by the admixture of copper is uncertain, but it may be due to the greater conductivity of the copper.

For the measurements with the resistance thermometers, an Acheson crucible was filled with I 200 grams of the alloy $7 \mathrm{rAg}-29$ $\mathrm{Cu}$; measurements were also made with the eutectic composition $72 \mathrm{Ag}-28 \mathrm{Cu}$, and with $73 \mathrm{Ag}-27 \mathrm{Cu}$. The observations are shown in Table ro and a summary is given in Table $\mathrm{r} 2$. The best value to assign to the eutectic temperature from these observations is $779^{\circ} .20 \pm 0.15$

This temperature is as sharply marked as the freezing point of most of the pure metals; a sample freezing curve is given in Plate VII. It will be noticed that the undercooling is slightly different from that of a pure metal. This undercooling is of the order of $0^{\circ} . \mathrm{I}$; but instead of the temperature rising rapidly to its maximum, as in the case of a metal, the rise is very slow, taking almost half of the time of duration of a freeze. This slight undercooling could not be avoided by stirring.

Copper-cuprous 0xide Eutectic.-Some measurements were made with thermocouples in order to determine the temperature and reproducibility of the $\mathrm{Cu}-\mathrm{Cu}_{2} \mathrm{O}$ eutectic point in both gas and electric furnaces. In agreement with the work of Heyn,* we find that the cooling curve for copper in the presence of its oxide when the mixture has been heated in a gas furnace does not, in general, correspond to the composition of the components originally put into the crucible, on account of the varying reducing and oxidizing action of the atmosphere in such a furnace. Unless the atmosphere is strongly reducing, however, the eutectic point is sharp to within $\mathrm{I}^{\circ}$ at $1063^{\circ}$. When the alloy of the eutectic composition $\left(\mathrm{Cu}_{2} \mathrm{O}=3.5\right.$ per cent) is introduced into an electric furnace of the type used in these experiments (Plate III), the eutectic temperature is as sharply defined as the freezing point of pure copper and is normally preceded by an undercooling of 2 or $3^{\circ}$. From six observations we find this eutectic temperature to be $1063^{\circ} .2 \pm 0.3$ on the temperature scale of this investigation (on which F.P. of $\mathrm{Cu}=1083^{\circ} .0$ ).

*C. Heyn, Kupfer und Sauerstoff, Mitt. Königl Tech. Versuchsanstalten 18, p. $315 ; 1900$. 
Aluminium.-No determinations of the freezing point of aluminium were made with the platinum-resistance thermometer. Two series of measurements were carried out, however, with thermocouples, one in 1905 and the other in 1909 , on the same material but with separate samples. The Pittsburgh Reduction Company in 1903 furnished us with a specially prepared sample of exceptional purity. The analysis of this sample was given as: $\mathrm{Al}, 99.78$; $\mathrm{Si}, 0.12 ; \mathrm{Fe}, \mathrm{o.I0} ; \mathrm{Cu}$, trace. The other samples were in the form of bars from Eimer \& Amend and from Kahlbaum.

On the temperature scale used in this investigation the following values were found for the freezing points of these aluminium samples:

F. P. of Aluminium-Thermoelectric determinations.

\begin{tabular}{|c|c|}
\hline Source & A1 F. P. \\
\hline Pittsburgh Reduction Co.. & 658.0 \\
\hline Kahlbaum, bars........ & 654.5 \\
\hline Eimer \& Amend, bars........ & 656.0 \\
\hline
\end{tabular}

The observations of 1905 and 1909 agree to within $I^{\circ}$, which is about the uncertainty in successive observations with the same thermocouple. The freezing point of aluminium is not sharp, even for the purest of these samples, so that this metal is the least adapted of all we have tried for defining a fixed temperature. Small quantities of an impurity, such as iron or silicon, lower the aluminium freezing point very considerably.

Metals from Different Sources.-The data on the freezing points of the metals from various sources may be grouped together so as to show the reproducibility of the fixed temperature that each defines. This has been done in Table II, in which are indicated, for each sample, the source of the material, a brief description, the date of purchase, and the freezing point. In the last column is given the "reproducibility factor" for each metal, which we have taken as the average deviation of a single observation in degrees $\mathrm{C}$ from the mean $\mathrm{F}$. P., including only those samples of C. P. grade. 
TABLE 11.

Reproducibility of Fixed Points by Means of Metals from Different Sources.

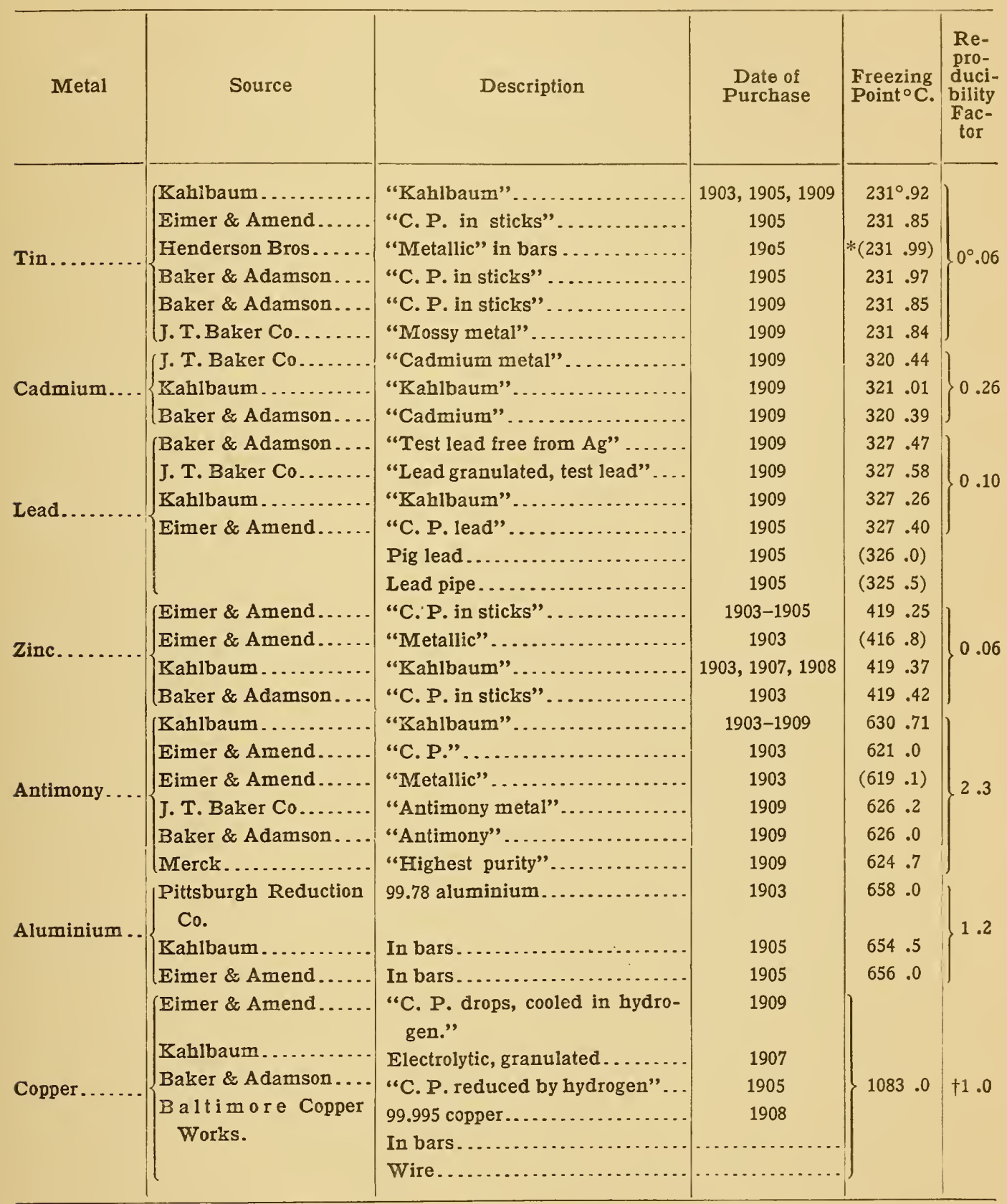

* Numbers in parentheses are not included in computing the "Reproducibility Factor." $\dagger$ This uncertainty is due more to oxidation than to impurities. 


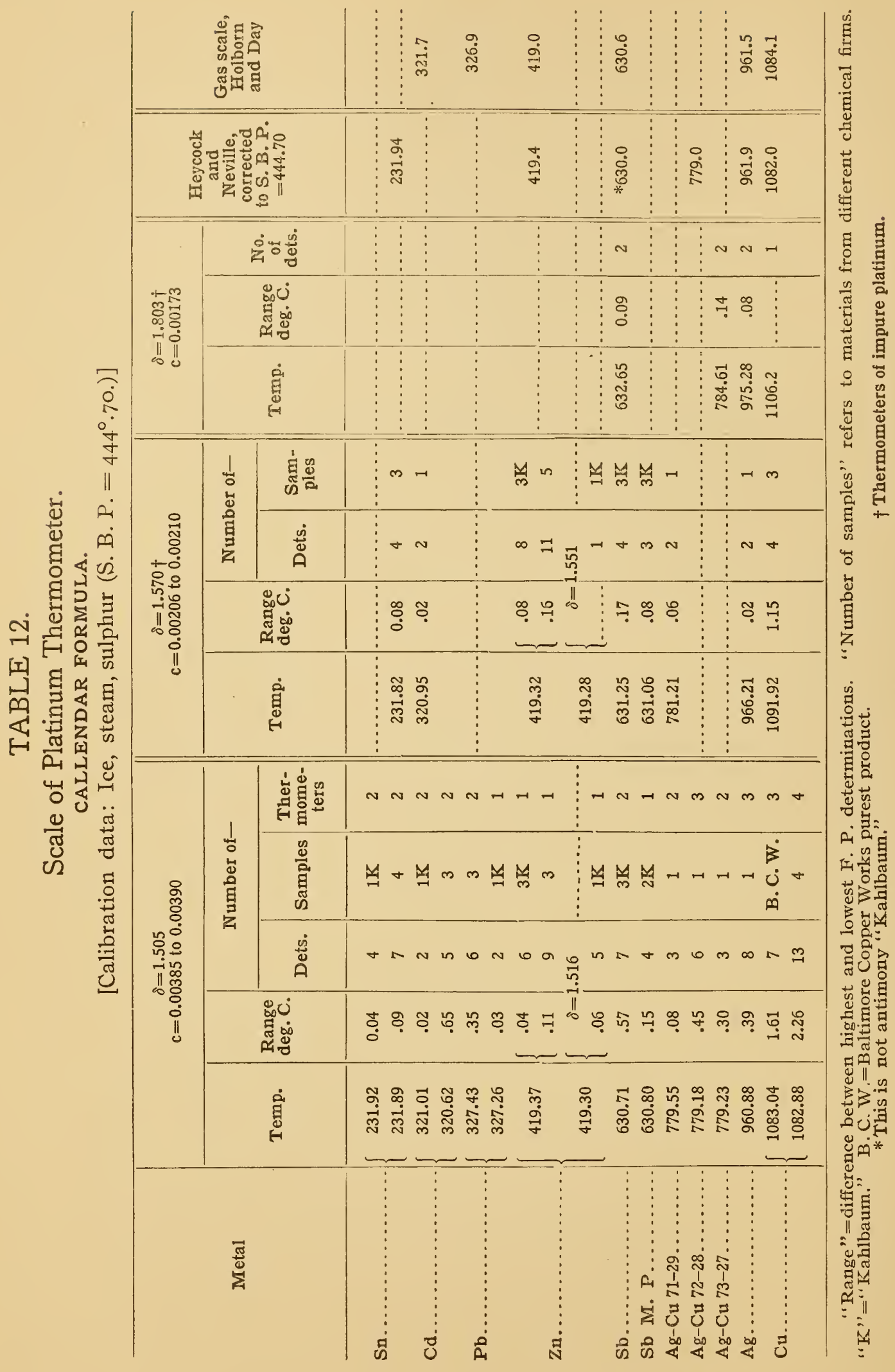




\section{THE SCALE OF THE PLATINUM THERMOMETER.}

The scale defined by the platinum thermometer, calibrated in ice, steam, and sulphur, may be best expressed in terms of the freezing points of the pure metals. In Table $\mathrm{r} 2$ are grouped the results of the determinations of a series of such freezing points as obtained with platinum of several grades of purity.

The temperatures determined with thermometers of pure platinum, for which the fundamental coefficient is 0.0039 , and the difference coefficient 1.50 , are evidently in very close agreement with temperatures on the gas scale. When, however, thermometers are made of impure platinum having $\delta=\mathrm{I} .57$ or $\mathrm{r} .8 \mathrm{o}$, as shown in the table, and the Callendar method of reduction is used, the agreement of the two temperature scales, platinum resistance and gas, is seen to be far from satisfactory.

The precision at the various fixed points is also shown in Table I 2, where the column headed "Range," when a single sample is used, gives a measure of this precision in terms of the difference between the highest and the lowest determinations, omitting none.

An idea of the reproducibility of these fixed points in terms of samples from several sources is also given by this same column, "range," for those cases in which several samples are used, as indicated in the column headed "number of samples."

The freezing points determined by Heycock and Neville ${ }^{27}$ with the resistance thermometer are also included in Table $\mathrm{I} 2$. They are computed for S. B. P. $=444^{\circ} \cdot 70$ instead of for S. B. P. $=444^{\circ} \cdot 53$.

Correction for Thermometers of Impure Platinum.-From the measurements with thermometers made of wires with various difference coefficients it is possible to find, graphically, the corrections necessary to reduce the indications of any thermometer of impure platinum to the scale of the thermometer of pure platinum.

Such a series of corrections is given in Table $\mathrm{I} 3$ for values of $\delta$ varying from $\mathrm{I} .525$ to $\mathrm{I} .900$, and for temperatures from $200^{\circ}$ to $\mathrm{I} \mathrm{OO} \mathrm{O}^{\circ}$. The corrections are in degrees $\mathrm{C}$ and reduce the apparent temperatures, calculated by the Callendar formula from readings at the ice, steam, and sulphur points, to the scale of the pure platinum thermometer of $\delta=\mathrm{I} .505$. 
Precision of Measurement with Platinum Thermometer.-The range of values of all the $\mathrm{F}$. P. determinations taken with a single thermometer in a given crucible of metal will serve as a measure of the precision of measurement attainable with that thermometer at the temperature in question.

In Table 14 is given the range of temperatures at a series of fixed points obtained with thermometers $1787 \mathrm{C}$. and $1787 \mathrm{~A}$., the former of pure platinum and the latter of platinum for which $\delta=\mathrm{I} .57$. It will be seen that the greatest range observed at any temperature up to the copper point is $0^{\circ} .4$, and the average range is only $0^{\circ}$.I I, or practically within the reproducibility of many of these metals from new samples. The thermometers of impure platinum give as good precision as those of pure platinum; but it is to be remembered that the constants of the impure metal undergo the greater changes with heating, necessitating more frequent recalibration of such thermometers.

Modification of Callendar's Formula.-For thermometers of impure platinum, used at high temperatures, Callendar's formula may be modified so as to give results agreeing very closely with temperatures on the scale of the thermometer of pure platinum or on the gas scale. If a fourth calibration point is taken, such as the copper or silver freezing point, the difference coefficint may be written in the form, $\delta=a+b t$. Platinum temperatures, $p t$, are then computed in the usual way; but the true temperatures are now obtained by using the interpolated value of $\delta$ for that temperature, which need be known only approximately.

Using the silver freezing point as the fourth calibration temperature to determine $a$ and $b$, we have calculated several of the freezing points of the metals by this method for thermometers of impure platinum and of palladium, as shown in Table 15 , where are also grouped for comparison the temperatures on the scale of pure platinum and for the thermometers of impure platinum, as reduced by the ordinary Callendar method of calibration (i.e., at ice, steam, and S. B. P.).

It is evident from an inspection of the table that for the impure platinum wires the calibration at four points by the modified Callendar method reproduces the temperature scale of pure platinum

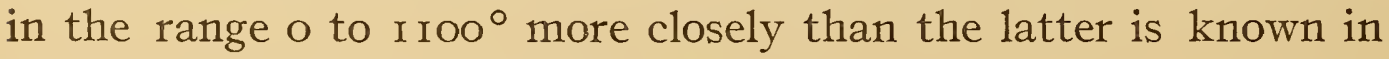
terms of the gas thermometer scale. 
TABLE 15.

Temperature Scale for Impure Platinum and Palladium. Modification of Callendar Formula.

$[\delta=a+b t$ (from S. B. P. and Ag F. P.). $]$

\begin{tabular}{|c|c|c|c|c|c|c|c|}
\hline \multirow{3}{*}{ Metal } & \multirow{3}{*}{$\begin{array}{l}\text { F. P. on } \\
\text { scale of } \\
\text { Therm. of } \\
\text { Pure Pt } \\
\delta=1.505\end{array}$} & \multicolumn{4}{|c|}{ Thermometers of Impure Pt } & \multirow{2}{*}{\multicolumn{2}{|c|}{$\begin{array}{c}\text { Pd Therm. } \\
\text { No. } 1787 \mathrm{G}\end{array}$}} \\
\hline & & \multicolumn{2}{|c|}{ No. 1787A } & \multicolumn{2}{|c|}{ No. 1787E } & & \\
\hline & & $\begin{array}{c}\delta=1.570 \\
\text { from } \\
\text { S. B. P. } \\
\text { calibration }\end{array}$ & $\begin{array}{c}\delta=a+b t \\
a=1.608 \\
b=-0.0_{4} 853\end{array}$ & $\begin{array}{c}\delta=1.803 \\
\text { from } \\
\text { S. B. P. } \\
\text { calibration }\end{array}$ & $\begin{array}{c}\hat{o}=\mathrm{a}+\mathrm{bt} \\
\mathrm{a}=1.900 \\
\mathrm{~b}=-0.0_{3} 219\end{array}$ & $\begin{array}{c}\hat{o}=2.890 \\
\text { from } \\
\text { S. B. P. } \\
\text { calibration }\end{array}$ & $\begin{array}{c}\hat{o}=\mathrm{a}+\mathrm{bt} \\
\mathrm{a}=3.020 \\
\mathrm{~b}=-0.03327\end{array}$ \\
\hline Sn . . . . . . . . . . . & $231^{\circ} .90$ & $231^{\circ} .82$ & $231^{\circ} .89$ & & & $231^{\circ} .62$ & $231^{\circ} .80$ \\
\hline Cd............ & 321.01 & 320.95 & 321.05 & & . . . . . & 320.52 & 320.74 \\
\hline $\mathrm{Sb} . . .$. & 630.7 & 631.2 & 630.5 & $632^{\circ} .6$ & $630^{\circ} .8$ & 633.0 & 629.2 \\
\hline $\mathrm{Ag}-\mathrm{Cu}$ & 779.2 & 781.2 & 779.1 & 784.6 & 779.3 & 787.6 & 777.1 \\
\hline $\mathrm{Ag} . .$. & 960.9 & 966.2 & $(961.0)$ & 975.3 & $(961.0)$ & 992.5 & $(961.0)$ \\
\hline $\mathrm{Cu}, \ldots \ldots \ldots \ldots$. & 1083.0 & 1091.9 & 1083.3 & 1106.2 & 1082.3 & 1152 & 1091 \\
\hline
\end{tabular}

For the palladium thermometer the modified Callendar formula is not sufficient to give true temperatures, although up to the silver point the greatest divergence is only about $2^{\circ}$.

Other Calibration Formulæ.-It was thought worth while to see if other calibration formulæ would represent the resistancetemperature relation for platinum and palladium. Dickson ${ }^{38}$ suggested the formula for platinum:

$$
(\mathrm{R}+a)^{2}=p(t+b)
$$

where $a, p$, and $b$ are constants, and applied it to the observations of several observers. This formula possesses the apparent theoretical advantage over Callendar's of not requiring a maximum for the resistance of platinum. We find that, for thermometers of platinum or of palladium, calibrated at $0^{\circ}, \mathrm{roo}^{\circ}$, and S. B. P., Dickson's formula does not give satisfactory values of the freezing points. For example, thermometer $1787 \mathrm{C}$., of pure platinum, calibrated in this way gives $232^{\circ} .13$ for tin, and $1051^{\circ} .3$ for copper. For thermometer $1787 \mathrm{G}$, of palladium, the freezing point of copper would be $1005^{\circ}$, and of the $\mathrm{Ag}$-Cu eutectic, $754^{\circ} .4$.

The adaptability of other types of formula has been discussed at length by Callendar. ${ }^{12}$

$$
\text { 5249-No. 2-09-3 }
$$


Other Methods of Calibration at High Temperatures.-The temperature scale defined by the resistance thermometer (of pure platinum), as used in this investigation and as almost universally used, is based on calibration in ice, steam, and sulphur. Higher temperatures are then determined by an extrapolation of the resistance-temperature relation thus found. If the thermometer is intended for use at temperatures much above S. B. P., it could be standardized at other known temperatures, for example, ice, S. B. P. or F. P. of $\mathrm{Zn}$, and the F. P. of $\mathrm{Ag}$ or $\mathrm{Cu}$, in which case extrapolation would be avoided. Instead of representing the parabolic resistance-temperature relation by the Callendar equation, it would be represented by the equivalent equation:

$$
R_{t}=R_{o}\left(\mathrm{I}+a t-\beta t^{2}\right)
$$

This method of standardization was not used in the present investigation for the reason that the usual method (ice, steam, and sulphur) leads to values for the freezing points of $\mathrm{Sb}, \mathrm{Ag}$, and $\mathrm{Cu}$, which are in such excellent agreement with the best gas thermometer determinations of these freezing points that the differences are almost, if not quite, within the accuracy of measurements attained up to the present time in gas thermometry.

\section{CHANGES IN CONSTANTS OF THERMOMETERS AT HIGH TEM- PERATURES.}

Changes with Discontinuous Heating.-If the calibration data of each thermometer are arranged chronologically, the changes produced in the thermometric constants $R_{o}, F I, c$, and $\delta$, due to the various temperatures to which the instrument has been subjected, become immediately apparent. Tables 16 to 23 show these changes for the thermometers used in this investigation.

A comparison of the behavior of thermometers made of different grades of platinum and subjected to similar heat treatment shows that the constants of pure platinum undergo less change than those of impure platinum, although it is difficult to eliminate the part played by the mica frame in causing variations in these constants. It may be noted that, generally, the pure platinum shows a tendency to become less pure, as is seen by the decrease in $c$ for thermometers $1787 \mathrm{~F}, 478,479$, although for $1787 \mathrm{C}$ the 
value of $c$ remained practically constant, while for thermometers made of less pure platinum the value of $c$ increased, as if the platinum were being purified by the loss by evaporation of impurities such as iridium, due to successive heatings. In support of this view it is to be noticed that the effect of continued annealing at $\mathrm{I} \mathrm{IOO}^{\circ}$ is the same for all of the thermometers, namely, to increase the value of $c$.

For the thermometers of pure platinum there is a slight rise in zero $\left(R_{o}\right)$ amounting only to a few tenths of a degree, while for those of impure platinum and of palladium the zero falls, and, in general, by relatively much greater amounts. For example, with $1787 \mathrm{~A}$, for which $\delta=1.57, R_{o}$ decreased by about $6^{\circ} .5$, and with $1787 \mathrm{C}$, for which $\delta=\mathrm{I} .50, R_{o}$ increased by less than $0^{\circ} .5_{5}$, for about the same heat treatment.

An examination of the behavior of the thermometers made of platinum of different grades shows the advantage of employing the purest metal for work of precision. It will also be seen that the changes in thermometric constants for all types are relatively small at temperatures up to the melting point of silver, but that they are often considerable at the copper point.

Thermometers $1787 \mathrm{~F}$ and $1787 \mathrm{G}$ were used by both the Bridge and Potentiometer methods, and in comparing results by these two methods, Tables $\mathrm{I} 7$ and 22 , it should be noted that the values of $R_{o}^{\prime}$ and $F I$ differ, due to the different resistance units of the measuring apparatus, and also because the thermometer is i.it exactly the same instrument when used by the two methods.

The changes produced in $\delta$ by heating, after the thermometer is well annealed, are extremely small, and no certain conclusions can be drawn regarding the slight variations observed, as they appear for the most part to be within the limit of experimental error.

Changes during a F. P. Determination.-In determining freezing points at the higher temperatures it is necessary to determine, by calibrating the thermometer both before and after the freezing-point measurement, the changes occurring while the freezing point was being taken. These changes become important, and allowance must be made for them in work to $0^{\circ}$.I above $700^{\circ}$, and in some cases at lower temperatures. This 
effect increases materially with the temperature, and is the main factor in reducing the precision attainable at high temperatures. An examination of the experiments on $\mathrm{Ag}, \mathrm{Cu}$, and $\mathrm{Ag}-\mathrm{Cu}$ (Tables 8,9 , and ro) shows that changes amounting to several tenths of a degree at these temperatures may arise from this cause. These changes are indicated in condensed form in Table 24 , for values of both $p t$ and $t$. In general, the temperature assigned to a freezing point was the mean value obtained from the calibrations before and after the freeze.

Some measurements made on two Leeds and Northrup resistance thermometers, Nos. 9837 and 9838, the coils of which were made of much larger platinum wire (diam. $=0.6 \mathrm{~mm}$ ), show a much greater constancy at high temperatures for thermometers made of thick wire. These coils were not mounted on mica frames but were freely suspended and were thus not subject to strains resulting from thickening of the mica frame (see Plate I). The resistance in ice was quite low, about o. I ohm, but a much larger measuring current could, of course, be used than with the fine wire thermometers, so that the sensitiveness was not reduced in proportion to the resistance. These two thermometers were submitted to the same heat treatment. After a very thorough annealing it was found that an exposure for five hours at $\mathrm{I}_{200^{\circ}}$, three and one-half hours at $1250^{\circ}$, and one hour at $1300^{\circ}$, in an electric furnace, caused a total increase of $R_{o}$ and a change in the FI corresponding to only a few tenths of a degree (see Table 23). The error at $\mathrm{I}_{200^{\circ}}$ at the close of the experiments, due to using the calibration found at the beginning of the experiments was of the order of $3^{\circ}$, the two thermometers showing approximately the same changes.

These thermometers were mounted in fairly clear quartz tubes, and it may be worthy of mention that while this material withstood with only slight crystallization the exposure to temperatures of $\mathrm{I} 200^{\circ}$ or $\mathrm{I}_{300^{\circ}}$ for some ten or fifteen hours, it deteriorated very rapidly after that, and developed numerous cracks and spots where transformations in the structure of the material were evident. 
Waidner.] Platinum Thermometry at High Temperatures.
Burges.

I 8 I

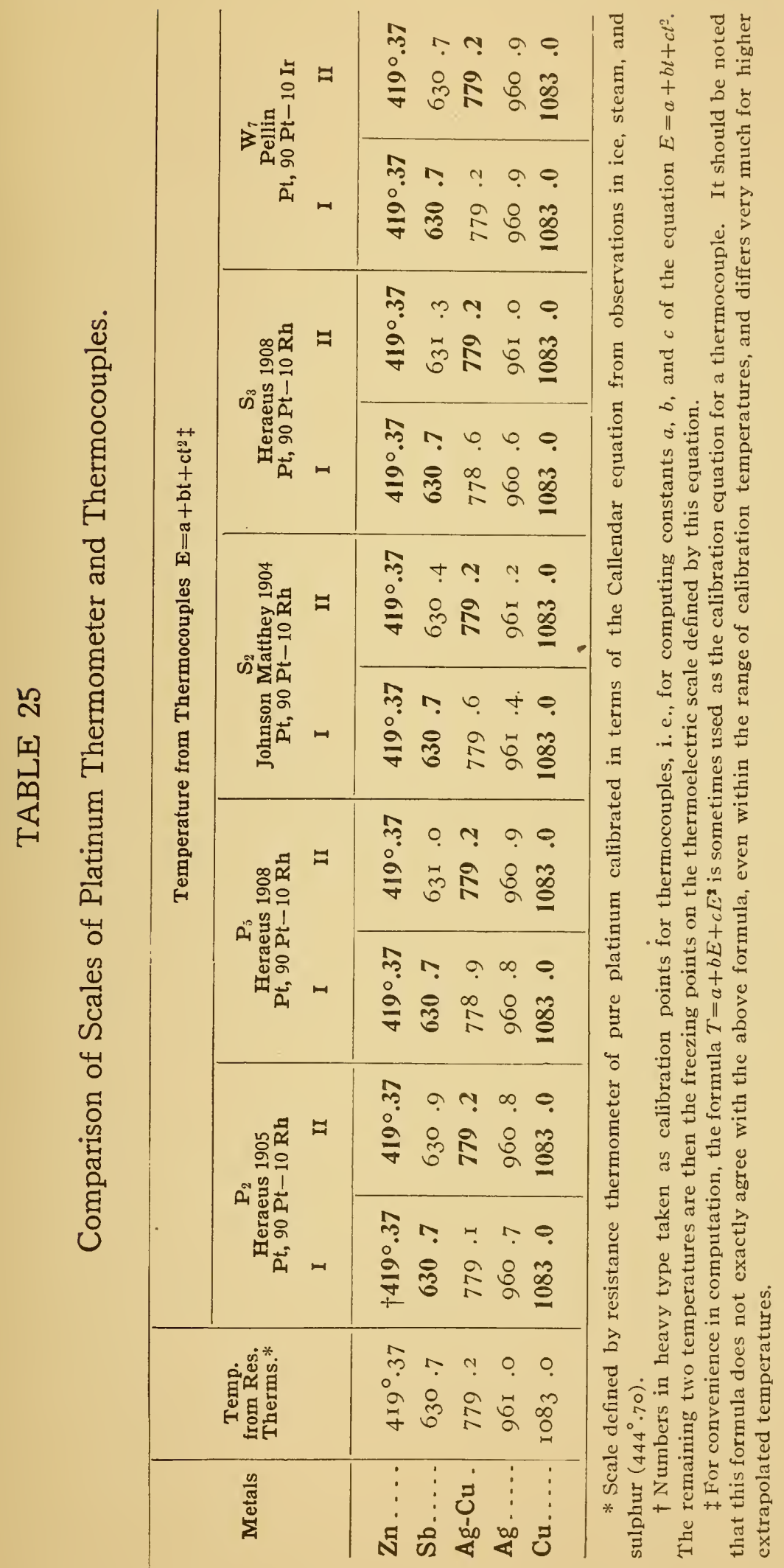




\section{COMPARISON OF RESISTANCE AND THERMOELECTRIC SCALES.}

To compare these two temperature scales a number of thermocouples were calibrated at the freezing points of the metals previously used with the resistance thermometers. The results are given in Table 25. The calibration equations of the couples, $E=a+b t+c t^{2}$, were computed from the observed electromotive forces, $E$, at three temperatures, indicated by heavy type in the table. The observations were reduced in two ways. In the first column under each thermocouple are given the computed values of the freezing point of the silver-copper eutectic alloy, and of silver, when the freezing points of zinc, antimony, and copper are taken as calibration temperatures. These are the fixed points often employed for the standardization of thermocouples. In the second column under each thermocouple are given the computed values of the freezing point of antimony and of silver, when the freezing points of zinc, $\mathrm{Ag}-\mathrm{Cu}$ eutectic, and copper are taken as calibration temperatures.

The observations show that the thermocouples calibrated at three temperatures are in excellent agreement at the intermediate temperatures, the average deviation from the mean of their indications being about $\mathrm{O}^{\circ} .2$, and the maximum deviation $\mathrm{O}^{\circ} \cdot 5$. Furthermore, the temperature scale defined by these couples calibrated at three temperatures (as given by the scale of the platinum thermometer) is in agreement at the intermediate temperatures with the scale of the platinum thermometer, as defined by the Callendar equation, to within $0^{\circ} \cdot 3$.

The method of comparing these temperature scales here adopted, viz, the determination of the freezing points of a number of metals, is capable of great precision and has some decided advantages over the usual method of intercomparison even in a most carefully compensated electric furnace. Harker, ${ }^{88}$ using the latter method, finds the gas, thermoelectric, and resistance scales to agree to within $2^{\circ}$ on the average, in the range $450^{\circ}$ to $1000^{\circ}$. 


\section{THE PALIADIUM THERMOMETER.}

It was thought of sufficient interest to include measurements made with a thermometer of pure palladium, as this would furnish evidence as to the generality of the Callendar formula for pure metals.

The constants of such a thermometer, $1787 \mathrm{G}$, calibrated in the same way as the platinum thermometer, are given in Table $I$; the individual observations on the freezing points of the metals in the several tables 3 to Io; the behavior of the constants $\mathrm{R}_{0}, F I$ and $c$ in Table 22; and a comparison of the results obtained with the platinum and palladium thermometers at the several freezing points in Tables 26 and 27.

It is evident that the palladium thermometer by no means satisfies the Callendar equation at the higher temperatures. It follows that this formula is not general in its applicability to metallic resistance thermometers, even for metals of the platinum group, in spite of the fact that for thermometers of pure platinum it may be used for extrapolation to at least $1100^{\circ}$ and give results in excellent agreement with the gas scale.

Between $0^{\circ}$ and nearly $600^{\circ}$, however, the Callendar equation gives, for the palladium thermometer, temperatures agreeing with those found by the platinum thermometer to within $\mathrm{I}^{\circ}$, and for the greater part of this range to within $0^{\circ} .5$.

The Callendar formula, modified by making $\delta=a+b t$, gives better values for temperatures obtained with the palladium thermometer than the simple Callendar formula (see Table i5). Dickson's equation (p. 177) does not satisfy the observations with palladium at all.

An independent equation for the temperature-resistance relation of paliadium to $\mathrm{I} \mathrm{IOO}^{\circ}$ appears to require five constants, so that it was considered impracticable to indicate such an equation.

The behavior of palladium as regards changes in its constants, due to heating (to $\mathrm{I}\left(\mathrm{IO}^{\circ}\right.$ ) is about the same as that of platinum wire having $c=0.002 \mathrm{I}$ and $\delta=\mathrm{I} .57$, see Tables 20 and 22 .

Another thermometer of palladium, Pd II, was made with metal from another source; but its calibration constants, Table $I$, as well as the thermoelectric behavior of the wire of which it was made, indicated a less pure material, and no further measurements were made with it. 


\section{THE BOILING POINT OF SULPHUR.}

Regnault ${ }^{4}$ made a series of observations on the relation between . pressure and temperature of the vapor of sulphur for pressures ranging from 250 to $3000 \mathrm{~mm}$. As only two of these observations were in the neighborhood of atmospheric pressure, various values for the S. B. P. have been deduced from these observations by different experimenters who have endeavored to utilize Regnault's results.* As these determinations were carried out in a thickwalled iron-tube boiling-point apparatus heated in a furnace, the observed temperatures were too high, due to superheating of the sulphur vapor, a fact which was recognized by Regnault.

After an extensive series of experiments with an iron-tube S. B. P. apparatus, Callendar and Griffiths ${ }^{15}$ were finally led to adopt a glass-tube apparatus. The sulphur was boiled in the outer tube of the well known Victor Meyer vapor-density apparatus, about $4 \mathrm{~cm}$ diameter, $40 \mathrm{~cm}$ long, and having a spherical enlargement at the lower end. The tube was protected against heat loss by a suitable asbestos covering extending from the center of the bulb to within about $4 \mathrm{~cm}$ of the upper end. To prevent superheating of the sulphur vapor, the heating by the Bunsen flame was limited to the lower half of the spherical bulb containing the sulphur, the depth of which was such that it somewhat more than filled the spherical enlargement. The supply of heat was regulated so that the line of condensation of the sulphur vapor remained fixed a short distance (about $2 \mathrm{~cm}$ ) above the asbestos covering. A series of instructive experiments carried out by these observers showed that in order to find the temperature of the vapor, or at least to attain a definite and reproducible temper-

* By the boiling point of sulphur, often abbreviated to S. B. P., will be understood the temperature on the scale of the gas thermometer of the saturated vapor of sulphur at standard atmospheric pressure (i. e., $760 \mathrm{~mm}$ of mercury at $o^{\circ}$ and at latitude $45^{\circ}$, sea level), as measured in a definite form of boiling-point apparatus and under carefully specified conditions.

Using the two observations nearest atmospheric pressure, Callendar and Griffiths ${ }^{15}$ deduce from Regnault's data $447^{\circ} .48$ for S. B. P. Weinhold ${ }^{7}$ deduces from Regnault's empirical formula $44^{\circ} .4$. From a recomputation of these observations Ramsay ${ }^{10}$ gives $44^{\circ} .34$. Taking the four observations of Regnault nearest to atmospheric pressure $\left(467.45 \mathrm{~mm}\right.$ to $\left.{ }^{1} 308.54 \mathrm{~mm}\right)$, Chappuis and Harker ${ }^{61}$ deduce from these data $447^{\circ} .5 \mathrm{I}$ as the S. B. P. 
ature, it is not sufficient merely to insert a thermometer in the vapor. They found that when the platinum thermometer was immersed in the sulphur vapor, unprotected by any radiation screens it read about $\mathrm{I}^{\circ} .2$ lower than when thoroughly shielded, owing to cooler liquid sulphur condensed in the upper parts of the tube running down over the bulb of the thermometer, and to loss of heat by radiation to the cooler walls of the tube. The effect of adding the umbrella (see Plate VIII) above the coil of the thermometer was to raise the observed temperature about $0^{\circ} \cdot 3$, and the effect of adding a glass-tube radiation screen and two perforated asbestos disks below was to produce a further rise of about $0^{\circ} .5$. Adding a second coaxial glass-tube radiation screen produced an additional rise of about $0^{\circ} .2$. Replacing the inner glass tube with a brass tube gave a further rise in temperature. In the final form of radiation screen used by these observers, shown in Plate VIII, the inner glass tube is covered with platinum foil. With this apparatus in its final form, these observers found for the S. B.P. $444^{\circ} .53$ at standard atmospheric pressure, on the scale of the constant pressure air thermometer, the platinum thermometers used in this determination having been previously compared with the constant pressure air thermometer.

A brief note ${ }^{25}$ on the results of a determination of the S. B. P. made at the Physikalisch-Technische Reichsanstalt, by means of several mercurial thermometers that had been compared with a constant volume porcelain bulb air thermometer, gave for the S. B. P. $444^{\circ} \cdot 5$. The temperature scale of the air thermometer on which this work is based was shown to be in satisfactory agreement with the temperature scale of the air thermometer of Wiebe and Böttcher.

Chappuis and Harker ${ }^{61}$ determined the boiling point of sulphur by means of two platinum thermometers in an apparatus similar in all essential details to that used by Callendar and Griffiths, using as a radiation screen a perforated asbestos cone, similar to that used by Heycock and Neville, ${ }^{27}$ as shown in Plate VIII. These thermometers had been previously compared with a constant volume nitrogen thermometer, having a bulb of Berlin porcelain. This work gave for the S. B. P. $445^{\circ} .2$. In this work the expan- 
sion of the porcelain was determined only for the interval $0^{\circ}$ to $100^{\circ}$, and the value at higher temperatures was determined by extrapolation. Subsequently, after Holborn and Day ${ }^{53}$ had determined the expansion of Berlin porcelain at high temperatures, Chappuis ${ }^{70}$ recomputed the results previously found in collaboration with Harker, and was led to the value $S . B . P .=444^{\circ} .7$ on the scale of the constant volume nitrogen thermometer.

Holborn $^{52}$ compared several thermometers of pure platinum wire with a constant volume nitrogen thermometer in the interval $300^{\circ}$ to $500^{\circ}$ and found that the results of observation were in agreement with the Callendar equation to within $0^{\circ} . x$, the value of $\delta$ being I.489. While Holborn did not use these thermometers in an actual determination of the S. B. P., it is evident that they would give $444^{\circ} .55$ for the S. B. P., since platinum of the same degree of purity as that used in these thermometers has a $\delta=\mathrm{I} .5 \mathrm{O}$, when this constant is determined by calibration in ice, steam, and sulphur, and when the boiling point of sulphur is taken as $444^{\circ} .70$.

Rothe ${ }^{80}$ determined the boiling point of sulphur in an electrically heated S. B. P. apparatus similar to that described and used by the authors in the present work, using for this purpose four gasfilled mercurial thermometers, the relation of the scales defined by these thermometers to the standard gas scale of the PhysikalischTechnische Reichsanstalt being known. The correction for emergent stem of the thermometer, which amounted to ${ }^{\circ} .5$ to $3^{\circ}$, was determined by means of a Mahlke fadenthermometer. A conical radiation screen of thin sheet iron, as shown in Plate VIII, was used. Rothe found for the S. B. P. $444^{\circ} .7$ on the constant volume scale of the air thermometer. With two thermocouples that were calibrated on the scale of the Holborn and Day constant volume ( $P t-I r$ bulb) nitrogen thermometer, the standard high temperature scale of the Reichsanstalt, but which was not primarily intended for the highest attainable accuracy at the lower range of temperatures, Rothe found for the S. B. P. $445^{\circ}$.o.

Variation of S. B. P. with Pressure.-The following relations for the variation in temperature of the S. B. P. with pressure have been used: 

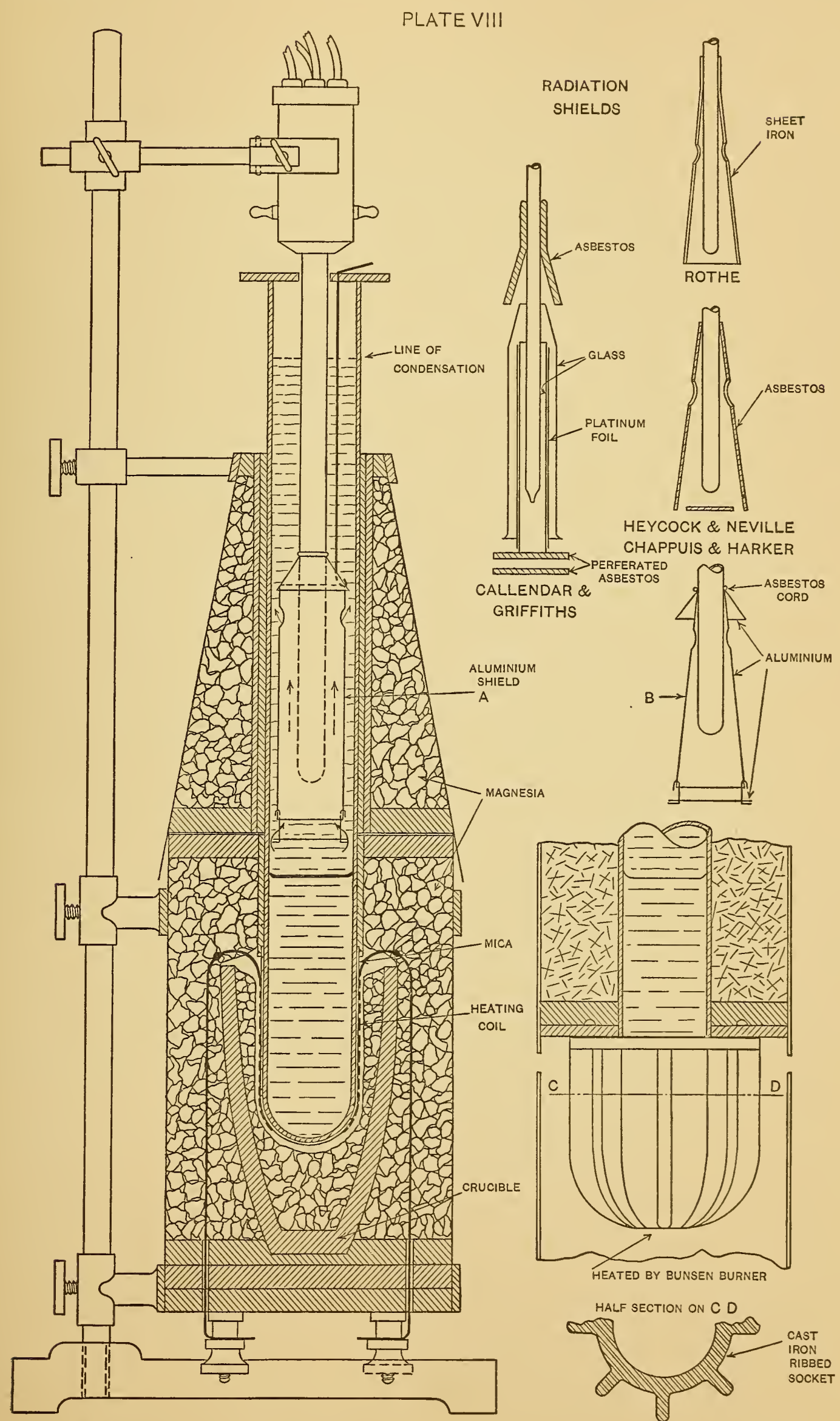

ELECTRICALLY HEATED S.B.P. APPARATUS
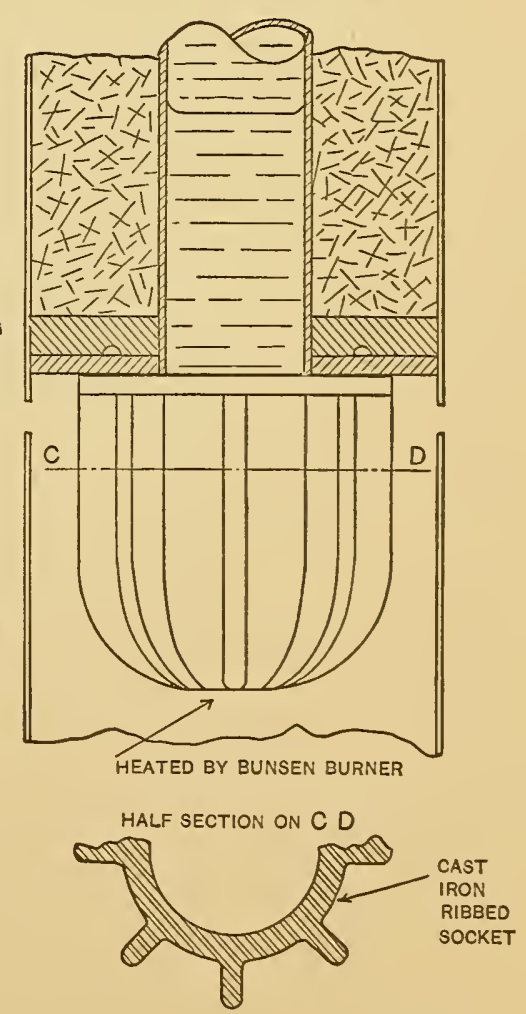


$$
\begin{aligned}
& t=t_{760}+0.082(\mathrm{p}-760) \\
& t=t_{760}+0.088(\mathrm{p}-760) \\
& t=t_{760}+0.090(\mathrm{p}-760)+0.0002(\mathrm{p}-760)^{2} \\
& t=t_{760}+0.09 \mathrm{I} 2(\mathrm{p}-760)-0.000042(\mathrm{p}-760)^{2} \\
& t=t_{760}+0.0904(\mathrm{p}-760)-0.00005 \mathrm{I} 9(\mathrm{p}-760)^{2}
\end{aligned}
$$

Equations (I) and (2) were deduced from Regnault's observations, the former by Griffiths from observations including a wide range of pressures, and the latter by Chappuis and Harker from the observations nearest atmospheric pressure. Equation (3) was computed by Chree ${ }^{57}$ from a large number of observations of the steam points of platinum thermometers carried out at different times at Kew Observatory, the total range of barometric pressure being, however, only about $30 \mathrm{~mm}$. Equations (4) and (5), the former given by Holborn and Henning ${ }^{130}$ and the latter by the Harker and Sexton ${ }^{127}$, are the results of experiments especially planned with a view to the determination of the temperaturepressure relation, and are, therefore, to be preferred. These equations, which are in very close agreement, were determined from experiments over a range of $\mathrm{ioo} \mathrm{mm}$ above and below standard atmospheric pressure.

S. B. P. Tubes.-The construction of the electrically heated S. B. P. apparatus in which most of our observations were made is shown in sectional drawing in Plate VIII. Two forms of gasheated tubes were also tried, one a Victor Meyer tube similar to that used by Callendar and Griffiths, in which the heating was done by a Bunsen flame applied directly to the lower part of the spherical enlargement at the bottom of the tube, the other in which the lower end of the glass tube was inclosed by the iron casting shown in Plate VIII, the heat being supplied to this iron jacket by a Bunsen flame.

The order of accuracy with which the S. B. P., observed in this way, serves to fix a definite and reproducible temperature, and the precautions that are necessary, will be seen from the following experiments which are briefly described:

Gas and Electric Heating.-A series of measurements made alternately with these three S. B. P. tubes,* using the same ther-

* We have had tubes which would last for a long time; at other times the cracking of the tubes was very annoying, and required frequent rebuilding of the apparatus due to the sulphur coming into contact with the heating coil. Heating coils of nickel, constantan, etc., were used at different times, but a heating coil of thin platinum ribbon was finally adopted. For these reasons the gas-heated type would probably prove more satisfactory for ordinary laboratory use. 
mometer and the same radiation shields, has shown that the tubes serve to define practically the same temperature, the S. B. P. observed in the two gas-heated tubes being $0^{\circ} .03$ and $0^{\circ} .04$ higher, respectively, than in the electrically heated tube.

Superheating.-To avoid superheating of the sulphur vapor, the depth of liquid sulphur should be such that its upper surface is some distance (several cms at least) above the upper end of the electric heating coil or that portion of the glass tube in contact with the heating surface (flame or hot gases). For example, with an electric heating coil $7 \mathrm{~cm}$ high and with a depth of $8 \mathrm{~cm}$ of sulphur, there were still evidences of superheating for a distance of some $7 \mathrm{~cm}$ above the surface of the liquid, the superheating being about $\mathrm{O}^{\circ}$.I, $\mathrm{O}^{\circ} . \mathrm{O} 5$, and $\mathrm{O}^{\circ} . \mathrm{Or}$, respectively, at distances of $4.5,5.5$, and $6.5 \mathrm{~cm}$ above the surface. With a depth of only 3.5 to $4 \mathrm{~cm}$ of liquid sulphur in the tube, the observed superheating at $6.5,10,17$, and $30 \mathrm{~cm}$ distance from the liquid surface (in a tube $55 \mathrm{~cm}$ long) was $20^{\circ}, 8^{\circ} \cdot 3,2^{\circ} \cdot 5$, and $\mathrm{I}^{\circ}$. I, respectively. With a depth of $\mathrm{I} 2 \mathrm{~cm}$ of sulphur the maximum variation in temperature, when taken as hereafter described, for the interval $4 \mathrm{~cm}$ above the surface to $20 \mathrm{~cm}$ above the surface was only about $0^{\circ} .02$ or $0^{\circ} .03$. When naphthalene is boiled in the electrically heated tube, the observed boiling point (with thermometer No. 479) for 8 and $16 \mathrm{~cm}$ depth of liquid in the tube was identical (viz, $218^{\circ}$. or), while when the depth of liquid was only $4 \mathrm{~cm}$ the observed boiling point was $\mathrm{O}^{\circ} .3 \mathrm{I}$ higher, showing the effect of superheating due to the contact of the vapor with the portion of the wall heated by the coil above the surface of the liquid.

By lowering the thermometer, with its attached radiation shields, into the liquid sulphur, it was found that the temperature of the liquid was some $5^{\circ} \cdot 4$ higher than the temperature observed in the vapor.

Radiation Shields.-We have repeated most of the experiments of Callendar and Griffiths on the effects of shielding the thermometer in the sulphur vapor and have made many additional experiments in order to determine the conditions to be specified in order to reproduce the S. B. P. with the highest accuracy. The two types of radiation shields used in this work are shown in Plate 
VIII. The temperatures observed with these two shields were very nearly identical, $A$ giving a temperature very slightly lower than $B$ (about $0^{\circ} .02$ ). With the lower disk of $A$ removed, which gives the type of shield used by Rothe, the observed temperature was very slightly lower $\left(0^{\circ}\right.$. or $\left._{5}\right)$. A shield exactly similar to that used by Callendar and Griffiths was also tried. It gave a temperature about $0^{\circ} .03$ or $0^{\circ} .04$ higher than the shield $B$. The effect of adding another aluminium cylinder around $B$ was to give a temperature about $0^{\circ} .03$ higher than the single cylindrical shield $B$. If all radiation shields are dispensed with the thermometer reads about $\mathrm{I}^{\circ} \cdot 3$ low, and if the small cone alone is used above the coil, the thermometer reads about $\mathrm{I}^{\circ}$ low.

Temperature Distribution within S. B. P. Tube.-To determine whether such circumstances as distance of thermometer coil from liquid surface, from line of condensation, etc., has any effect on the observed S. B. P., the thermometer, together with its shield, was moved up and down along the axis of the S. B. P. tube and observations were taken with the coil of the thermometer at various distances from the liquid surface (from about $7 \mathrm{~cm}$ from center of coil to surface of sulphur to a position where the top of the radiation shield is just below the condensation line on the S. B. P. tube). With the thermometer in shield $B$, mounted so that the lower end of the porcelain tube was in the plane of the base of the surrounding aluminium cylinder, the temperature remained constant (within $0^{\circ} . \mathrm{or}$ ) until the top of the shield was about I cm below the line of condensation of the sulphur, in which position it read $0^{\circ} .02$ low, the observed temperature falling off very rapidly upon further raising the thermometer. A similar experiment was also tried with the thermometer coil mounted about $4.5 \mathrm{~cm}$ farther up in the shield with the same result. Notwithstanding the excellent agreement $\left(0^{\circ} .01\right.$ or $\left.0^{\circ} .02\right)$ in the observed temperatures when the coil of the thermometer was placed in these two different positions within the radiation shield, thermocouples (of $P t, P t-I r$, and $P t, P t-R h$ ), used to explore the distribution of temperature within that portion of a porcelain tube (similar to the thermometer tube) under the radiation shield, showed very appreciable point-to-point variations within this region, amounting, as will be seen later, to as much as $0^{\circ} .5$. 
While the conical shield $A$ gives a temperature only about $\mathrm{O}^{\circ} . \mathrm{O} 2$ lower than the cylindrical shield $B$, it must be placed farther down in the sulphur vapor, well below the line of condensation. With the conical shield $A$ there is a marked drop in temperature when the thermometer, with its shield, is raised, which is noticeable when the top of the shield is still some 4 or $5 \mathrm{~cm}$ below the condensation line. By putting an additional small umbrella above the shield $A$ this effect disappears, and the thermometer, with its shield, can be raised so that the top of the shield is within I $\mathrm{cm}$ of the condensation line without producing a change in the observed temperature exceeding $\mathrm{O}^{\circ}$.O I.

Temperature Distribution within Radiation Shield.-As has been stated, the observed resistances of a platinum thermometer when mounted in the two different positions within the shield, as already described, were almost identical. Notwithstanding this fact, when the temperature distribution inside a porcelain tube, similar to the thermometer tube, was explored with a thermocouple, it gave evidence of very appreciable point-to-point variations of temperature of the order of $0^{\circ} .4$ or $0^{\circ} .5$. If these are true variations in temperature, one would expect to find a different resistance for the coil of the platinum thermometer when mounted in different positions within the shield, especially as the thermometer set-up was sensitive to well within $0^{\circ}$.or. It is possible that a part of the variation observed with the couples is apparent rather than real, due, perhaps, to the heterogeneity of the wires of the couple, which would give slightly different electromotive forces with variable depth of immersion in the heated region. Heræus couples of $P t, P t-R h$, and of $P t, P t-I r$, however, both gave about the same temperature-distribution curve. Further experiments are contemplated with a special resistance thermometer, having a very short coil of a few millimeters of fine (Wollaston) platinum wire.

On the Uncertainty in the Accepted Value of the S. B. P.On account of the satisfactory agreement of the determinations of the sulphur boiling point by different observers using different gas thermometers it has been very generally assumed that this temperature was known to $0^{\circ}$. I or $0^{\circ} .2$. A consideration of some recent work with the gas thermometer, however, throws some 
doubt on this conclusion and would seem to show that the uncertainty in the present accepted value of the S. B. P. $\left(444^{\circ} \cdot 5\right.$ to $\left.444^{\circ} .7\right)$ may be as much as ${ }^{\circ}$.

In the present investigation the value assumed for the S. B. P.viz, $444^{\circ} .70$-gives $419^{\circ} .37$ for the $\mathrm{F}$. P. of zinc, as determined by the platinum resistance thermometer. Day and Clement ${ }^{125}$ have recently published the preliminary results of a series of elaborate and painstaking measurements with a constant volume nitrogen thermometer and find for the $F$. P. of zinc $418^{\circ} \cdot 5$. If this temperature were taken as one of our known calibration temperatures for the platinum thermometer, the other two temperatures being that of ice and of steam, it would give for the S. B. P. $443^{\circ} .7$ - that is, $I^{\circ}$ lower than the generally accepted value. The desirability of further careful work with the gas thermometer is therefore evident. In this connection it is of interest to note the value of the S. B. P. recently found by Eumorfopoulos, ${ }^{128}$ using the Callendar form of compensated constant pressure air thermometer, viz, $443^{\circ} .6$. The uncertainty in the coefficients of expansion used for the glass bulb of his air thermometer is such, however, that this value of the S. B. P. may be in error by more than $\mathrm{I}^{\circ}$, as is recognized by both Messrs. Eumorfopoulos and Callendar. ${ }^{124}$

If the true temperature of the vapor of sulphur, boiling at standard atmospheric pressure and measured under the conditions specified by the several investigators who have determined this point, should ultimately be found to be $443^{\circ} .7$ instead of $444^{\circ} .7$, as we have taken it, it would result in changing the value of $\delta$ from $\mathrm{I} .505$ to $\mathrm{I} .447$ and in lowering the resulting values of the freezing points of $\mathrm{Sn}, \mathrm{Cd}, \mathrm{Pb}, \mathrm{Zn}, \mathrm{Sb}, \mathrm{Ag}-\mathrm{Cu}, \mathrm{Ag}, \mathrm{Cu}$, by o ${ }^{\circ} .19,0^{\circ} .44,0^{\circ} .47,0^{\circ} .87$, $2^{\circ} \cdot 3,3^{\circ} \cdot 9,6^{\circ} .5,8^{\circ} .8$, respectively.

The Callendar method of calibration in ice, steam, and sulphur would not then be applicable for extrapolation to high temperatures, as it would give for the $\mathrm{F}$. P. of copper $\mathrm{I}, \mathrm{O} 74^{\circ}$ instead of $\mathrm{I}, \mathrm{O} 83^{\circ}$ and the experimental evidence availiable makes it reasonably certain that the latter value can hardly be in error by more than $2^{\circ}$ or $3^{\circ}$.

While the agreement of the scale of the platinum thermometer with the Holborn-Day gas scale is remarkable when we consider 
that the former scale is dependent on an extrapolation from the boiling point of sulphur, yet on account of the purely empirical nature of the Callendar equation this agreement can not be used as an argument in favor either of the correctness of the present accepted values of the freezing points of the metals or to decide between these two values of the S. B. P., although, taken in connection with the other corroborative experimental evidence previously referred to, the higher value of the S. B. P. $\left(444^{\circ} .70\right)$ and the resulting temperature scale as used in this investigation appear the more probable.

S. B. P. on Thermodynamic Scale.-Berthelot ${ }^{137}$ and Buckingham ${ }^{138}$ have recently discussed the probable differences between the temperature scales of the constant volume and the constant pressure gas thermometer and the absolute thermodynamic scale. The S. B. P. found by Callendar and Griffiths $\left(444^{\circ} .53\right.$ on the constant pressure air scale) and by Harker and Chappuis $\left(444^{\circ} .70\right.$ on the constant volume nitrogen scale), when reduced in accordance with the conclusions of the above authors, is $444^{\circ} .9$ on the thermodynamic Centigrade scale. In some recent work with the platinum resistance thermometer, Holborn and Henning ${ }^{130}$ have used the value $445^{\circ}$.o.

\section{GENERAL CONCLUSIONS.}

\section{a. Temperature Scales.}

I. Temperatures defined by the resistance thermometer of pure platinum calibrated by Callendar's formulæ at $0^{\circ}$, $100^{\circ}$, and $444.70^{\circ}$, the boiling point of sulphur, agree with temperatures on the generally accepted gas scale in the range o to $1 \mathrm{IOo}^{\circ} \mathrm{C}$, to within the degree of reproducibility of the latter.

\begin{tabular}{|c|c|c|c|c|c|c|c|}
\hline Freezing Point of: & Sn & $\mathrm{Cd}$ & $\mathrm{Zn}$ & $\mathrm{Sb}$ & $\mathrm{Ag}_{3}-\mathrm{Cu}_{2}$ & $\mathrm{Ag}$ & $\mathrm{Cu}$ \\
\hline Thermometers of Pure Pt......... $\left\{\begin{array}{l}\mathrm{C}=0.0039 \\
\delta=1.50\end{array}\right.$ & $231^{\circ} .90$ & $321^{\circ} .01$ & $419^{\circ} .37$ & $630^{\circ} .71$ & $779^{\circ} .20$ & $960^{\circ} .88$ & $1083^{\circ} .0$ \\
\hline Thermometer of Impure Pt 1787 A.. $\left\{\begin{array}{l}c=0.0021 \\
\delta=1.57\end{array}\right.$ & 231.82 & 320.95 & $419 \quad .32$ & 631.25 & 780.86 & 966.21 & 1091.9 \\
\hline Thermometer of Impure Pt $1787 \mathrm{E} . .\left\{\begin{array}{l}\mathrm{c}=0.0017 \\
\delta=1.80\end{array}\right.$ & & & & 632.65 & 784.60 & 975.22 & 1106.2 \\
\hline
\end{tabular}


2. Thermometers made of impure platinum, and calibrated in the same way, do not define the same temperature scale as that of pure platinum, the divergence increasing with the impurity of the metal, as shown in the preceding table.

3. If thermometers of impure platinum are calibrated at a fourth temperature, such as the silver freezing point, and the difference coefficient of the Callendar formula is written $\delta=a+b t$, then the scale so defined by these thermometers is brought into very close agreement with that of the thermometer of pure platinum, as follows:

\begin{tabular}{|c|c|c|c|c|c|c|}
\hline Freezing Point of: & $\mathrm{Sn}$ & $\mathrm{Cd}$ & $\mathrm{Sb}$ & $\mathrm{Ag}_{3}-\mathrm{Cu}_{2}$ & $\mathrm{Ag}$ & $\mathrm{Cu}$ \\
\hline Thermometers of Pure Pt............. $(\delta=1.50)$ & $231^{\circ} .90$ & $321^{\circ} .01$ & $630^{\circ} .7$ & $779^{\circ} .2$ & $960^{\circ} .9$ & $1083^{\circ} .0$ \\
\hline Thermometer of Impure Pt 1787A... & 231.89 & 321.05 & 630.5 & 779.1 & $(961.0)$ & 1083.3 \\
\hline Thermometer of Impure Pt $1787 \mathrm{E} . .$. & & & 630.8 & 779.3 & $(961.0)$ & 1082.3 \\
\hline
\end{tabular}

For Thermometer $\mathrm{I}_{7} 87 \mathrm{~A}, \delta=\mathrm{I} .608-0.0_{4} 853 t$.

For Thermometer $r_{7} 8 \mathrm{E}, \hat{o}=3.020-0.0_{3} 327 t$.

4. The Dickson formula $(R+a)^{2}=p(t+b)$ is not applicable to either platinum or palladium thermometers at high temperatures.

5. The palladium thermometer, calibrated by the Callendar method, gives temperatures agreeing to $\mathrm{I}^{\circ}$ with the scale of the platinum thermometer up to $600^{\circ}$. It requires a fourth degree equation to express its resistance-temperature relation from o to $1100^{\circ}$.

6. The following table of freezing points represents the scale of the resistance thermometer of pure platinum as determined from this investigation, using only the purest metals:

\begin{tabular}{|c|c|c|c|c|c|c|c|c|c|c|}
\hline Metal & $\mathrm{Sn}$ & $\mathrm{Cd}$ & $\mathbf{P b}$ & $\mathrm{Zn}$ & $\mathrm{Sb}$ & Al & $\mathrm{Ag}_{3}-\mathrm{Cu}_{2}$ & $\mathrm{Ag}$ & $\mathrm{Cu}$ & $\mathrm{Cu}-\mathrm{Cu}_{2} \mathrm{O}$ \\
\hline Freezing Point. & $231^{\circ} .92$ & $321^{\circ} .01$ & $327^{\circ} .43$ & $419^{\circ} .37$ & $630^{\circ} .71$ & $658^{\circ} .0$ & $779^{\circ} .20$ & $960^{\circ} .9$ & $1083^{\circ} .0$ & $1063^{\circ} .2$ \\
\hline $\begin{array}{l}\text { Average deviation for purest } \\
\text { metal . . ..................... }\end{array}$ & .02 & .02 & .10 & .02 & .30 & .5 & .25 & .20 & .5 & .3 \\
\hline Reproducibility factor . . . . . & .06 & .26 & .10 & .06 & 2.3 & 1.2 & & & 1.0 & \\
\hline
\end{tabular}

The average deviation of a single observation is a measure of the precision attained when two or more thermometers were used in a single metal sample. The reproducibility factor is the average deviation of the metals, designated as C. P. or better, from their mean F. P.

7. Thermocouples of $P t, 90 P t-10 R h$ and $P t, 90 P t-10 I r$, calibrated at three temperatures in terms of the formula $\mathrm{E}=\mathrm{a}+\mathrm{bt}+\mathrm{ct}^{2}$,

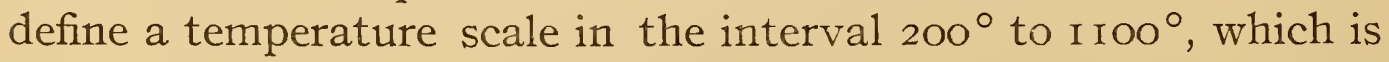
in agreement with the platinum resistance scale at intermediate temperatures to within $0^{\circ} \cdot 3$. 
b. Behavior of Platinum Thermometers.

8. When used at high temperatures the constants of platinum thermometers undergo gradual changes, which necessitate frequent recalibration in work of high precision. The use of thermocouples for work above the F. P. of silver is therefore much less laborious.

9. These changes in thermometric constants are greatly reduced but not completely eliminated, by annealing the thermometers for at least several hours, at a temperature higher than that at which they are subsequently to be used.

ı. For thermometers of pure platinum, the changes in their constants after the thermometers have been annealed, are very much less than for those of impure platinum; thus, $R_{0}$ changes only by a few tenths of a degree for pure platinum but by several degrees for impure.

II. These changes are least for pure platinum wires of large diameter and suspended free from strains. For such thermometers, made of wire $0.6 \mathrm{~mm}$ in diameter, $R_{0}$ changed by only a few tenths of a degree after repeated and continued heatings at I $200^{\circ}$ to $1300^{\circ}$.

I2. For impure platinum wire the effect of high temperatures is to decrease $R_{0}$ and to increase the fundamental coefficient, $c$, that is, the effect is as if the wire became purer, possibly because of the evaporation of impurities, for example, iridium. If the platinum is pure, the slight changes indicate a contamination of the wire and the effect of strains, as is evidenced by decrease in $c$ and the increase in $R_{0}$. The total change observed is a resultant of the effects of strains, of annealing, and of contamination and purification. In the use to which these thermometers were subjected in this investigation, the changes in the value of $\delta$ were almost within the limits of experimental error. For impure platinum there is evidence of a slight decrease in this constant.

\section{c. Calibration Temperatures.}

I3. The freezing points of the pure metals are the most satisfactory calibration temperatures, being superior to boiling points in constancy, ease of manipulation, and reproducibility. Unless 
a very slow rate of heating is used, melting points are less satisfactorily fixed and apparently slightly higher than freezing points.

I4. The temperature of the separation of the silver-copper eutectic is an entirely satisfactory fixed point at $779^{\circ} .2$, when the alloy is of the eutectic composition, or about $72 \mathrm{Ag}-28 \mathrm{Cu}$. The eutectic point of copper-cuprous oxide is also a satisfactory calibration temperature at $1063^{\circ} .2$, when proper experimental precautions are taken to maintain the eutectic composition.

\section{d. The Boiling Point of Sulphur.}

I5. The temperature defined by the vapor of sulphur boiling at known pressure and under carefully specified conditions is a most satisfactory fixed point, reproducible to a few hundredths of a degree. These conditions are briefly:

(a) Sulphur to be boiled in a glass tube 4 to $5 \mathrm{~cm}$ diameter and of sufficient length to insure ample depth of immersion in the vapor (tube about $40 \mathrm{~cm}$ satisfactory);

(b) Sufficient depth of liquid sulphur to avoid superheating;

A criterion for the above conditions is absence of change in the observed resistance when the thermometer with its attached radiation shield is moved some centimeters up and down the tube;

(c) Surrounding coil of thermometer with a suitable radiation shield to avoid the cooling effects of the condensed sulphur running down the stem of the thermometer and of radiation to the cooler parts of the apparatus.

I6. Both gas and electrically heated S. B. P. tubes were used; the former gave a temperature $0^{\circ} .03$ or $0 .{ }^{\circ} \mathrm{O} 4$ higher than the latter.

I 7. The determinations of the S. B. P. by different observers is discussed at length. The determinations of these observers are in satisfactory agreement, the values found ranging, with one exception, from $444^{\circ} \cdot 5$ to $444 \cdot{ }^{\circ} 7$. The bearing of some recent work with the gas thermometer on the value of the S. B. P. is considered, which shows that the above value may be too high. The evidence, however, is not sufficient as yet to warrant any change in the generally accepted and widely used value of the S. B. P. 
Waidner.
Burgess. $\quad$ Platinum Thermometry at High Temperatures.

We take great pleasure in acknowledging the assistance rendered by Messrs. J. J. Crowe and H. A. Ginsburg, both in the experimental work and in the computations involved in this investigation.

WASHINGTON, June 26, I909. 


\section{APPENDIX.*}

\section{TABLE 2.}

Heating Effect of Measuring Current.

[Thermometer $1787 \mathrm{C}$.]

\begin{tabular}{|c|c|c|c|c|c|c|}
\hline Amperes & $\mathbf{R}_{0}$ & $\mathbf{R}_{100}$ & $\mathbf{R}_{444: 33}$ & F. I. & $\mathrm{pt}_{\mathrm{s}}$ & $\delta$ \\
\hline $2.50 \times 10^{-3}$ & 3.48160 & 4.82275 & 9.13220 & 1.34115 & $421^{\circ} .33$ & 1.503 \\
\hline $5.00 \times 10^{-3}$ & 3.48164 & 4.82277 & 9.13220 & 1.34113 & 421.33 & 1.503 \\
\hline $10.00 \times 10^{-3}$ & 3.48174 & 4.82287 & 9.13213 & 1.34113 & 421.31 & 1.505 \\
\hline $25.0 \times 10^{-3}$ & 3.48286 & 4.82401 & 9.13308 & 1.34115 & 421.30 & 1.505 \\
\hline $50.0 \times 10^{-3}$ & 3.48705 & 4.82819 & 9.13608 & 1.34114 & 421.21 & 1.511 \\
\hline $100.0 \times 10^{-3}$ & 3.50373 & 4.84546 & 9.14832 & 1.34173 & 420.69 & 1.545 \\
\hline
\end{tabular}

\begin{tabular}{|c|c|c|c|c|}
\hline \multirow{2}{*}{\multicolumn{2}{|c|}{ Amperes }} & \multicolumn{3}{|c|}{ Heating of Pt Coil above Surrounding Temperature } \\
\hline & & $\Delta \mathrm{T}_{0}$ & $\Delta \mathbf{T}_{100}$ & $\Delta \mathrm{T}_{\mathrm{s}}$ \\
\hline \multicolumn{2}{|c|}{$2.50 \times 10^{-3}$} & $0^{\circ} .001 \pm$ & $0^{\circ} .001 \pm$ & \\
\hline \multicolumn{2}{|c|}{$5.00 \times 10^{-3}$} & .004 & .002 & \\
\hline \multicolumn{2}{|c|}{$10.00 \times 10^{-3}$} & .011 & .010 & \\
\hline \multicolumn{2}{|c|}{$25.0 \times 10^{-3}$} & .095 & .095 & $0^{\circ} .067$ \\
\hline \multicolumn{2}{|c|}{$50.0 \times 10^{-3}$} & .41 & .41 & .29 \\
\hline \multicolumn{2}{|c|}{$100.0 \times 10^{-3}$} & 1.65 & 1.69 & 1.20 \\
\hline \multicolumn{2}{|c|}{ R at F. P. of Silver } & \multirow{2}{*}{$\mathrm{pt}_{\mathrm{Ag}}$} & \multirow{2}{*}{$\delta$} & \multirow{2}{*}{$\mathrm{t}_{\mathrm{Ag}}$} \\
\hline 0.100 amp. & 0.0100 amp. & & & \\
\hline \multirow[t]{3}{*}{14.7079} & \multirow[b]{2}{*}{14.6995} & $835^{\circ} .06$ & 1.545 & $963^{\circ} .64$ \\
\hline & & 836.43 & 1.504 & 960.83 \\
\hline & \multirow[t]{2}{*}{14.7009} & \multirow{2}{*}{$\begin{array}{ll}836 & .54 \\
835 & .24\end{array}$} & 1.504 & 960.98 \\
\hline 14.7104 & & & 1.545 & 963.89 \\
\hline
\end{tabular}

* The following tables are in the text: $\mathrm{I}$ on $\mathrm{p}$. 156 , I I on p. $173, \mathrm{I} 2$ on p. I74, 15 on p. 177,25 on p. 181 .

198 


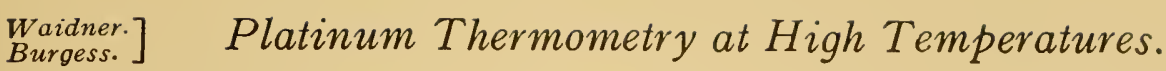

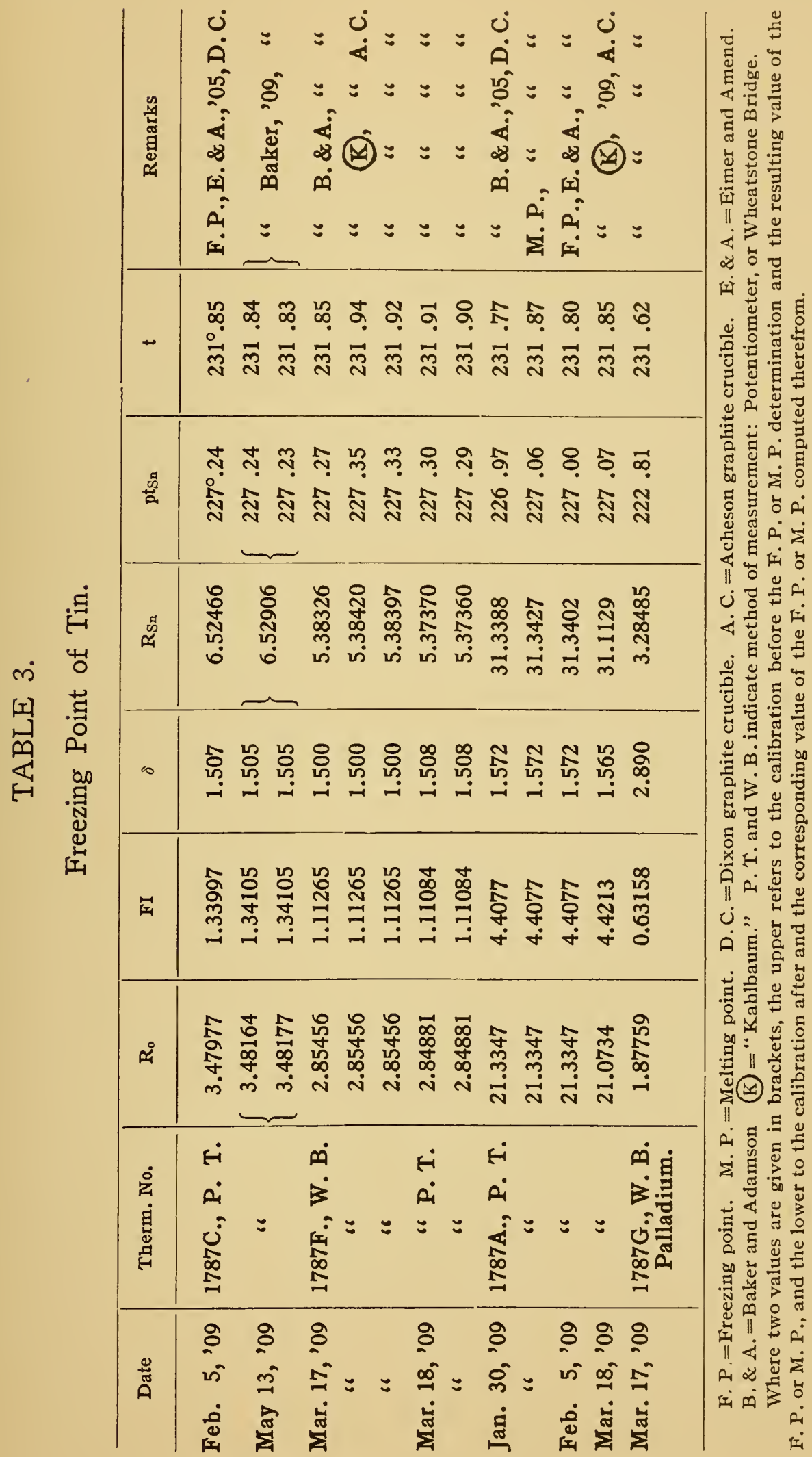




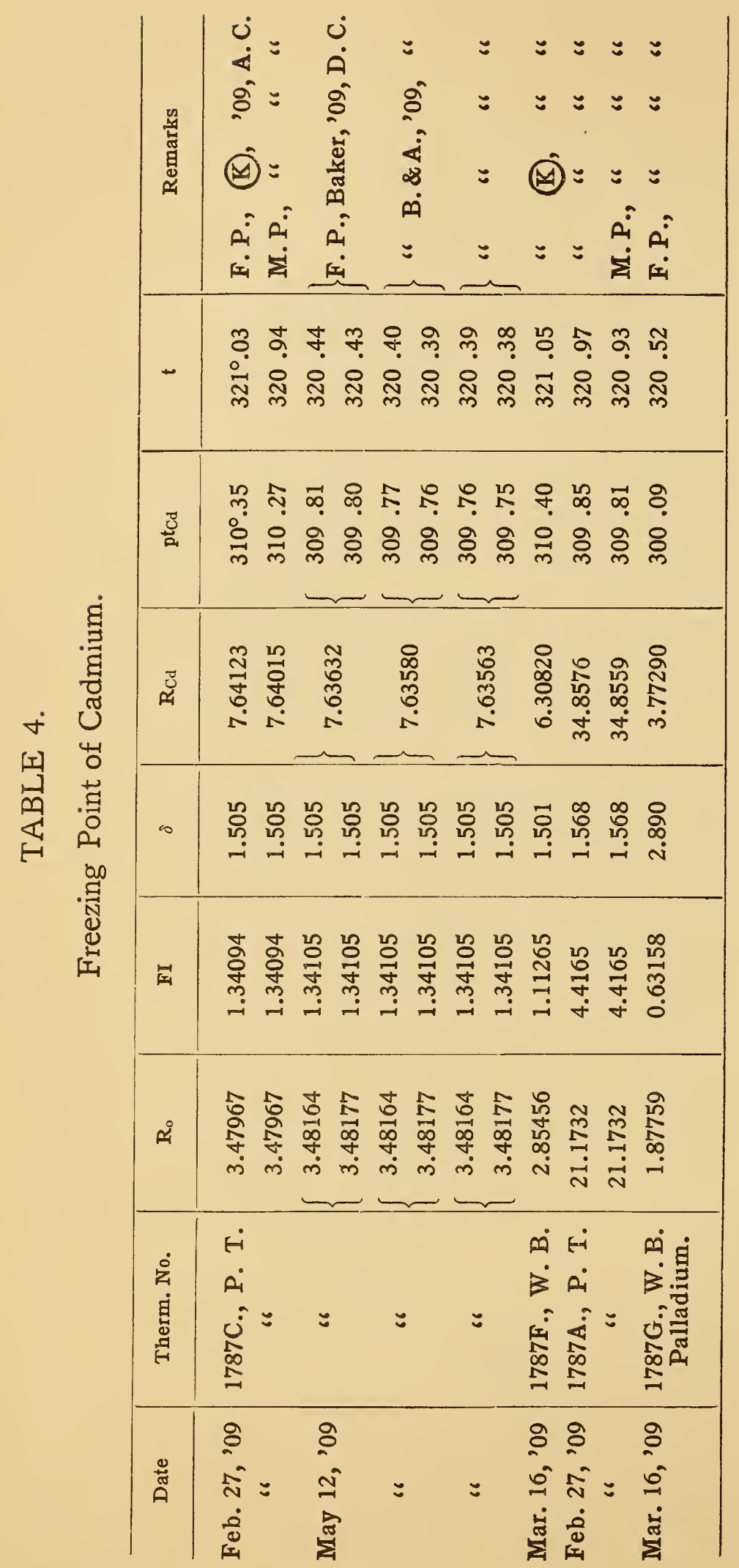


Waidner.] Platinum Thermometry at High Temperatures.

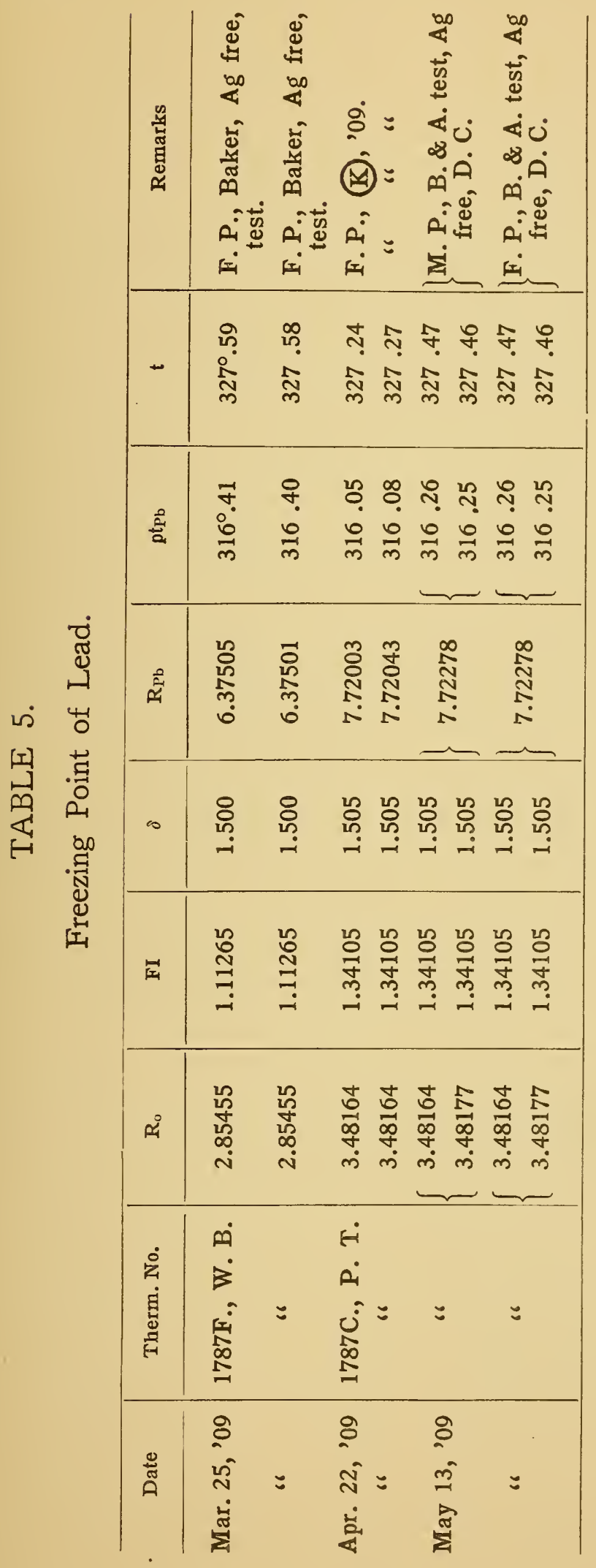




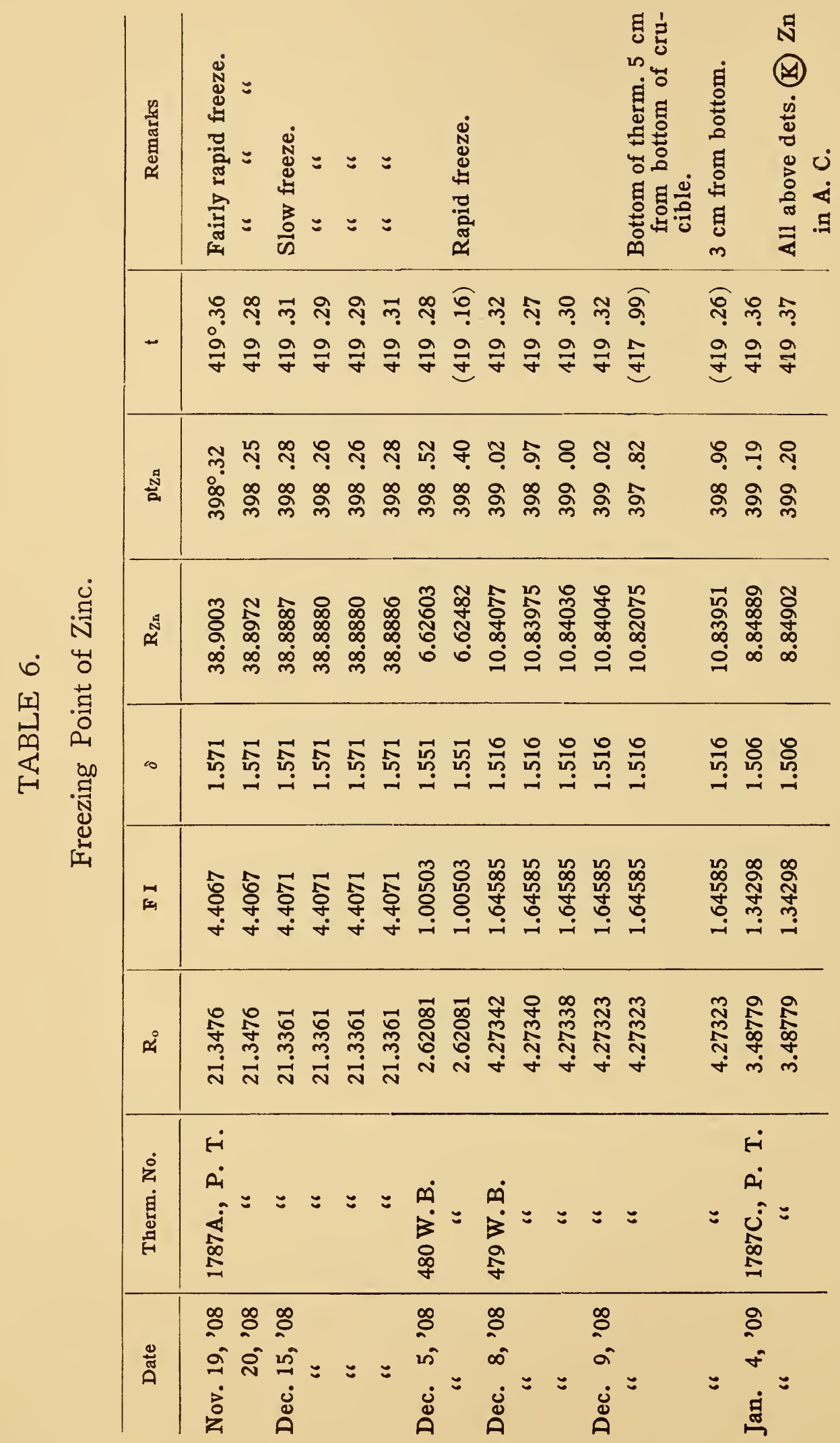


Waidner.] Platinum Thermometry at High Temperatures.

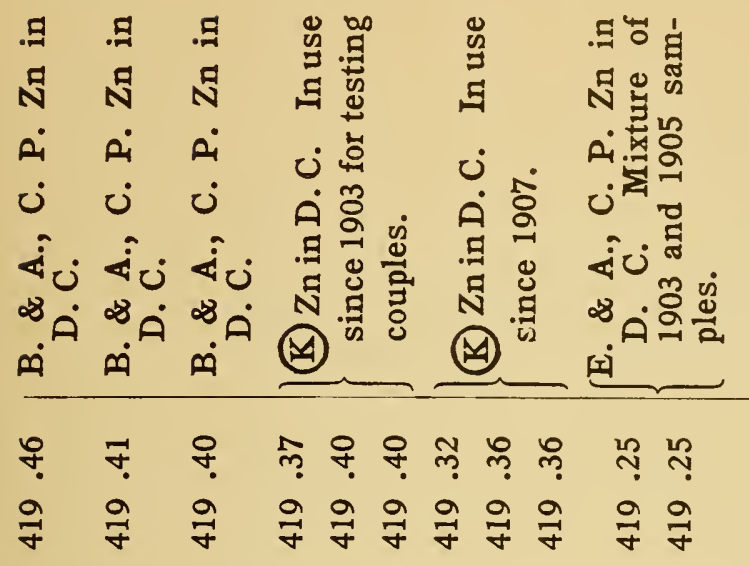

শึ

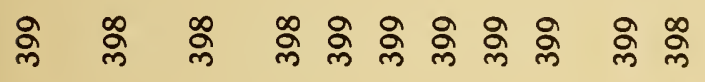

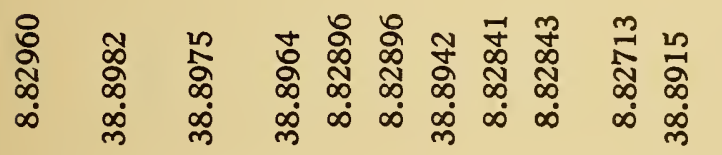

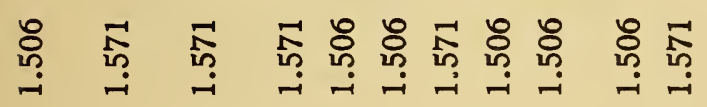

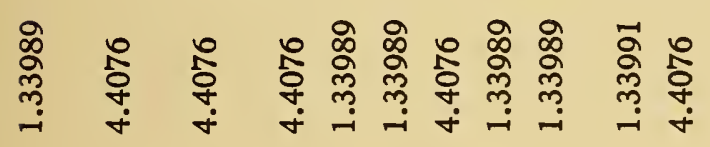

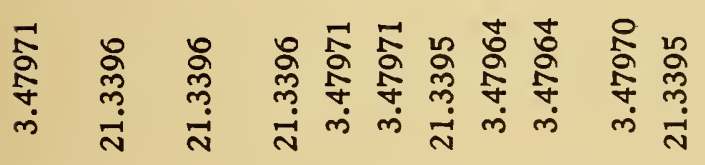

\begin{tabular}{|c|c|c|c|c|c|c|c|}
\hline$=$ & 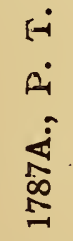 & $=$ & $=$ & $\begin{array}{l}\dot{H} \\
\dot{0} \\
\sum_{\infty}^{\infty} \\
\stackrel{\infty}{N}=\end{array}$ & 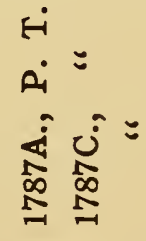 & $=$ & 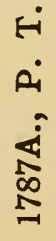 \\
\hline g & \&े & & 요 & & : & : & \\
\hline $\begin{array}{l}\text { ते } \\
\text { ฌं }\end{array}$ & $\tilde{N}$ & $\Xi$ & 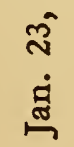 & $=$ & 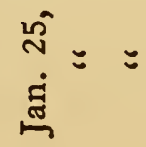 & 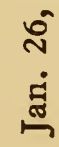 & $=$ \\
\hline
\end{tabular}




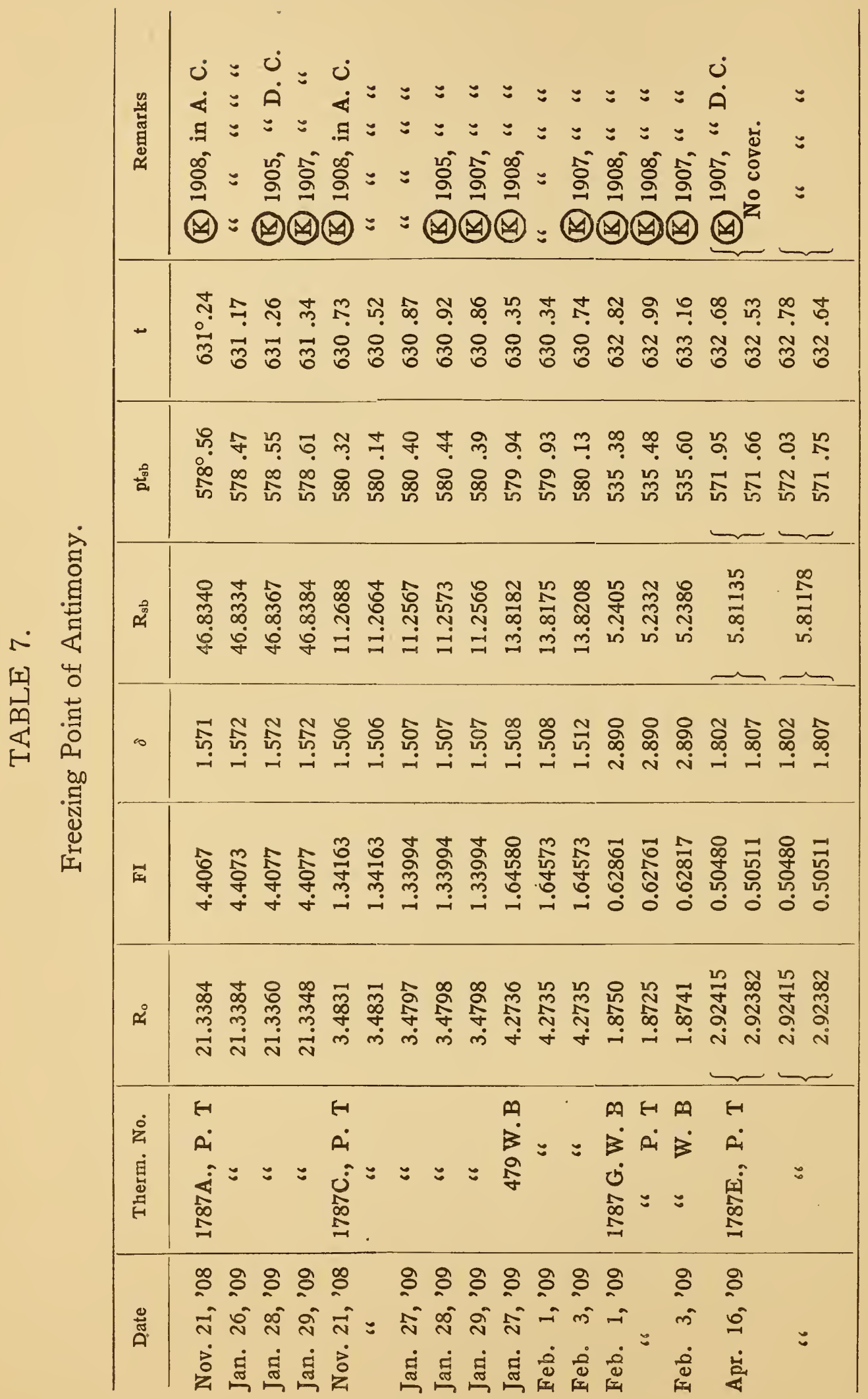




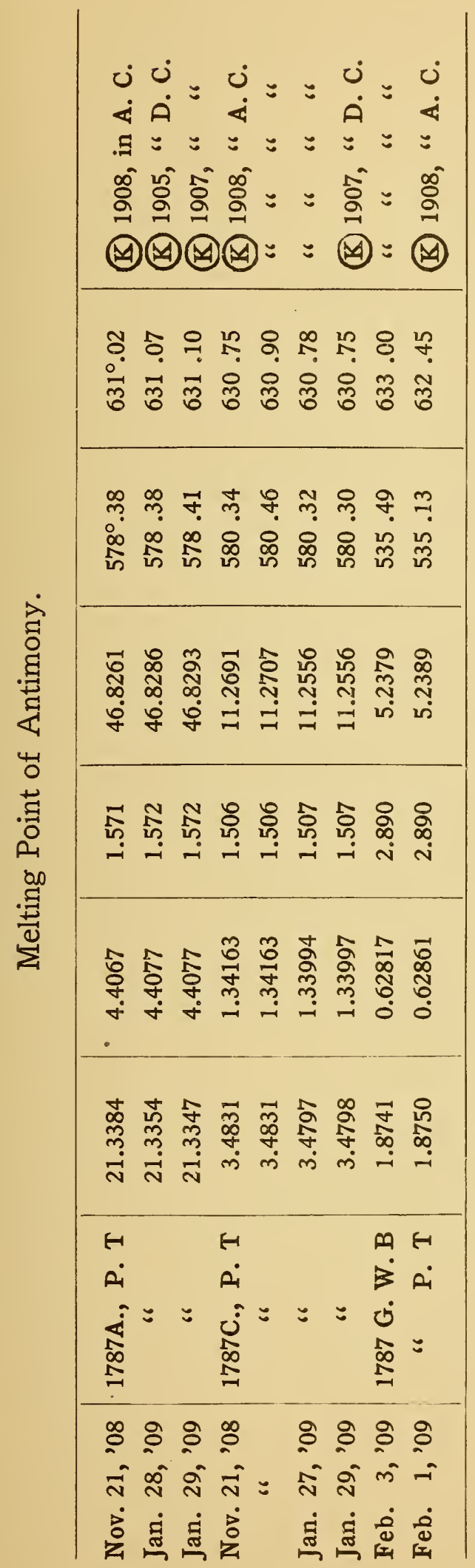




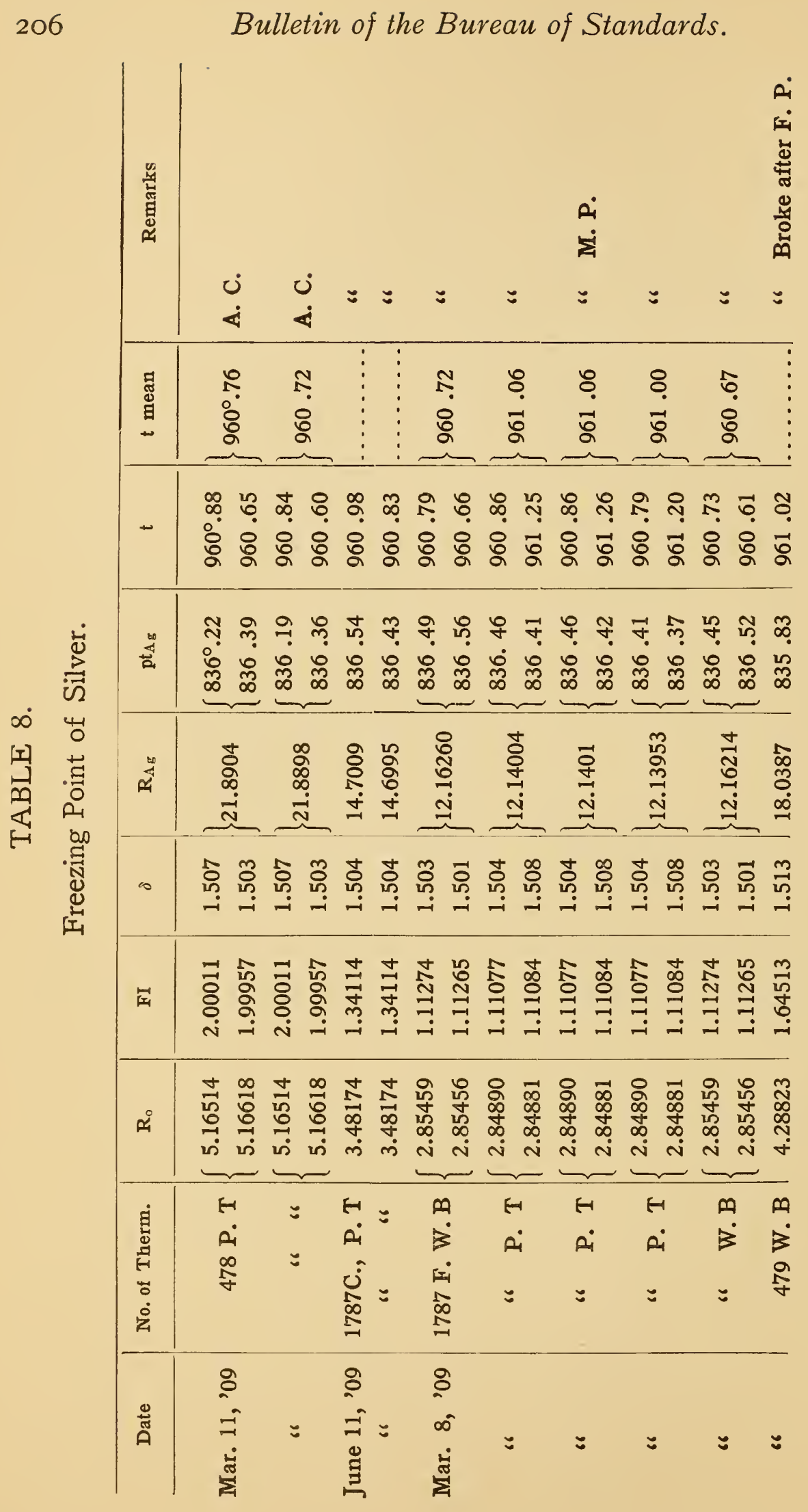


Waidner.] Platinum Thermometry at High Temperatures.
Burgess.

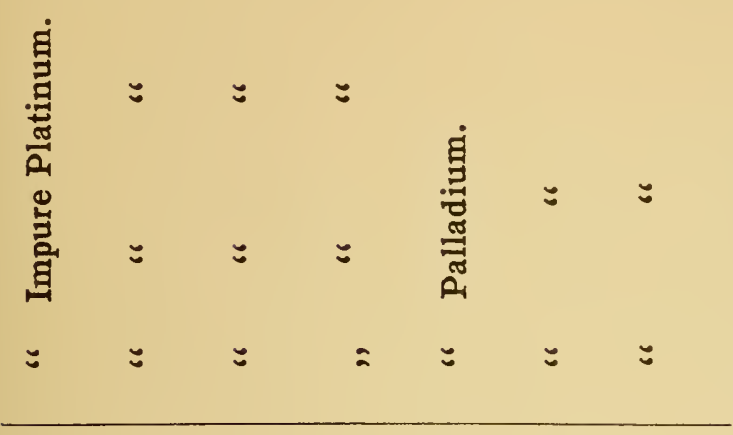

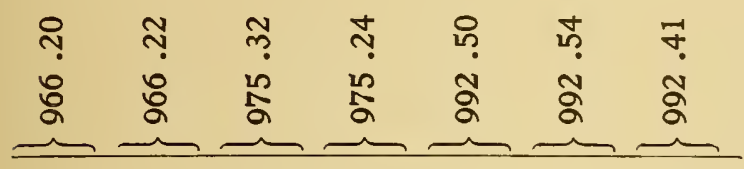

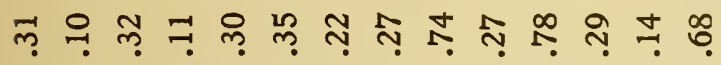

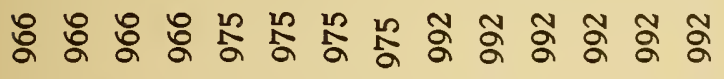

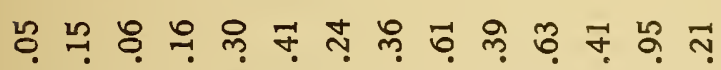

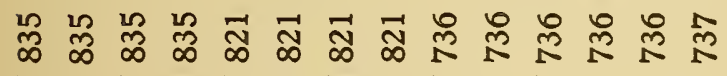

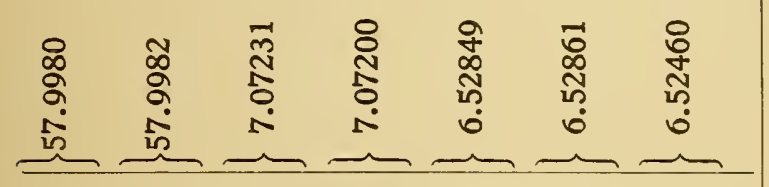

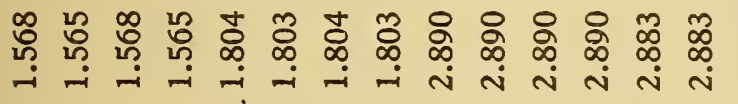

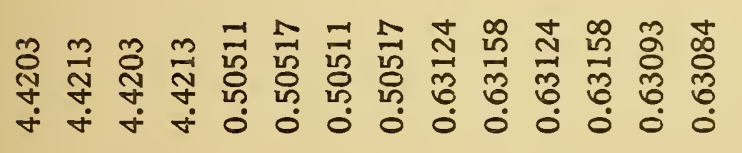

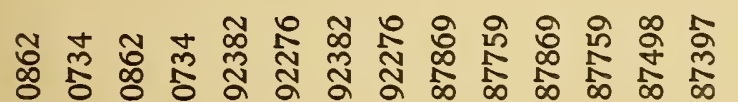

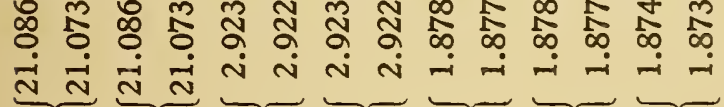

\begin{tabular}{|c|c|c|c|c|c|c|}
\hline 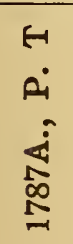 & $=$ & 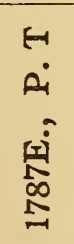 & $=$ & $\begin{array}{l}m \\
\dot{B} \\
0 \\
0 \\
0 \\
0 \\
0\end{array}$ & $=$ & $\vec{H}$ \\
\hline 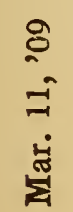 & $=$ & $\begin{array}{l}8 \\
\text { 今- } \\
\dot{0} \\
\dot{8}\end{array}$ & $=$ & $\begin{array}{l}8 \\
0 \\
\stackrel{0}{0} \\
\dot{\tilde{J}}\end{array}$ & $=$ & $=$ \\
\hline
\end{tabular}




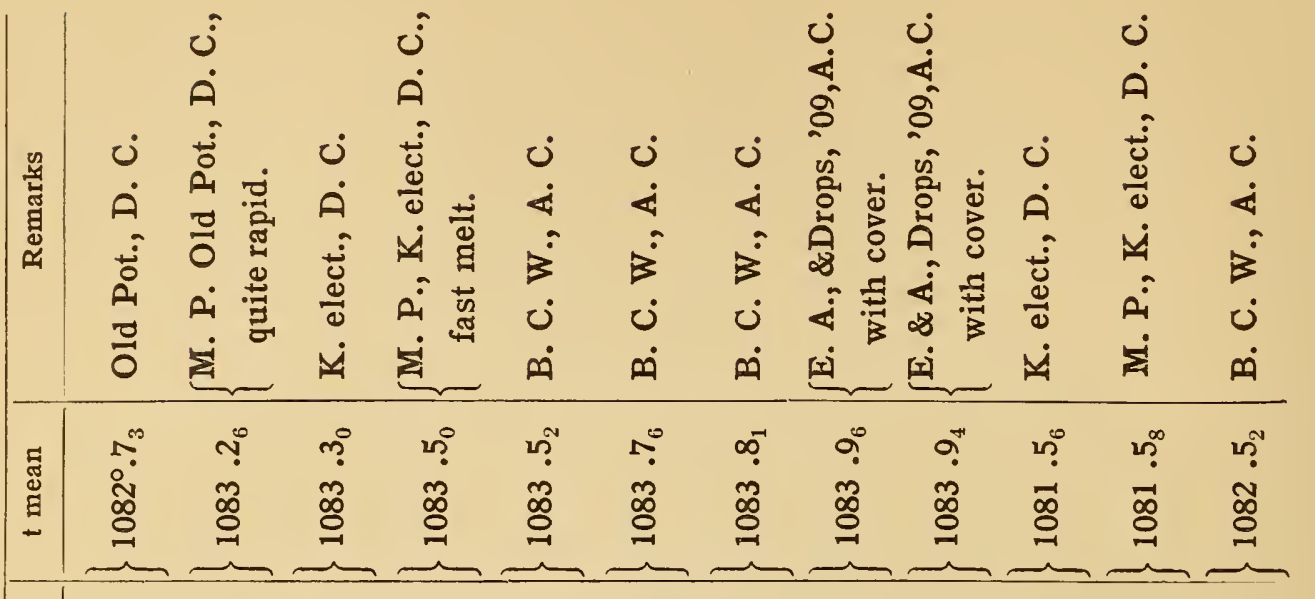

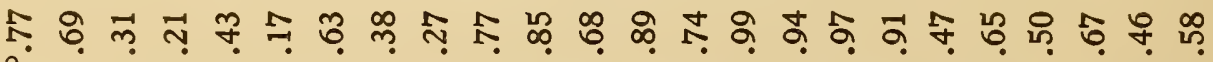

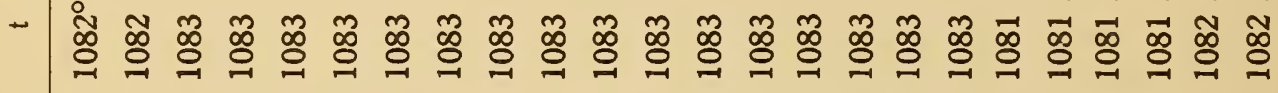

总 ᄁุ

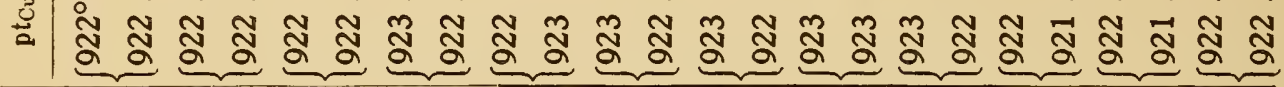

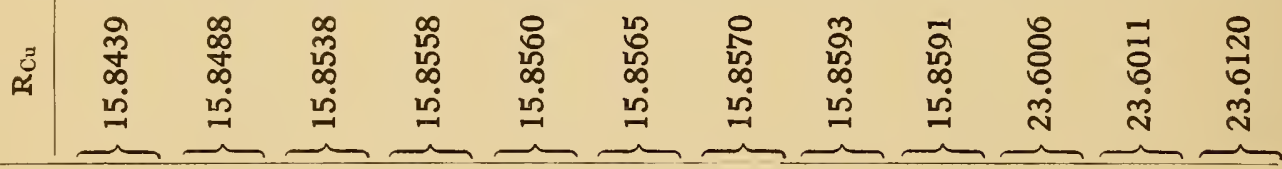

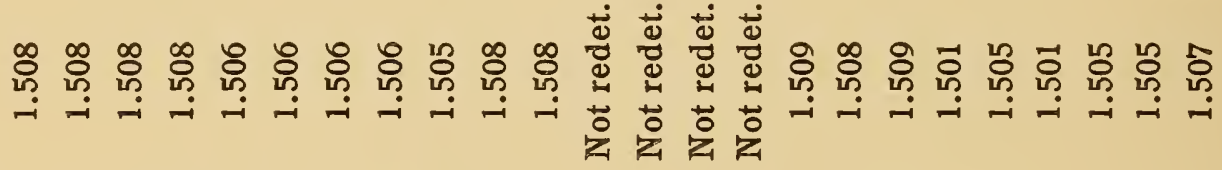

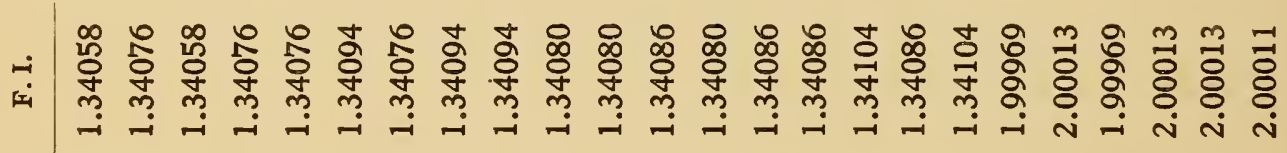

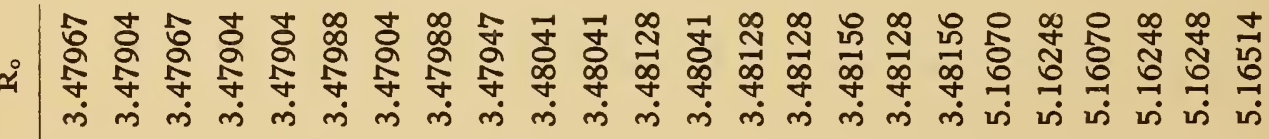

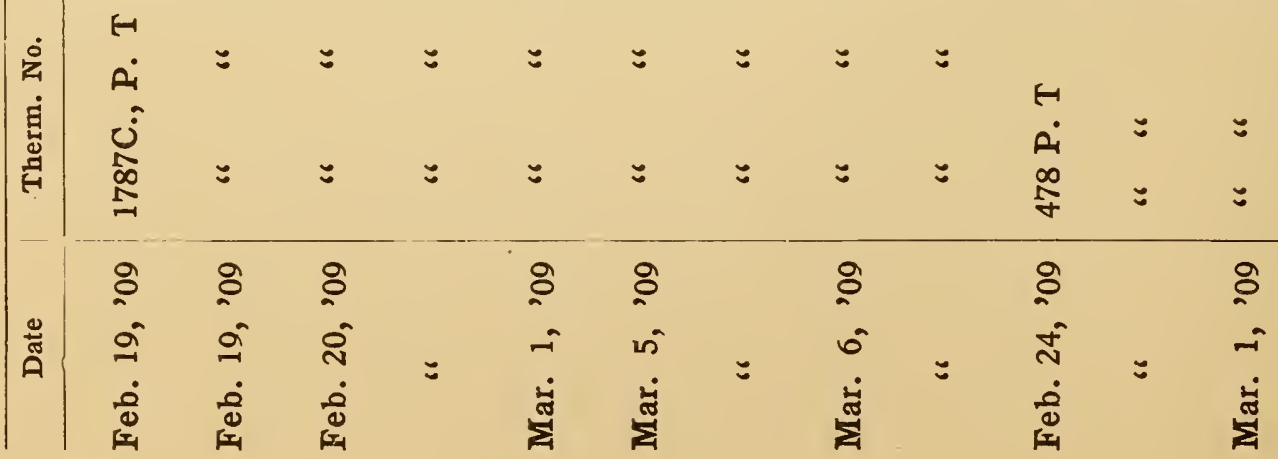


Waidner.] Platinum Thermometry at High Temperatures.
Burges

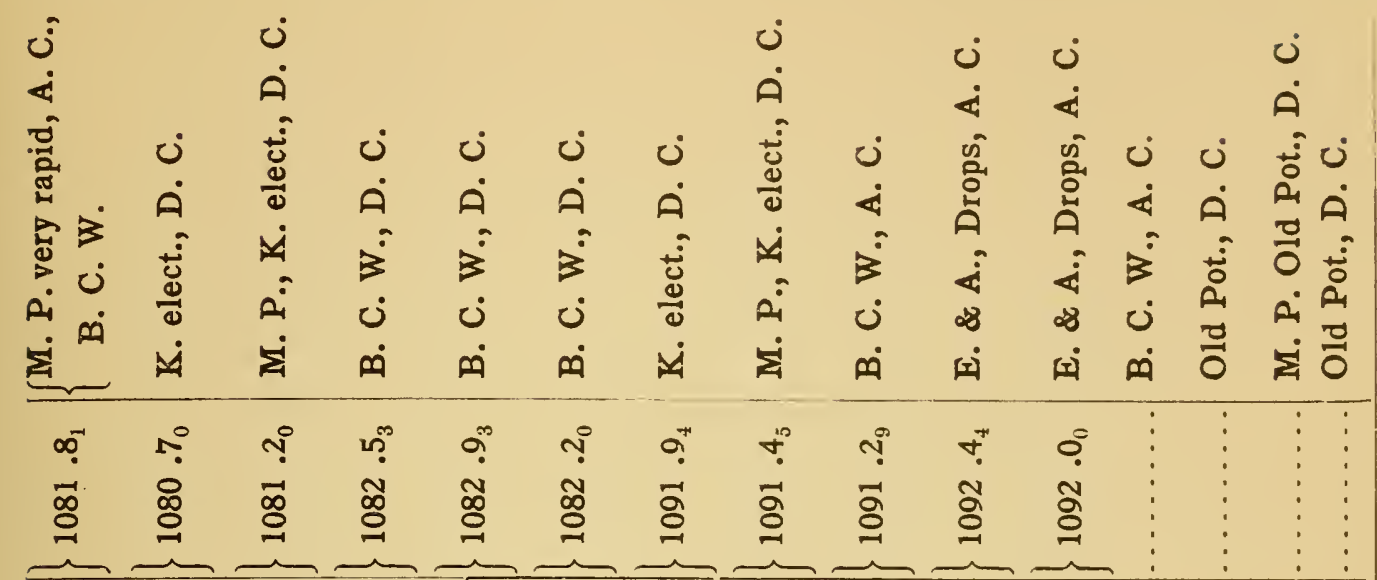

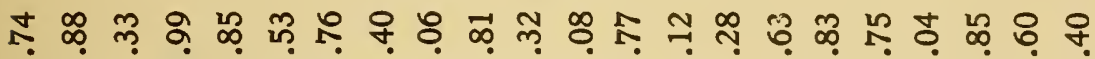

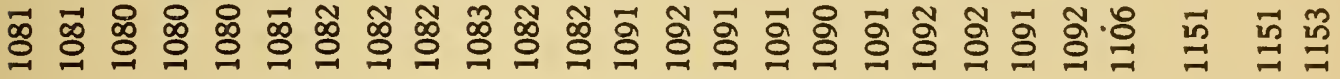

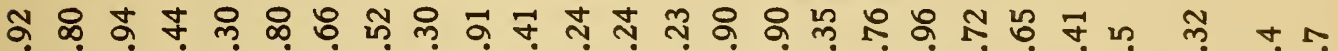
సี

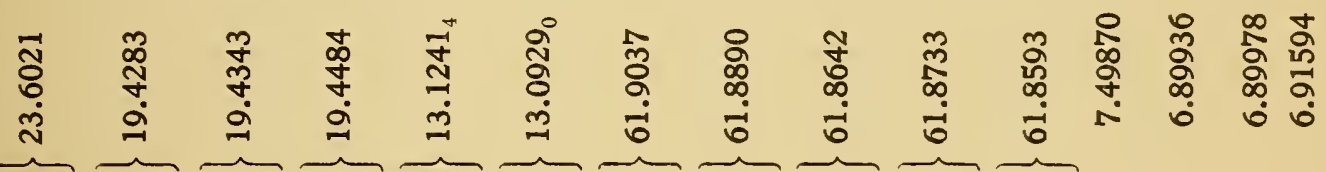

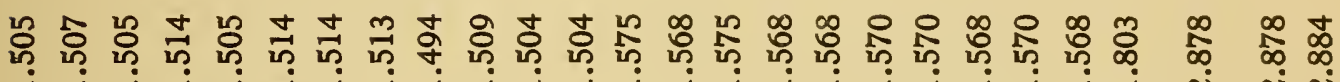

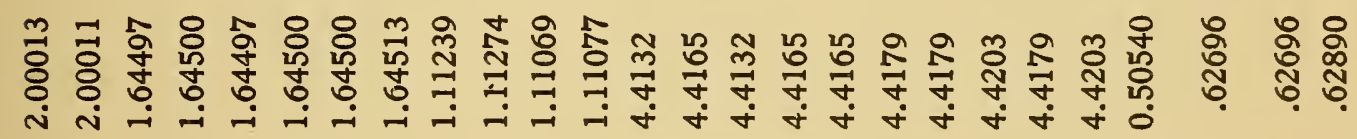

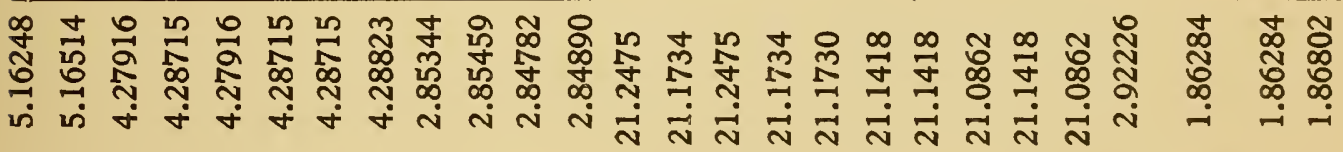

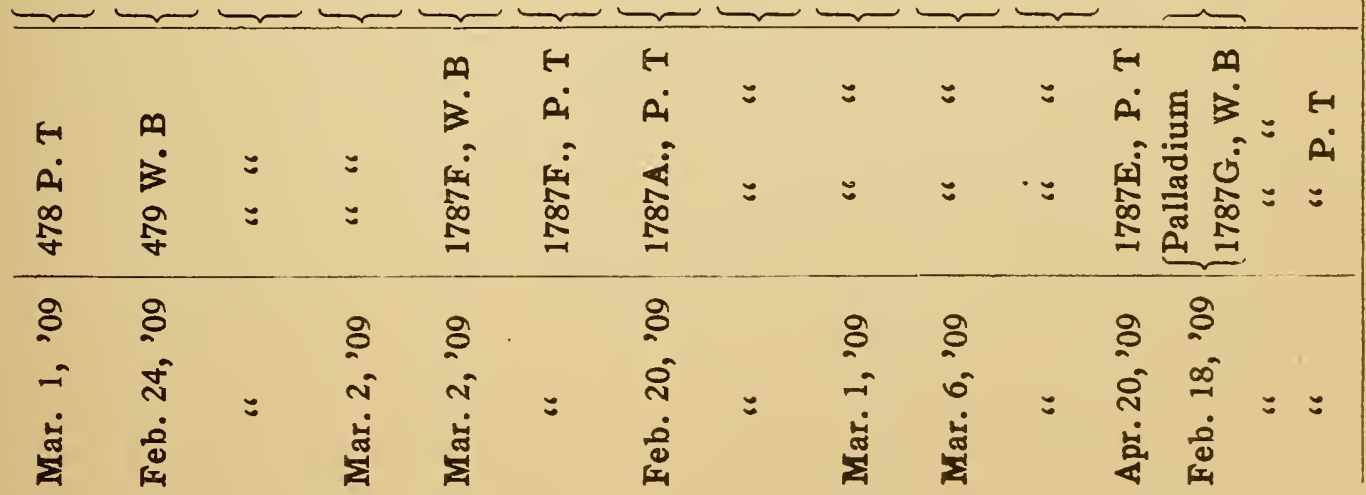

5249-No. 2-09-5 


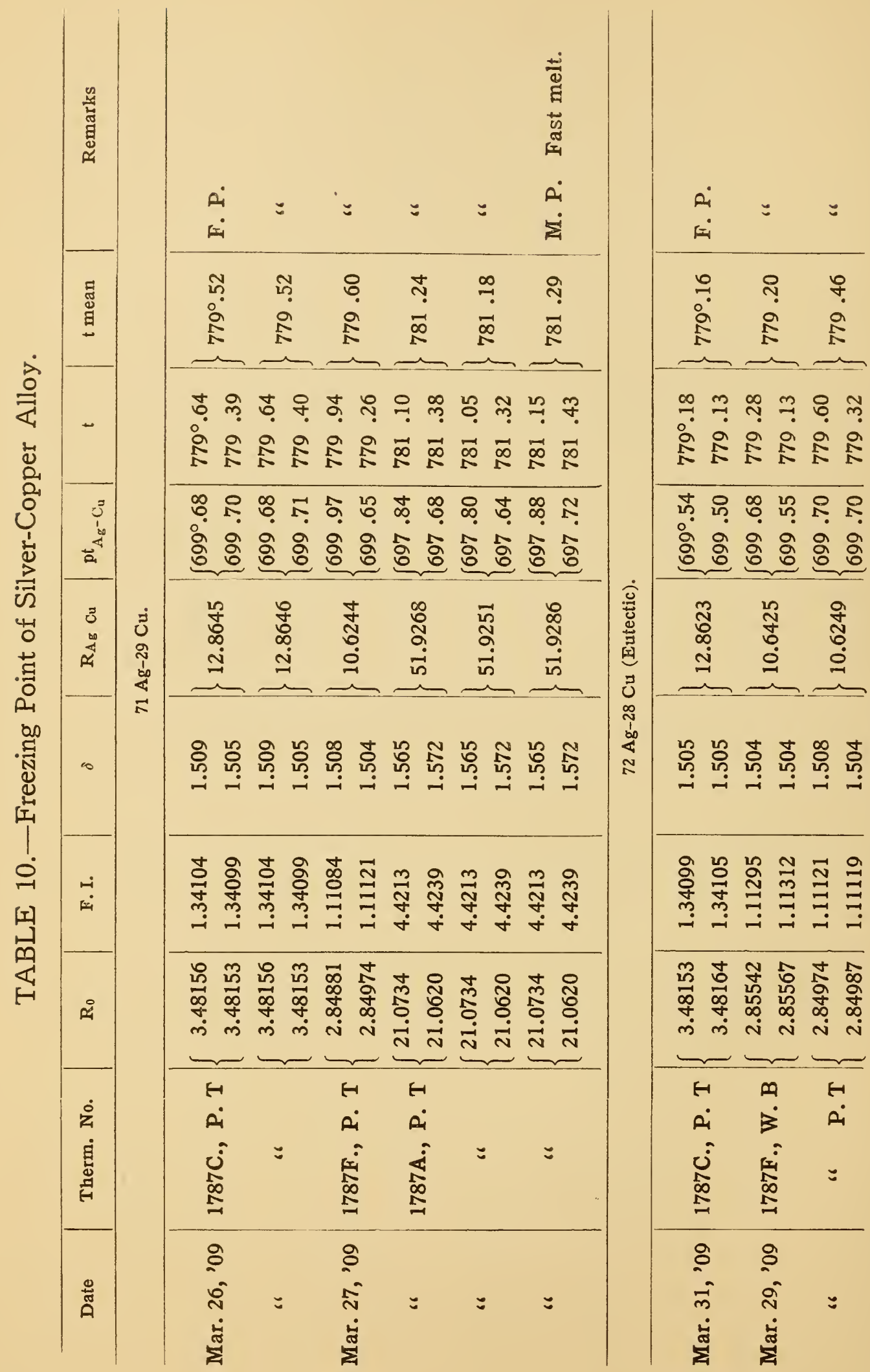




\begin{tabular}{|c|c|c|c|}
\hline$=$ & $\begin{array}{l}A^{2} \\
\dot{\Sigma}\end{array}$ & f & $=$ \\
\hline$\approx$ & 오 & $\approx$ & ஜூ \\
\hline 尺 & $\stackrel{尺}{5}$ & $\stackrel{\infty}{\leqslant}$ & 定 \\
\hline
\end{tabular}

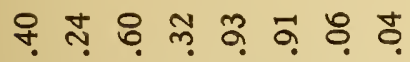

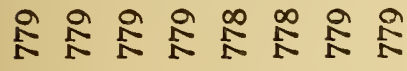

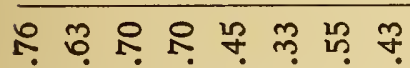

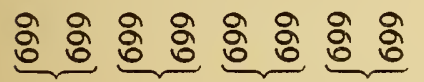

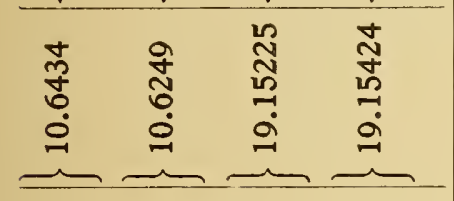

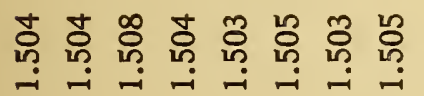

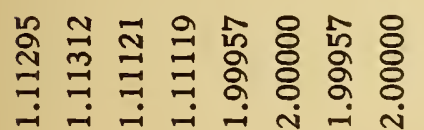

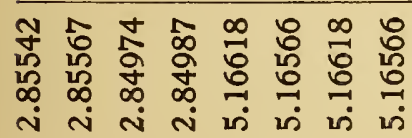

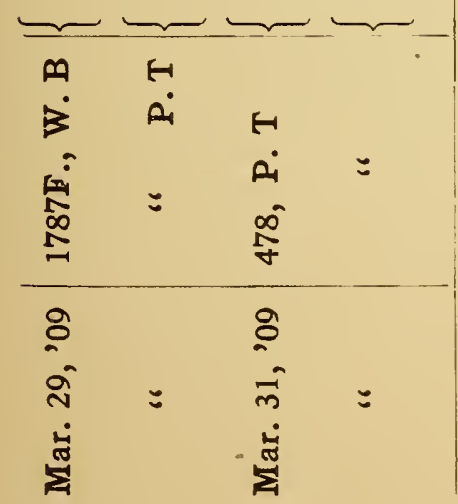

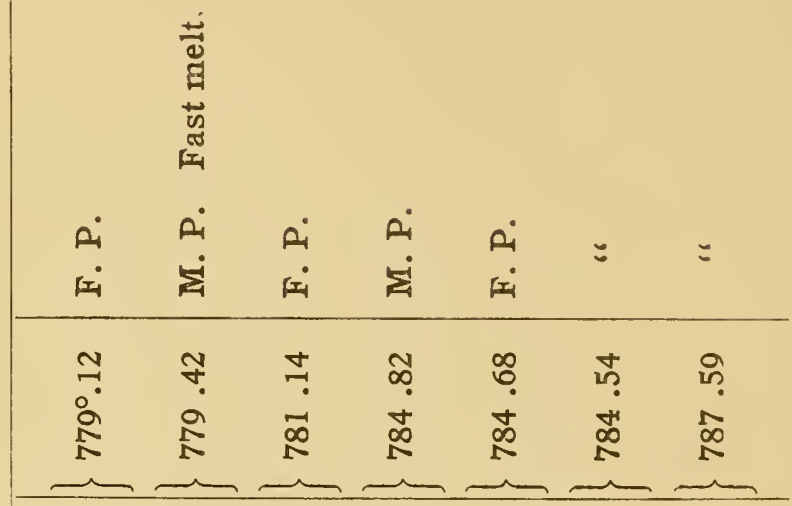

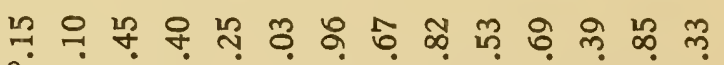

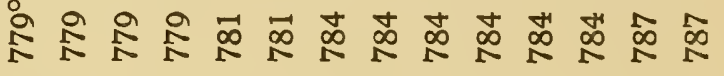

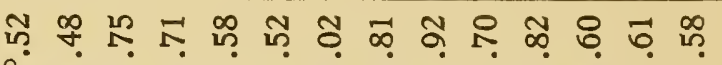

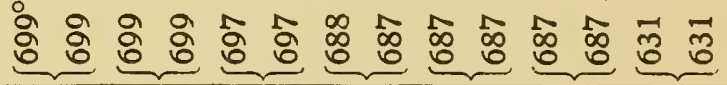

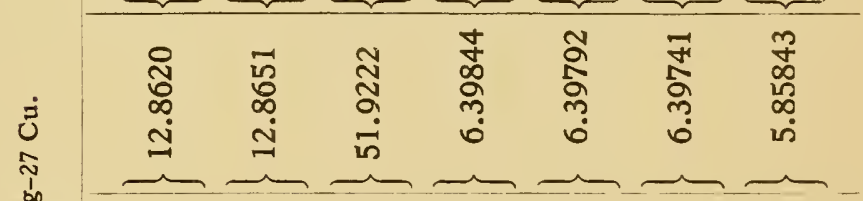

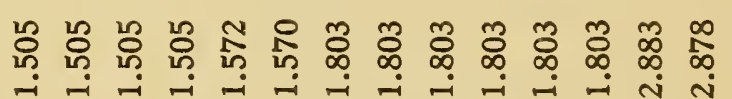

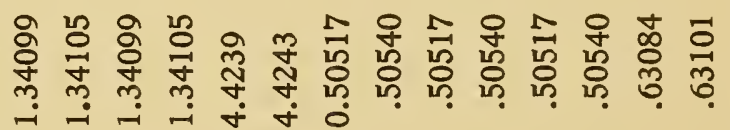

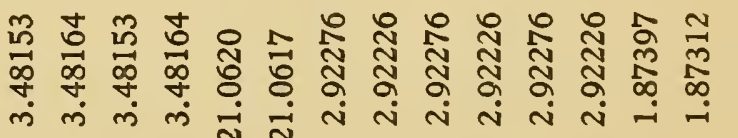

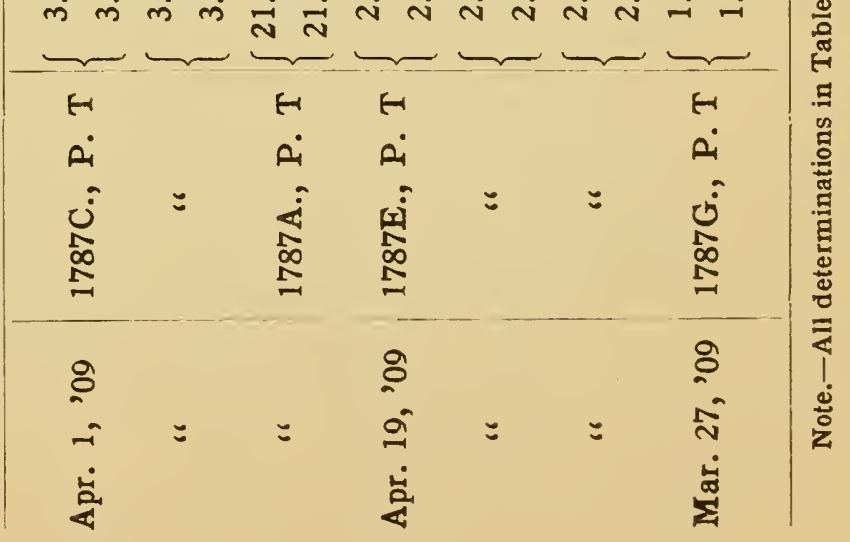


TABLE 13.-Temperature Corrections for Platinum of Different $\delta$.

[Thermometer calibrated by Callendar method, ice, steam, and S. B. P.]

\begin{tabular}{|c|c|c|c|c|c|c|c|c|}
\hline \multirow{2}{*}{ Temp. ${ }^{\circ} \mathrm{C}$} & \multicolumn{8}{|c|}{ Correction in ${ }^{\circ} \mathrm{C}$ for values of $o$ given below } \\
\hline & 1.525 & 1.550 & 1.575 & 1.600 & 1.650 & 1.700 & 1.800 & 1.900 \\
\hline $200^{\circ}$ & +0.02 & +0.05 & +0.08 & +0.10 & +0.14 & +0.16 & +0.20 & +0.21 \\
\hline $300^{\circ}$ & +.02 & +.05 & +.08 & +.11 . & $+\quad .19$ & $+\quad .27$ & +.45 & +.55 \\
\hline $400^{\circ}$ & .00 & .00 & +.01 & +.03 & +.08 & +.14 & +.29 & +.37 \\
\hline $500^{\circ}$ & -.02 & -.05 & $-\quad .09$ & -.11 & -.18 & -.24 & $-\quad .39$ & -.57 \\
\hline $600^{\circ}$ & -.09 & -.18 & -.30 & -.40 & -.62 & $-\quad .88$ & -1.42 & -1.96 \\
\hline $700^{\circ}$ & -.33 & -.70 & -1.03 & -1.32 & -1.78 & -2.2 & -2.9 & -3.5 \\
\hline $800^{\circ}$ & -.90 & -1.65 & -2.24 & -2.7 & -3.6 & -4.4 & -5.8 & -7.1 \\
\hline $900^{\circ}$ & -1.90 & -3.1 & -4.0 & -4.9 & -6.5 & -8.1 & -10.8 & -13.5 \\
\hline $1000^{\circ}$ & -3.3 & -5.2 & -6.8 & -8.2 & -10.7 & -13.1 & -17.1 & -20.8 \\
\hline $1100^{\circ}$ & -5.5 & -8.1 & -10.3 & -12.2 & -15.7 & -18.7 & -24.3 & -29.1 \\
\hline
\end{tabular}

TABLE 14.--Precision with Thermometer 1787C.

\begin{tabular}{|c|c|c|c|}
\hline Metal & Freezing Point & $\begin{array}{l}\text { Number of } \\
\text { Dets. }\end{array}$ & Range \\
\hline Cd, Baker \& Adamson... & $320^{\circ} .39$ & 2 & $0 . .01$ \\
\hline $\mathrm{Pb}$, Baker \& Adamson. . & 327.47 & 2 & .01 \\
\hline Zn, "Kahlbaum"...... & 419.36 & 4 & .01 \\
\hline Sb, "Kahlbaum," 1908. . & 630.71 & 3 & .35 \\
\hline Sb, "Kahlbaum," M. P. & 630.81 & 3 & .15 \\
\hline $71 \mathrm{Ag}-29 \mathrm{Cu} . . . . . . . .$. & 779.52 & 2 & .00 \\
\hline Ag, Mint....... & 960.90 & 2 & .10 \\
\hline $\mathrm{Cu}$, B. C. W............ & 1083.30 & 3 & .29 \\
\hline $\mathrm{Cu}$, E. \& A. drops...... & 1083.95 & 2 & .02 \\
\hline $\mathrm{Cu}, \mathrm{Kahlb}$. Electrolytic. . & 1083.40 & 2 & .10 \\
\hline
\end{tabular}

Precision with Thermometer 1787A.

\begin{tabular}{|c|c|c|c|}
\hline Sn, Baker \& Adamson. & $231^{\circ} .89$ & 2 & $0^{\circ} .10$ \\
\hline Cd, "Kahlbaum"...... & 321.05 & 2 & .04 \\
\hline $\mathrm{Zn}$, Baker \& Adamson. & 419.40 & 2 & .01 \\
\hline Sb, "Kahlbaum"..... & 630.50 & 2 & .07 \\
\hline $71 \mathrm{Ag}-29 \mathrm{Cu} . . . .$. & 779.40 & 2 & .04 \\
\hline Ag, Mint......... & 961.00 & 2 & .02 \\
\hline Cu, E. \& A. drops.... & 1083.3 & 2 & .40 \\
\hline
\end{tabular}


Waidner.] Platinum Thermometry at High Temperatures.
Burgess.

\begin{tabular}{|c|c|c|c|}
\hline 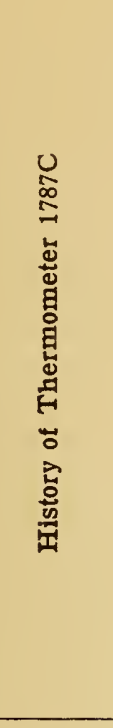 & 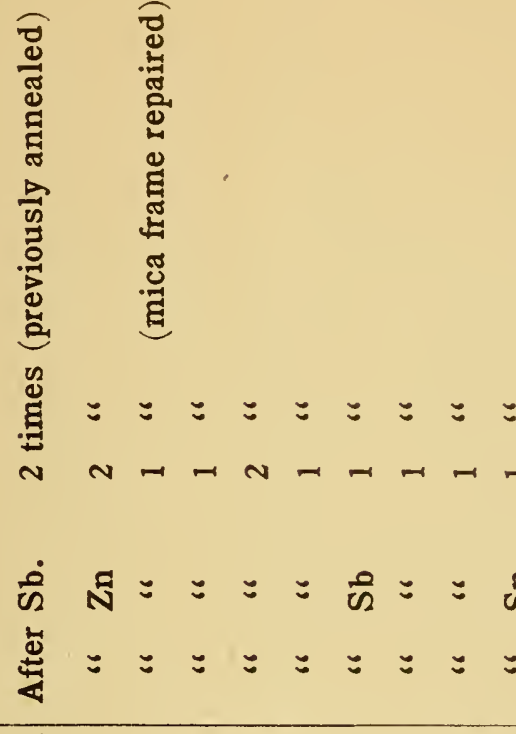 & 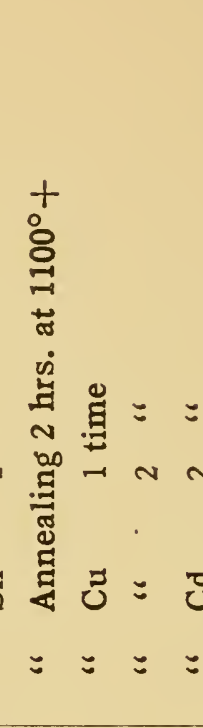 & 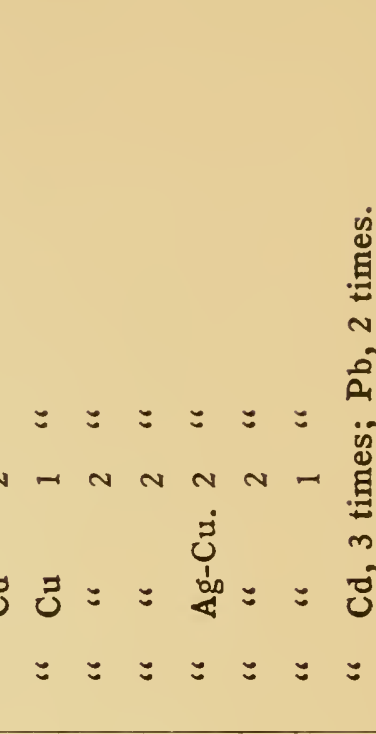 \\
\hline 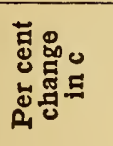 & 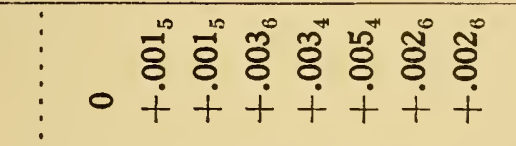 & 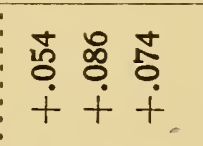 & 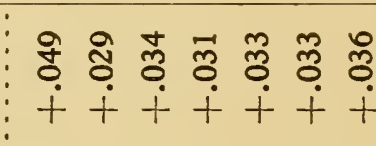 \\
\hline 。 & 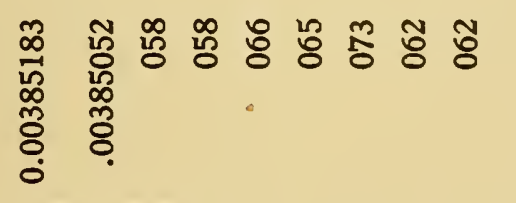 & 怘 芯 命 & స్ \\
\hline 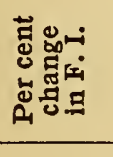 & 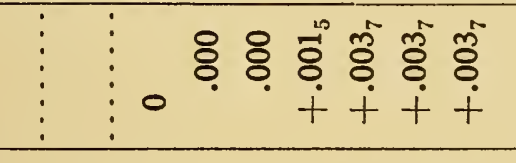 & 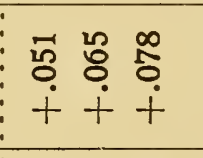 & 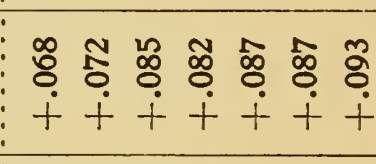 \\
\hline$\dot{\vec{x}}$ & 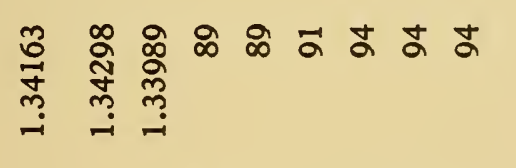 & 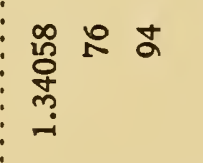 & 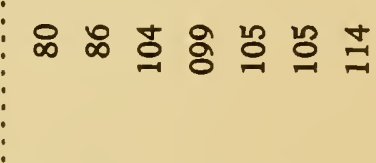 \\
\hline 采: & \multicolumn{3}{|c|}{ 。 } \\
\hline$\varkappa^{\circ}$ & \multicolumn{3}{|c|}{ 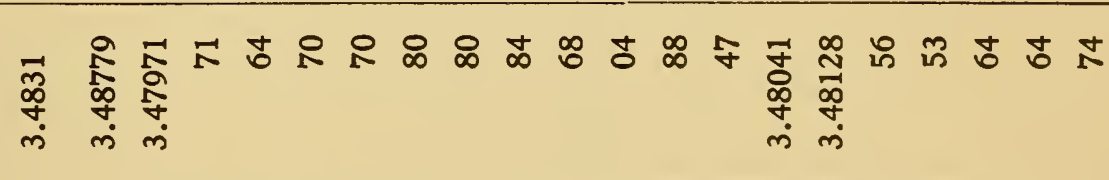 } \\
\hline$\stackrel{\Delta}{0}$ & \multicolumn{3}{|c|}{ 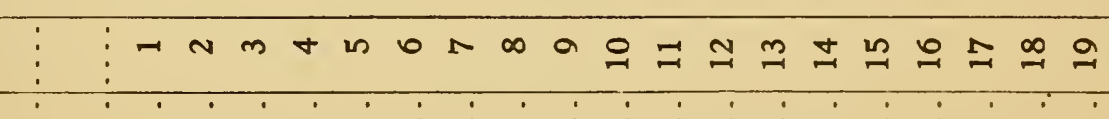 } \\
\hline$\stackrel{\circ}{\stackrel{\circ}{\Delta}}$ & 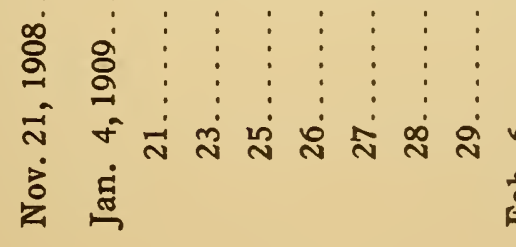 & & 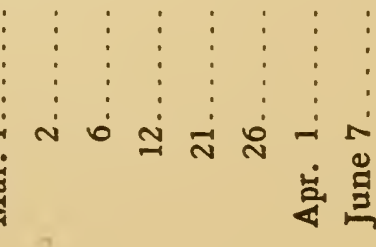 \\
\hline
\end{tabular}




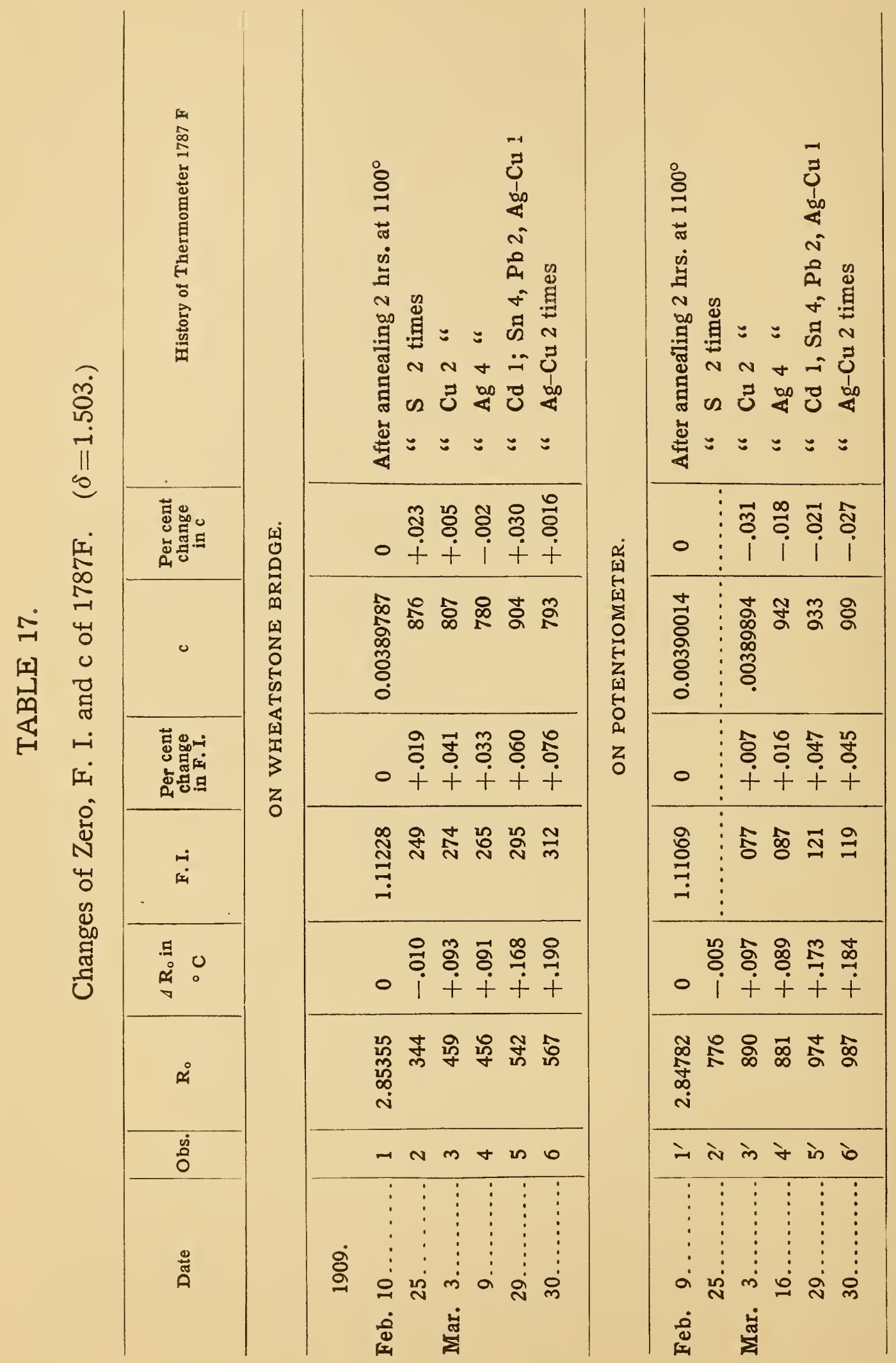


Waidner.] Platinum Thermometry at High Temperatures.

\begin{tabular}{|c|c|c|}
\hline \multirow{9}{*}{ 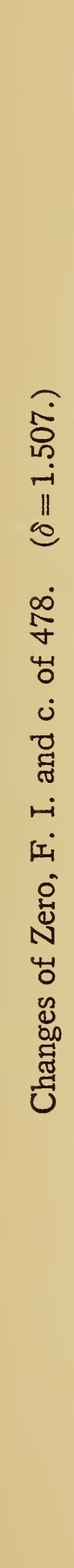 } & 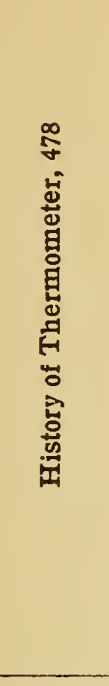 & 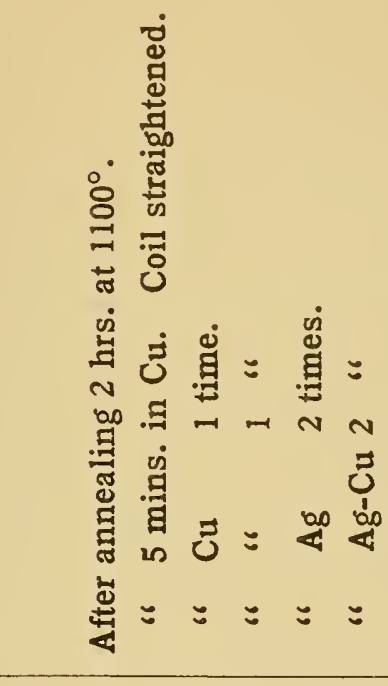 \\
\hline & 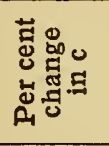 & 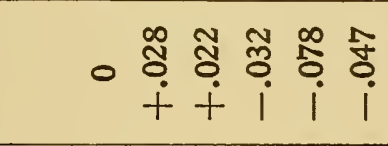 \\
\hline & 0 & 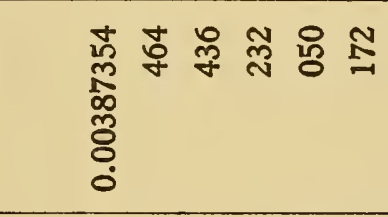 \\
\hline & 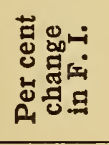 & 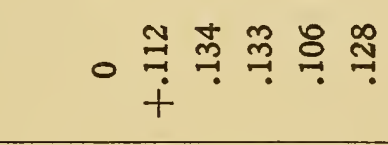 \\
\hline & شि & 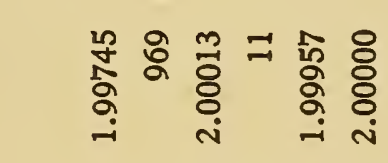 \\
\hline & 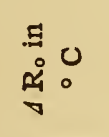 & ○ \\
\hline & ஷ̊ & 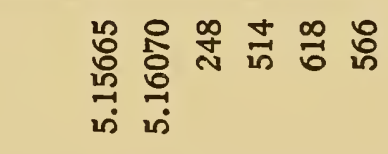 \\
\hline & :̊ & $\rightarrow N m+m o$ \\
\hline & 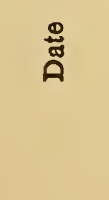 & 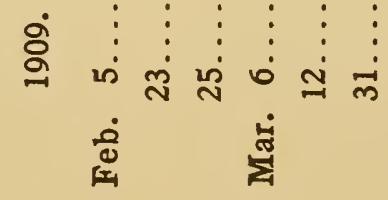 \\
\hline
\end{tabular}




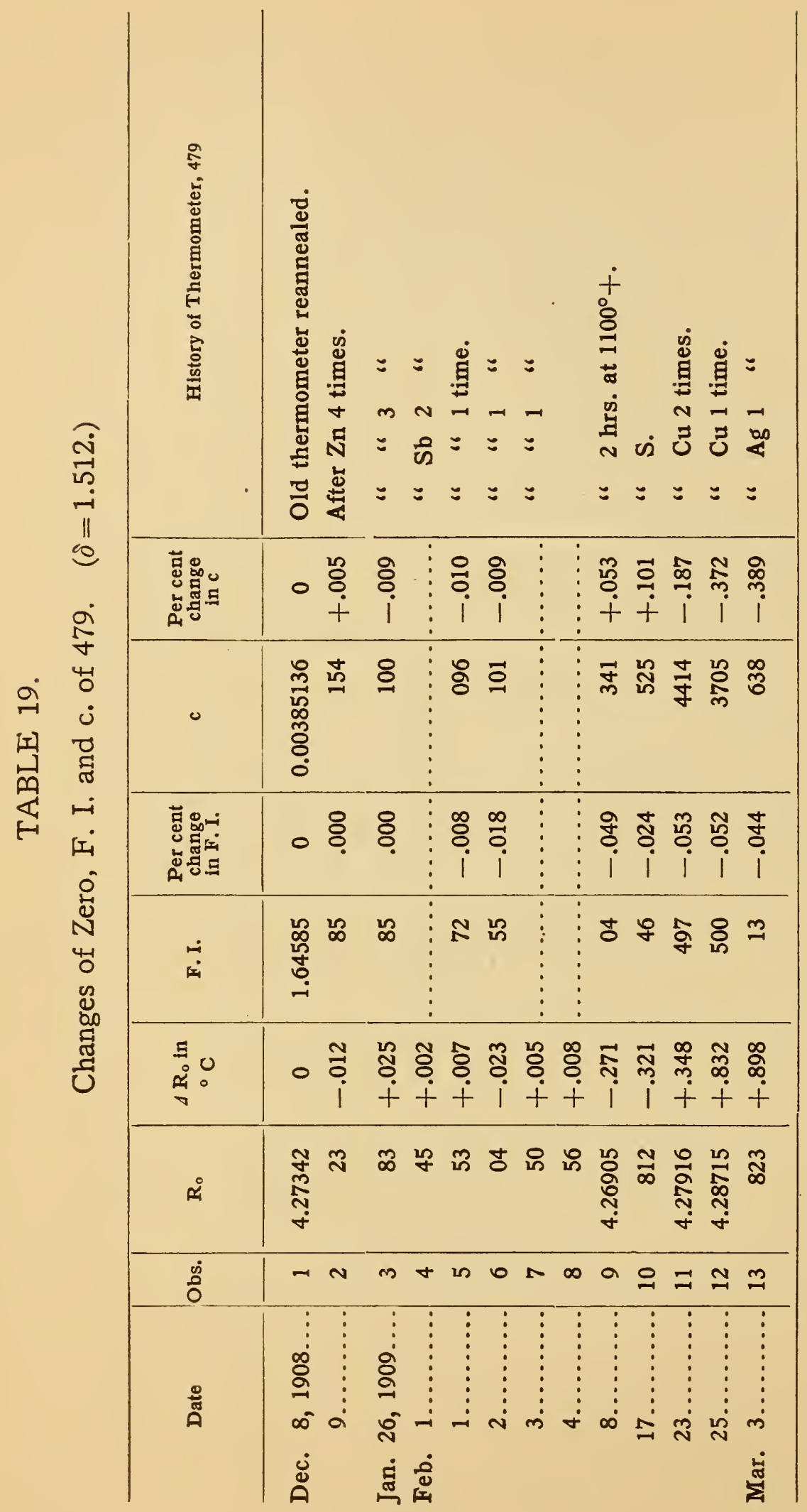




\begin{tabular}{|c|c|}
\hline 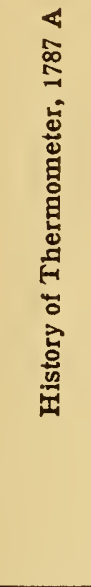 & 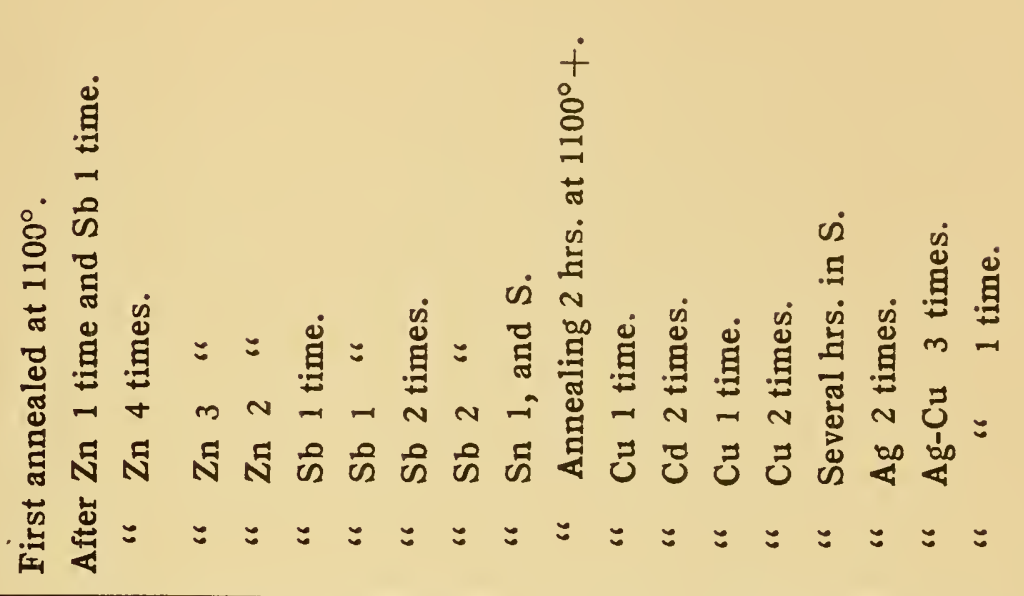 \\
\hline 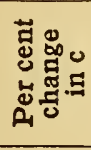 & 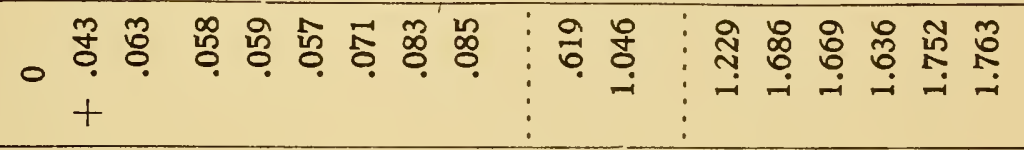 \\
\hline 0 & 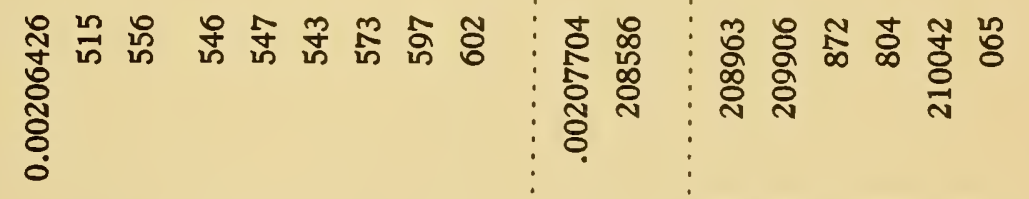 \\
\hline 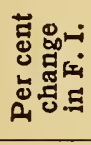 & ○ \& \\
\hline$\stackrel{\leftrightarrow}{4}$ & 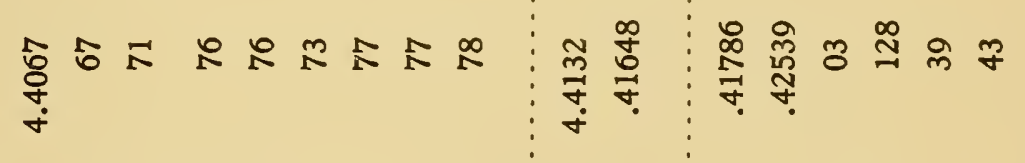 \\
\hline $\begin{array}{l}\text { 풍 } \\
\text { : } 0 \\
\text { \&. }\end{array}$ & 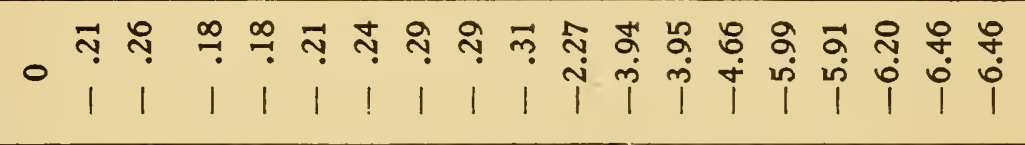 \\
\hline ஷ̊ & 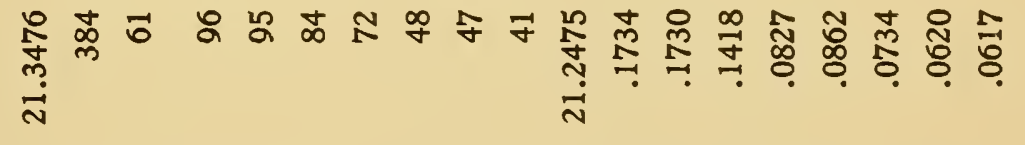 \\
\hline ڤ̊ํํ & 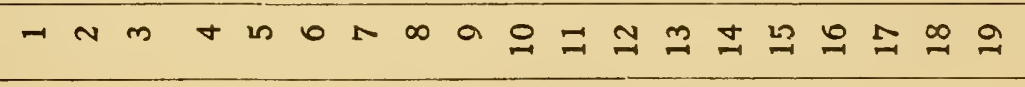 \\
\hline คั๊ & 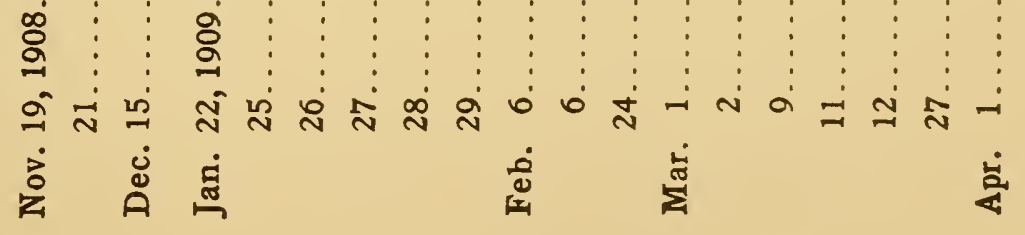 \\
\hline
\end{tabular}




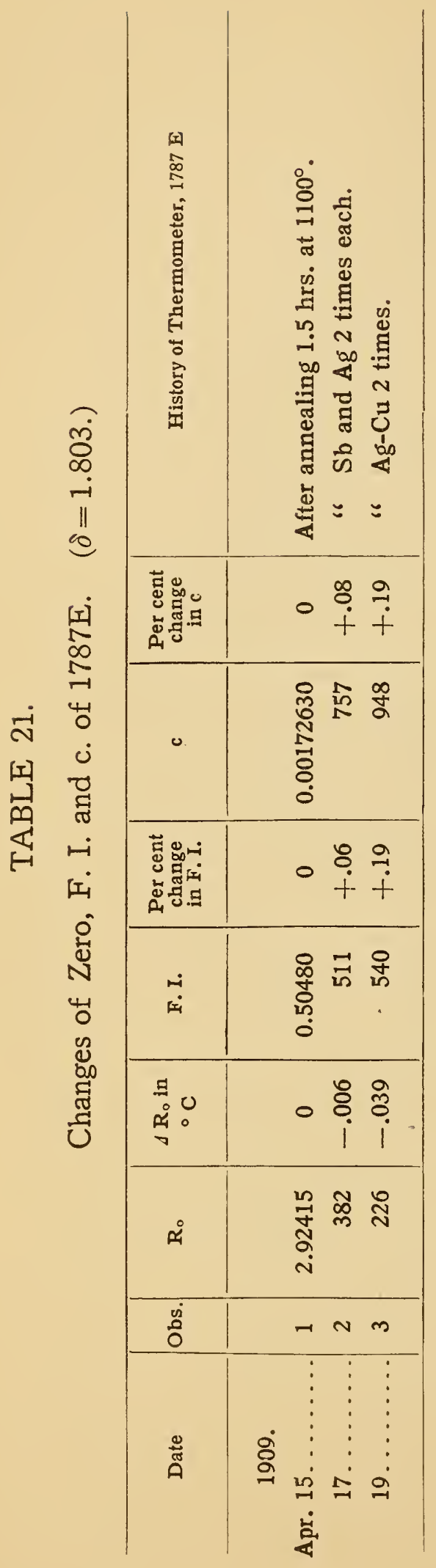


Waidner.
Burgess. $\quad$ Platinum Thermometry at High Temperatures.

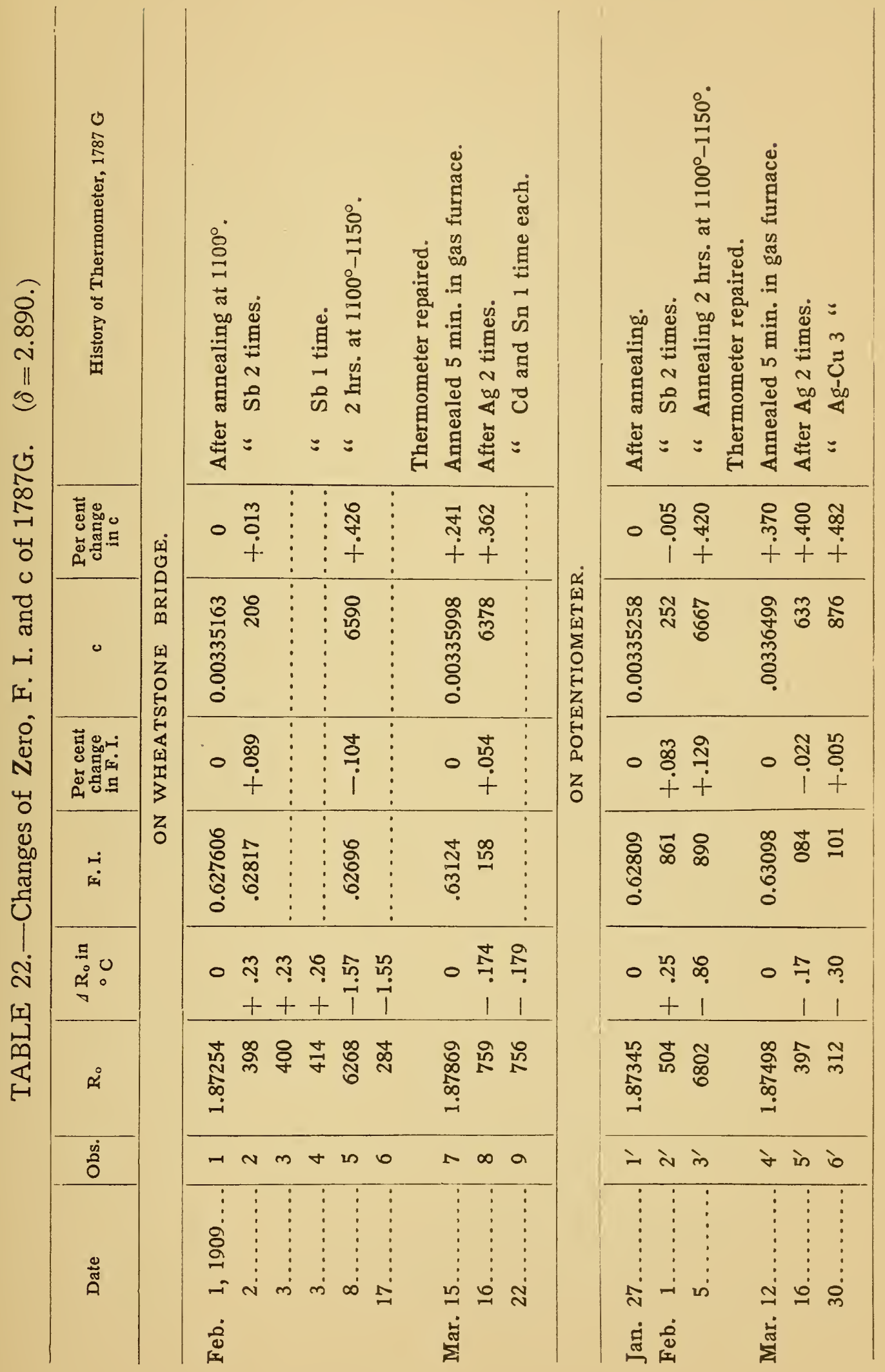


Waidner.] Platinum Thermometry at High Temperatures.
Burgess.]

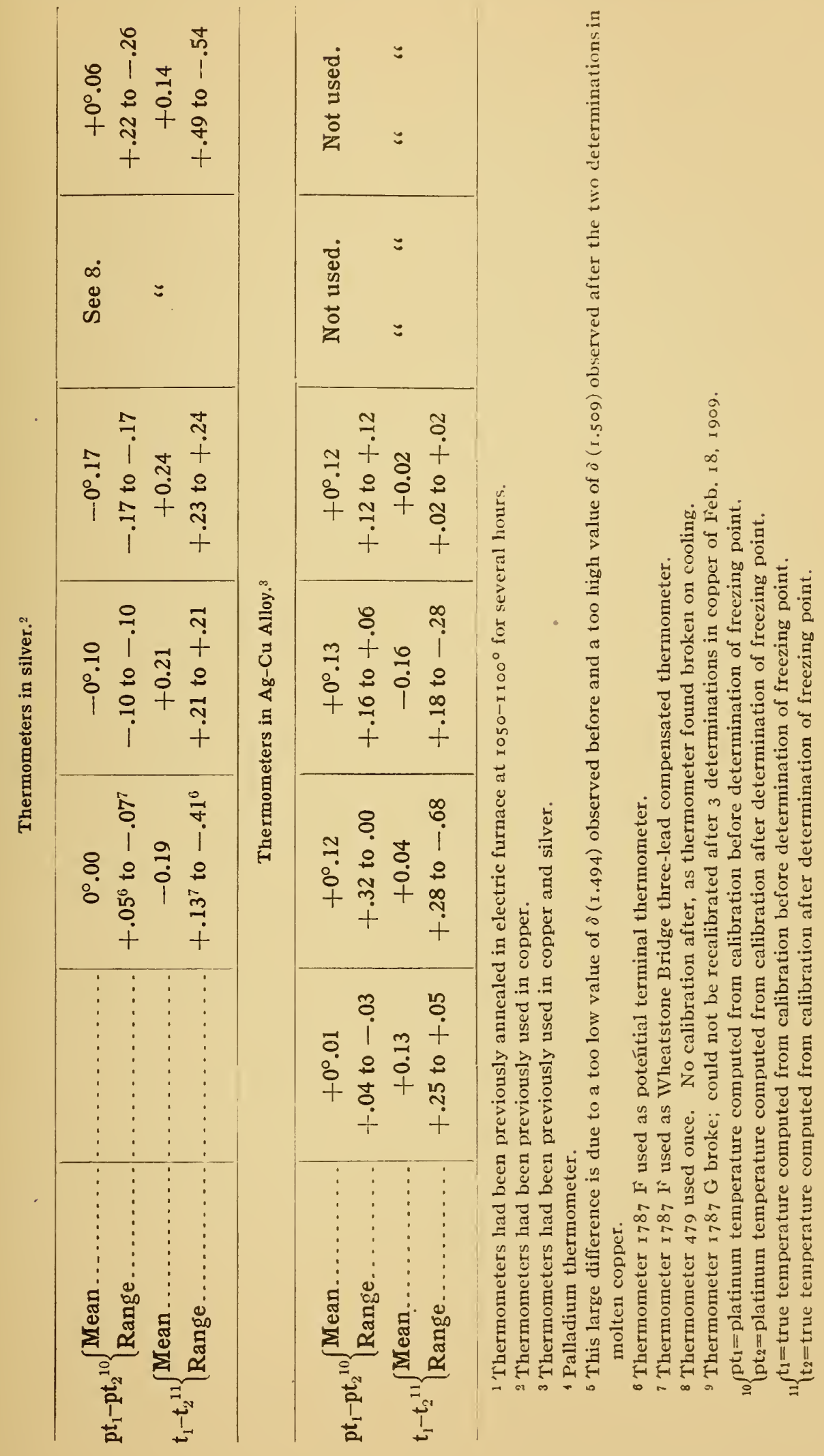




\section{TABLE 26.}

Comparison of Platinum and Palladium Thermometers at Freezing Point Temperatures.

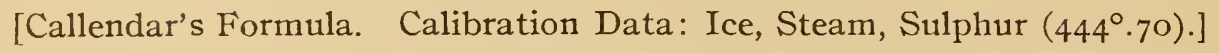

\begin{tabular}{|c|c|c|c|c|c|c|}
\hline \multicolumn{4}{|c|}{ Platinum $\left\{\begin{array}{l}\delta=1.505 \\
c=0.00385 \text { to } 389\end{array}\right.$} & \multicolumn{3}{|c|}{ Palladium $\left\{\begin{array}{l}\delta=2.890 \\
\varepsilon=0.00336\end{array}\right.$} \\
\hline \multirow{2}{*}{ Metal. } & \multirow{2}{*}{$\begin{array}{l}\text { Temperature by } \\
\text { Platinum Therm. }\end{array}$} & \multirow{2}{*}{$\begin{array}{l}\text { Temperature by } \\
\text { Palladium Therm. }\end{array}$} & \multirow{2}{*}{$\stackrel{d}{\mathrm{Pd}-\mathrm{Pt}}$} & \multirow{2}{*}{$\begin{array}{c}\text { Range, } \\
\circ \mathrm{C} .\end{array}$} & \multicolumn{2}{|c|}{ Number of- } \\
\hline & & & & & Obs. & Samples \\
\hline Sn. & $231^{\circ} .90$ & $231^{\circ} .62$ & $+0^{\circ} .28$ & & 1 & 1 \\
\hline $\mathrm{Cd}$. & 321.01 & 320.52 & -.49 & 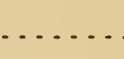 & 1 & 1 \\
\hline $\mathrm{Pb}$. & 327.58 & 326.90 & $-\quad .68$ & $\ldots \ldots$ & 1 & 1 \\
\hline $\mathrm{Sb}$. & 630.71 & 632.99 & +2.28 & 0.34 & 3 & $2 \mathrm{~K}$ \\
\hline Ag.-Cu. & 779.20 & 787.59 & +8.39 & ...... & 1 & 1 \\
\hline Ag. & 960.88 & 992.49 & +31.61 & .13 & 3 & 1 \\
\hline $\mathrm{Cu}$. & $1,083.0$ & 1,152 & +69 & 2 & 2 & 1 \\
\hline
\end{tabular}

TABLE 27.

Corrections to the Palladium Thermometer.

[Palladium Temperatures computed by Callendar's Formula. Calibration Data, Ice, Steam, Sulphur $\left(444^{\circ} \cdot 70\right)$.]

\begin{tabular}{c|c|c}
\hline $\begin{array}{c}\text { Temperatures centigrade } \\
\text { (Platinum Therm.) }\end{array}$ & $\begin{array}{c}\text { Temperatures centigrade } \\
\text { (Palladium Therm.) }\end{array}$ & $\begin{array}{c}\text { Correction to temperatures } \\
\text { with Palladium Therm. }\end{array}$ \\
\hline $200^{\circ}$ & $199^{\circ} .80$ & $+0^{\circ} .20$ \\
300 & 299.56 & +.44 \\
400 & 399.70 & +.30 \\
500 & 500.40 & -.40 \\
600 & 601.5 & -1.5 \\
700 & 704.7 & -4.7 \\
800 & 810.5 & -10.5 \\
900 & 921.0 & -21.0 \\
1,000 & $1,040.8$ & -40.8 \\
1,100 & $(1,175)$ & $-75)$ \\
\hline
\end{tabular}




\section{BIBLIOGRAPHY.}

The following is not intended to be a complete bibliography of electrical resistance thermometry, but it is hoped that all the more important original contributions to the subject are included, as well as a sufficient number of technical papers treating of the applications of the resistance thermometer. Many duplicate references, mainly from the engineering press and reviewing journals, are omitted. Most of the English papers and many of the others will be found abstracted in the London Electrician.

Some references are given which deal with those properties of platinum which are of interest in connection with a study of its resistance at high temperatures.

As the establishment of the sulphur boiling point is fundamental in the calibration of resistance pyrometers, references to such determinations, as well as to some recent papers on the gas scale of temperatures, are also included.

I. MÜLLER J., Abnahme der Elektricitätsleitung in Metallen bei stärke TemperaturErhöhung.

Pogg. Ann., 103, p. I76; I858.

2. MATTHIESSEN A., Ueber die elektrische Leitungsfähigkeit der Metallen.

Pogg. Ann., 103, p. 428 ; 1858.

3. MatThIESSEN and v. Bose On the Influence of Temperatures on the Electric Conducting Power of Metals.

Phil. Trans., 80, p. I; 1862.

Pogg. Ann., 115, p. 353; 1862.

4. Regnault, (Sulphur Boiling Point) Relation des Expériences, 2, p. 526; 1862.

5. Siemens W., On the Increase of Electrical Resistance in Conductors with Rise of Temperature, and its Application to the Measure of Ordinary and Furnace Temperatures; also on a simple Method of Measuring Electrical Resistances.

Bakerian Lecture, 1871. Proc. Roy. Soc., 19, p. 351; 187 I.

6. Benorr R., Sur la Resistance Electrique des Metaux.

C. R., 76, p. $342 ; 1873$.

7. WeINHOLD (Sulphur Boiling Point).

Pogg. Ann., 149, p. 23I; 1873.

8. Report of Committee of British Assoc. on new Pyrometer of Mr. Siemens.

British Association Reports, p. 242; 1874.

9. Siemens W., Trans. Soc. Telegraph Engs.; 1879.

Io. Ramsay W., (Sulphur Boiling Point).

Phil. Mag., 20, p. 524; 1885.

II. SCHLEIERMACHER A., Ueber die Abhängigkeit der Wärmestrahlung von der Temperatur und das Stefan'sche Gesetz.

Ann. d. Phys., 26, p. 287; 1885 . 
12. Callendar H. L., On the Practical Measurement of Temperature.

Proc. Roy. Soc., 41, p. 231 ; 1886.

Phil. Trans., 178, p. I60-230; 1887.

I3. Barus C., Certain Generic Electrical Relations of the Alloys of Platinum. Am. J1. Sci., (3) 36, p. 427; 1888.

i4. Cailletet L. and Colardeau E., Mesure des Bases Températures.

J1. de Phys., (2) 7, p. 288; 1888.

15. Callendar H. L. and Griffiths E. H., On the Determination of the Boiling Point of Sulphur and on a Method of Standardizing Platinum Resistance Thermometers by Reference to it.

Proc. Roy. Soc., 49, p. 56; 1890.

Phil. Trans., 182 A, p. 43-72, II9-I 57 ; r 892.

I6. Comn P., Ueber Nachwirkungsänderungen des Widerstandes hartgezogener Drähte.

Ann. d. Phys., 41, p. 7 I ; 1890.

I 7. Griffiths E. H., A Comparison of a Platinum Thermometer with some Mercury Thermometers at Low Temperatures.

British Assoc. Report, p. I 30 ; I 890.

i 8. Callendar H. L., On the Construction of Platinum Thermometers.

Phil. Mag., 32, p. I04; I89I.

I9. GRIFFiths E. H., On the Determination of Some Boiling and Freezing Points by the Platinum Thermometer.

Phil. Trans., 182 A, p. I43; I 89 I.

20. Dewar J., On the Electrical Resistance of Pure Metals, Alloys, and Non-Metals at the Boiling Point of Oxygen.

Phil. Mag., 34, p. 326; 1892.

2I. GRIFFiths and CLARK, Note on the Determination of Low Temperatures by Platinum Thermometers.

Phil. Mag., 34, p. 515 ; 1892.

22. Defar and Fleming, The Electrical Resistance of Metals and Alloys at Temperatures Approaching the Absolute Zero.

Phil. Mag., 36, p. 271; I 893.

23. CAREy Foster, Platinum Resistance Thermometer.

Nature, 50, p. 399; 1894.

24. Griffiths, The Mechanical Equivalent of Heat.

Phil. Trans., 184 A, p. 36I-504; 1893.

Appendix to above: Proc. Roy. Soc., 55, p. 23; 1894.

25. Thätigkeit der P. T. Reichsanstalt, Boiling Points of Hg and S.

Zs. f. Instrumentenkunde, 14, p. 304; 1894.

26. Burstali N. F. W., The Measurement of Cyclically Varying Temperature.

Phil. Mag., 40, p. 282; 1895.

27. Heycock C. T. and Neville F. H., On the Determination of High Temperatures by means of Platinum Resistance Thermometers.

J1.Chem. Soc., 57, p. 376, 1890;67, p. 160; 1024; I895. Phil. Tr. 189, p. 25 ; 1897.

28. Holborn L. and Wien W., Ueber die Messung hoher Temperaturen.

Ann. d. Phys., 56, p. 360 ; 1895.

29. DEWAR, Thermoelectric Powers of Metals and Alloys between the Temperatures of the Boiling Point of Water and the Boiling Point of Liquid Air.

Phil. Mag., 40, p. 97; 1895. 
30. Olszewsin K., Determination of the Critical and Boiling Temperature of Hydrogen.

Phil. Mag., 40, p. 202; 1895.

3I. APPLEYARD R., A direct reading Platinum Thermometer.

Phil. Mag., (5) 41, p. 62; 1896.

32. Clarke C. M., The Measurement of Temperature: An Application of the Measurement of Resistance.

Electrician (Lond.) 38, p. 175, 241, 273, 371, 747; 1896-97.

33. Griffitrs, An Account of the Construction and Standardization of Apparatus recently acquired by Kew Observatory for the Mearsurement of Temperature. Nature, 53, p. 39; 1896.

34. GRIFFITHS, The Measurement of high Temperatures.

Nature, 53, p. 389; 1896.

35. HOLBORN and WIEN, Ueber die Messung tiefer Temperaturen.

Ann. der Phys., 59, p. 213; 1896.

Sitzber. Berlin Akad. IViss., p. 673; 1896.

36. Witkowski A. W., Electric Thermometer for low Temperatures.

Phil. Mag., 41, p. 312; I896.

37. CALLENDAR, An Electrical Method of Measuring the Temperature of a Metal Surface on which Steam is Condensing.

British Assoc. Report, p. 422; 1897.

38. Dickson J. D. H., On Platinum Temperatures.

Phil. Mag., 44, p. 445; I 897.

39. Morris D. K., On the Magnetic Properties and Electrical Resistance of Iron as dependent upon Temperature.

Phil. Mag., 44, p. 213; 1897.

40. Tory H. M., On a Research in Thermo-electricity by means of a Platinum Resistance Thermometer.

British Assoc. Report, p. 588; 1897.

4I. Waidner C. W. and MaLiory F., A Comparison of Rowland's Mercury Thermometers with a Callendar-Griffiths Platinum Thermometer, etc.

Johns Hopkins Univ. Circ., 16, p. 42; 1897.

Phil. Mag., 44, p. 165; 1897.

Phil. Mag., 48, p. I-45; I899.

Phys. Rev., 8, p. 193; 1899.

42. Calimndar and Nicholson, Measurements of Steam Temperatures in Steam Engine Cylinder.

Proc. Inst. C. E., p. I3I; I898.

43. Dickson, On the Reduction to Normal Air-Temperatures of the PlatinumTemperatures in the Low-Temperature Researches of Professors Dewar and Fleming.

Phil. Mag., 45, p. 525; 1898.

44. Rambaut A. A., Underground Temperatures at Oxford, etc.

Phil. Trans., 195 A, 1898.

45. WADE E. B. H., On a Method of facilitating the Measurement of Temperatures by means of Platinum Thermometry.

Proc. Cambr. Soc., 9, p. 526; 1898.

Wied. Beibl., 23, p. 693; 1899.

5249 -No. 2-09-6 
46. Callendar, Notes on Platinum Pyrometry.

Phil. Mag., 47, p. 191, 519; 1899.

47. Callendar, On a Practical Thermometric Standard.

Phil. Mag. (5), 48, p. 5 19-547; 1899.

48. Callendar, Platinum Recording Pyrometer.

Engineering (Lond.), 67, p. 675; 1899

49. Callendar, Proposals for a Standard Scale of Temperature based on the Platinum Resistance Thermometer.

British Assoc. Report, p. 242; 1899.

50. Callendar, Temperature Measurements vith Platinum Resistance Thermometers.

Phil. Mag., 47, p. 191; 1899.

Zs. f. Instrumentenkunde, 19, p. 185; 1899.

5I. DEWAR, On Electrical Resistance Thermometry at the Temperature of Boiling Hydrogen.

Proc. Roy. Institution, Jan., I 899.

Proc. Roy. Soc., 73, p. 244; 1904.

52. HolBorn, Untersuchungen über Platinwiderstände und Petroläther Thermometer.

Zs. f. Instrumentenkunde, 19, p. 123; 1899.

Ann. der Phys., 6, p. 242-258; I 901 .

53. Holborn and DAy, On the Gas Thermometer at High Temperatures.

Am. J1. Sci., (4), 8, p. 170; 1899.

Ann. d. Phys., 68, p. 817; 1899. 2, p. 505; 1900.

54. StewarT W., On the Disintegration of Platinum and Palladium Wires at High Temperatures.

Phil. Mag., 48, p. 48I; 1899 . (With references to previous work in this field.)

55. Barus, Les Progrès de la Pyrométrie.

Rapports au Congrès Int. de Phys., Paris, I900; 1, p. I70.

56. Chappuis P., Notes on Gas Thermometry.

Phil. Mag., (5), 50, p. 433; 1900.

57. Chree C., Platinum Thermometry at the Kew Observatory.

Proc. Roy. Soc., 67, p. 3; 1900.

58. Le Chatelier H. and Boudouard O., Mesure des Températures Elevées, Paris, Igoo.

59. Tory, A Comparison of Platinum Thermometers of Different Degrees of Purity. Phil. Mag., 50, p. 42 I; 1900.

60. WADE, Report on Use of Platinum Resistance Pyrometers.

Survey Dept., Cairo.

61. Chappuis P. and Harker J. A., On a Comparison of Platinum and Gas Thermometers.

Proc. Roy. Soc., 65, p. 377; 1899.

Phil. Trans., 194 A, p. 37 ; 1900.

Trav. et Mém. du Bureau International des Poids et Mesures, 89 pp., I9oz.

British Association Report, p. 243; 1899.

Jour. de Phys., (3), 10, p. 20; I90I.

Zs. f. Instrumentenkunde, p. 303; 1900.

62. Burstal, Second Report to the Gas-Engine Research Committee.

Proc. Inst. Mech. Eng., p. IO3I; I90I. 
63. Chroustchoff P., Recherches Cryoscopiques.

C. R., 131, p. 833 ; 1900. 132 , p. 955 ; 1901.

64. HOLBORN, Untersuchungen über Platinwiderstände und Petrolätherthermometer. Ann. der Phys., 6, p. 242; 1901.

65. Kucera G., Modified Callendar-Griffiths Key. Phys. Zs., 2, p. 381; 1901.

66. Le Chatelier, Boudovard, Burgess, High Temperature Measurements. Ist Am. Ed., I901; 2d Am. Ed., enlarged, 1904; Wiley and Sons.

67. Rosenhain W., Electric Pyrometers. Elec. Chem. and Met., June, I 901.

68. BARNES H. T., On the Capacity for Heat of Water between the Freezing and Boiling Points.

Phil. Trans., 199 A, p. I49; 1902.

69. CalLENDAR, Continuous Flow Calorimetry.

Phil. Trans., 199 A, p. 55; 1902.

70. Chappuis, Notes on Gas Thermometry.

Phil. Mag. (6), 3, p. 243; 1902.

71. Holborn and Henning, Über die Zerstäubung und die Rekrystallization der Platinmetalle.

Sitzber. Berlin Akad. Wiss., 1902, p. 936.

72. Melink, Comparison of the Platinum Thermometer with the Hydrogen Thermometer.

Proc. Acad. Sci. Amsterdam, 4, p. 495; 1902.

Com. Phys. Lab. Leiden, 77, p. I; 1902.

73. Shearer J. S., References to Papers on Low Temperature Research.

Phys. Rev., 15, p. 243; 1902.

74. Whipple R. S., Temperature Indicator, etc.

Lond. Phys. Soc., 18, p. 235; 1902.

75. BARnes and McInTosh, New Form of Platinum Resistance Thermometer.

Phil. Mag., 6, p. 353; 1903.

76. HEYCOCK and NEVILLE, On the Constitution of the Copper-Tin Series of Alloys (Used Callendar Recorder).

Phil. Trans., 202 A, pp. I-69; 1903.

77. Holborn and Austin, Die Zerstäubung elektrische geglühter Platinmetalle in verschiedenen Gasen.

Sitzber. Berlin Akad. Wiss., 12, p. 245; 1903.

78. JäGER und V. STEINWEHR, Erhöhung der Kalorimetrischen Messgenauigkeit durch Anwendung von Platinthermometern.

Verhand1. D. Phys. Ges., 5, p. 353; 1903.

79. Ibid., Bestimmung des Wasserwertes eines Berthelotschen Kalorimeter in Elektrischen Einheiten.

Verhand1. D. Phys. Ges., 5, p. 50; 1903.

80. Rothe R., Bestimmung des Schwefelsiedepunkts.

$Z$ s. f. Instrumentenkunde, 23, p. 364; 1903.

81. THiessen M., Über ein Platinthermometer.

Zs. f. Instrumentenkunde, 23, p. 363; 1903.

82. Campbell IVm., Notes on Platinum and its Deterioration.

Electroch. Indus., July, p. 259; 1904.

83. Darwin H., An Electric Thermostat.

Astrophys. J1., 20, p. 347; 1904. 
84. Edwards H., Notes on Resistance Measurements in Platinum Thermometry. Contrib. Jefferson Phys. Lab., 2, p. 549; 1904.

Proc. Am. Acad. Sci, 40, (No. I4).

85. GoldDSEIN E., Über Sauerstoffentziehung durch Platin.

Ber. Chen1. Ges., 37, p. 4147; 1904.

86. HAAGEN E., Quartz-glass Resistance Thermometer.

Zs. Angew. Chem., 20, p. 565 .

87. R. A. Hadfield, I. E. Stead, B. H. Brough, Pyrometers Suitable for Metallurgical Work.

The Iron and Steel Magazine, p. 77; 1904.

Report to Iron and Steel Institute.

Abstract in London Electrician, July 22, 1904.

88. HARker J. A., On the High Temperature Standards of the Natl. Phys. Lab.

Proc. Roy. Soc., 67, p. 3.

Phil. Trans., 203 A, p. 343; 1904.

- Collected Researches, Natl. Phys. Lab., 1, p. Io7.

89. MELINk, Comparison of Platinum Thermometer with Hydrogen Thermometer and, with Gold Thermometer.

Proc. Acad. Sci., Amsterdam, 7, p. 290; 1904.

Com. Phys. Lab. Leiden, 93, p. I; I904.

90. SchuTz H., Die Neuesten Fortschritte in der Messung hoher Temperaturen.

Zs. d. Verein. D. Ing., Jan. 30, 1904.

9I. Waidner C. W., Methods of Pyrometry.

Proc. Soc. Engs., Western Penna., 20, p. 313; 1904.

92. WAIDner and Dickinson, Apparatus for Platinum Thermometry.

Phys. Rev., 19, p. 5 I; 1904.

93. Whipple, Thermometers and Pyrometers with some of their Industrial Applications.

Proc. Cleveland Inst. of Engrs., Dec., I904.

94. WÖHLER L., Die Oxyde des Platins.

Zs. Anorg. Chem., 40, p. 422 ; I904.

95. BARnES, Application of the Telephone to Electrical Resistance Thermometers and Pyrometers.

Canad. Engin. Toronto, 12, p. 311 ; 1905.

96 Callendar, Electrical Methods of Measuring Temperature.

Engineering (Lond.), 77, p. 336, 370, 402; 1905.

97. CAmpbeli, A., On Direct Reading Resistance Thermometers Phil. Mag., (6), 9, p. 713; 1905.

98. Darwin, A High or Low Temperature Alarm.

Engineering (Lond.), March 10, 1905.

99. DEWAR, The Thermoelectric Junction as means of determining Lowest Temperatures.

Proc. Roy. Soc., June 8, 1905.

Am. J1. Sci., 20, p. 153; 1905.

IOO. DREYRa F., Methods of Low Temperature Measurement.

Annales Polyt. Inst. St. Petersburg, 3, p. 5 15; 1905.

IOI. JÄGER and V. STEINWEHR, Kalorimetrische Messungen von Verbrennungswärmen.

Zs. Phys. Chem., 53, p. 153; 1905.

102. WhIPPLE, A suggested Application of the Bonus System.

Engineering (Lond.), p. 813; 1905. 
103. WÖHLER, Oxidation of Palladium and Platinum.

Zs. Elektrotech., 11, p. 836; 1905.

Abstr. Elec. Chem. and Met. Ind., p. 25, Jan., $190^{\circ} 6$.

104. BARNES, Ice Formation.

(Pub. by Wiley \& Sons) 1906.

105. BARnes, The Theory and Practice of Continuous Flow Calorimetry.

Trans. Am. Electroch. Soc., 2, p. I97; 1906.

106. BRUGER, Elektrische Wiederstands-Thermometer.

Elektro-Tech. Zs., 27, p. 531; 1906.

107. Hopkinson B., The Explosion of Gaseous Mixtures, and the Specific Heat of the Products.

Engineering (Lond.), 81, p. 777; 1906.

108. Kamerlingh OnNes H. and Clay J., A Comparison of the Platinum Resistance Thermometer with the Hydrogen Thermometer and with the Gold Thermometer.

Proc. Akad. Sci. Amsterdam, 9, p. 207; 1906.

Com. Phys. Lab. Leiden, 95, p. 37, 49; 1906.

I09. JäGER W., Die Empfindlichkeit der Wiederstands Thermometer.

Zs. f. Instrumentenkunde, 26, p. 278; 1906.

I IO. JÄGER and V. STEINWEHR, Eichung eines Berthelotschen Verbrennungskalorimeters in elektrischen Einheiten mittels des Platinthermometers.

Ann. d. Phys., (4), 21, p. 23; 1906.

III. JÄGER and V. STEINWEHR, Die Elimination von Thermometrischer Nachwirkung usw. in der Kalorimetrie.

Zs. Phys. Chem., 54, p. 428; 1906.

I12. Ibid., Anwendung des Platinthermometers bei Kalorimetrischen Messungen.

Zs. f. Instrumentenkunde, 26, p. 237; 1906.

II3. NorThrup E. F., Measurement of Temperature by Electrical Means.

Proc. A. I. E. E., 25, p. 219 ; 1906.

II4. Travers and GWyer, Comparison of the Platinum Thermometer with the Normal Thermometer between $444^{\circ}$ and $-190^{\circ} \mathrm{C}$.

Proc. Roy. Soc., 74, p. 528; 1905.

Zs. f. Phys. Chem., 52, p. 437; 1905.

I15. CalleENdar and Dalby, On the Measurement of Temperatures in the Cylinders of a Gas Engine.

Engineering (Lond.), 84, p. 887; 1907.

Proc. Roy. Soc., 80, p. 57 ; 1907 .

I 6. Darling C. R., Pyrometry in Modern Workshop Practice.

Engineering (Lond.), June 14, 1907.

II7. Dickinson H. C. and MUELLER E. F., Calorimetric Resistance Thermometers and the Transition Temperature of Sodium Sulphate.

Bull. Bur. Standards, 3, p. 64I; 1907.

I 18. Hopkinson, On the Measurement of Gas-Engine Temperatures.

Phil. Mag., (6), 13, p. 84; 1907.

119. Misura Elettrica delle Temperature.

Elettricita, July I2, 1907.

120. NiccolaI G., Resistivity of certain Metals at very high and very low Temperatures.

Accad. Lincei. Atti., 16, p. 906; 1907. 
121. Whipple, Practical Pyrometry.

J1. West. Soc. Engs., Apr. 1907.

122. Whipple, Thermometers and Pyrometers.

Iron Age, Feb. 7, 1907.

123. Appleyard, The measurement of Electrical Conductivity.

Elec. Rev. Lond., June 5, 1908.

124. Callendar, Note on the Boiling Point of Sulphur.

Proc. Roy. Soc., 81, p. 363; 1908.

125. Day and Clement, Some New Measurements with the Gas Thermometer.

Am. J1. Sci., 26, p. 405; 1908.

I26. Fischer E. and WREDE F., Über die Bestimmung der Verbrennungswärme organischer Verbindungen mit Benützung des Platinwiderstands Thermometers.

Sitzber. Berlin Akad. Wiss., 5, p. I 29; 1908.

I27. Harker and Sexton, (Variation of Sulphur Boiling Point with Pressure).

Report British Assoc., 1908.

128. Eumorfopoulos N., The Boiling Point of Sulphur on the Constant Pressure Air Thermometer.

Proc. Roy. Soc., 81, p. 339; 1908.

129. HARRIS, Deflectional Resistance Thermometer.

Elect. Lond., 62, p. 430; 1908.

I30. Holborn and Henning, Über das Platinthermometer und den Sättigungsdruck d. Wasserdamfes zwischen 50 und $200^{\circ}$.

Ann. d. Phys., 26, p. 833; 1908.

13I. BECKeR O. M., Temperature Determination and Control for High-Speed Steel Treatment.

Engineering Mag., May, June, 1909.

I32. NoRThrup, Cooling Curves and a New Type of Apparatus for their Autographic Registration.

Proc. Am. Electrochem. Soc., May, 1909.

133. WAIDNER and Burgess, The Platinum Thermometer at High Temperatures.

Phys. Rev., 28, p. 467, 1909.

I34. Kamerlingh Onnes, C. Brank, and J. Clay, Determinations for Testing Purposes with the Hydrogen Thermometer and the Resistance Thermometer.

Proc. Amsterdam, 10, p. 4.22; 1907.

Com. Phys. Lab. Leiden, 101, p. II; 1908.

135. Dickinson and Muelier, The Specific Heat of Some Calcium Chloride Solutions. Phys. Rev., 26, 1908.

Congrès Int. du Froid, I908.

136. Stern J. G. L., Eine neue Form des Platinwiederstandsthermometers und Moleculargewichtsbestimmung, etc.

Zs. f. Phys. Chem., 65, p. 667; 1909.

137. BERTHELOT D., Sur les Thermomètres à Gaz et sur la Réduction de leurs Indications à l'Echelle absolue des Températures.

Trav. et Mém. du Bureau International, 13, 1907.

138. Buckingham E., On the Establishment of the Thermodynamic Scale of Temperature, etc.

Bull. Bureau of Standards, 3, p. 237; 1907. 